AIR ENTRAPMENT

and DROP FORMATION

in INKJET PRINTING

$-408$
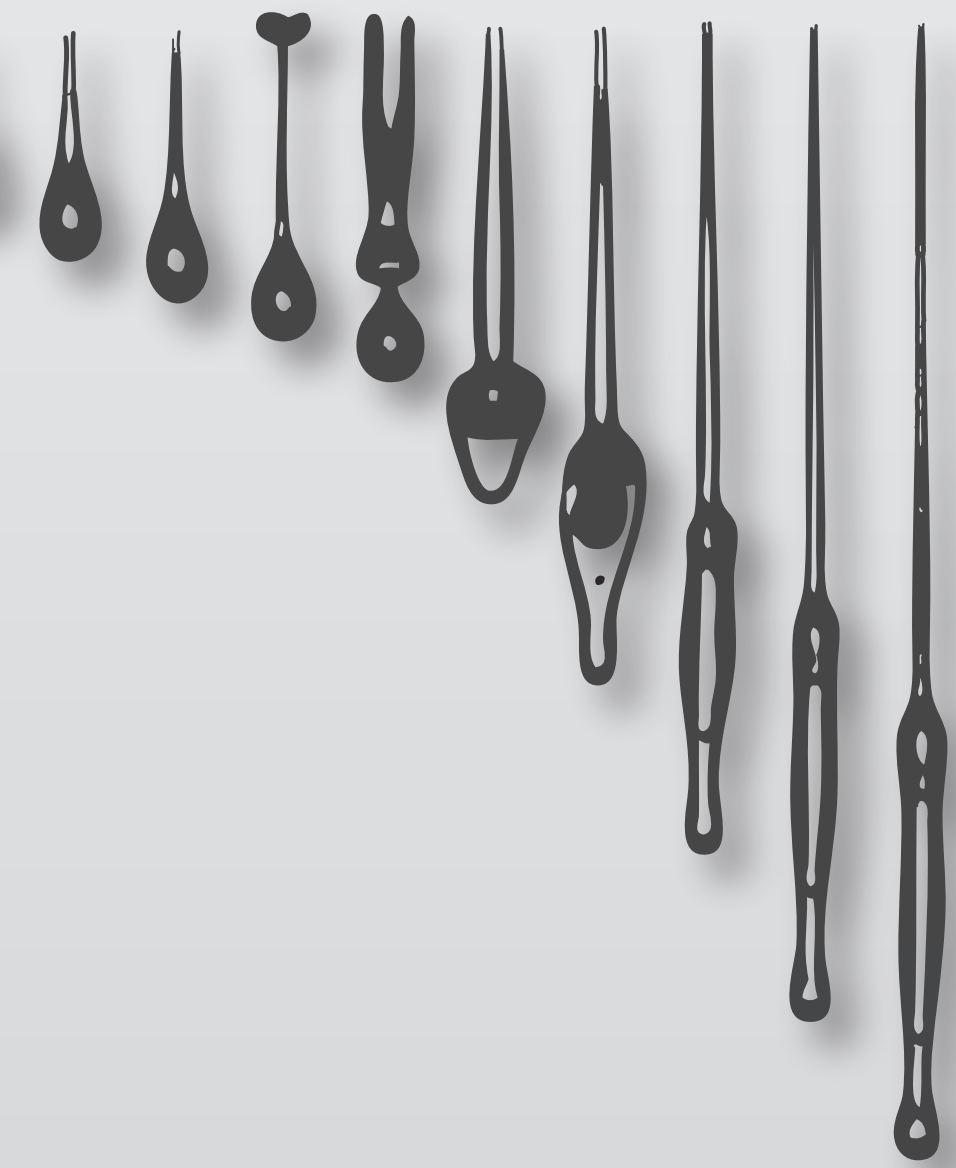

Arjan van der Bos 


\section{AIR ENTRAPMENT AND DROP FORMATION IN PIEZO INKJET PRINTING}

Arjan van der Bos 


\section{Samenstelling promotiecommissie:}

Prof. dr. G. van der Steenhoven (voorzitter, secretaris) Universiteit Twente, TNW Prof. dr. rer. nat. D. Lohse (promotor) Universiteit Twente, TNW Dr. A.M. Versluis (assistent promotor) Universiteit Twente, TNW Prof. dr. ing. D. Blank Universiteit Twente, MESA+ Prof. dr. S. Lemay

Prof. dr. ir. M. van Sint Annaland

Ir. H. Reinten

Dr. M.J. van den Berg Universiteit Twente, MESA+ Eindhoven University of Technology Océ Technologies B.V. Océ Technologies B.V.
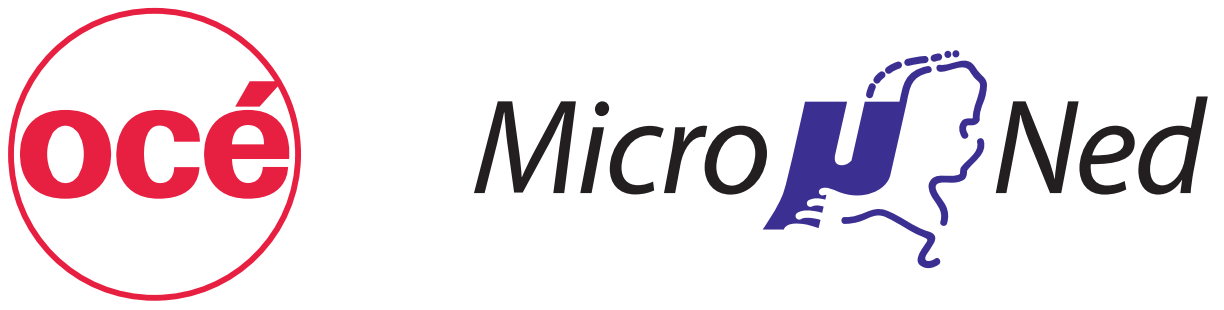

Part of the work presented in this thesis is done in the II-A atomization research program of MicroNed. This thesis was carried out at the Physics of Fluids group of the Faculty of Science and Technology of the University of Twente.

This work is financially supported by Océ Technologies B.V., Venlo

Nederlandse titel:

Piezo inkjet printen: invangen van luchtbellen en druppelvorming

Publisher:

Arjan van der Bos, Physics of Fluids, University of Twente, P.O. Box 217, 7500 AE Enschede, The Netherlands http://pof.tnw.utwente.nl j.a.vanderbos@alumnus.utwente.nl

Cover design: Arjan van der Bos Print: Digital 4 B.V., Goor

(C) Arjan van der Bos, Enschede, The Netherlands 2010.

No part of this work may be reproduced by print, photocopy or any other means without the permission in writing from the publisher.

ISBN 978-90-365-3144-3 


\section{AIR ENTRAPMENT AND DROP FORMATION IN PIEZO INKJET PRINTING}

\section{PROEFSCHRIFT}

ter verkrijging van

de graad van doctor aan de Universiteit Twente,

op gezag van de rector magnificus, prof. dr. H. Brinksma,

volgens besluit van het College voor Promoties

in het openbaar te verdedigen

op vrijdag 14 januari 2011 om 16.45 uur

door

Jan Aart van der Bos

geboren op 20 september 1979

te Ermelo 
Dit proefschrift is goedgekeurd door de promotoren:

Prof. dr. rer. nat. Detlef Lohse

en de assistent promotor:

Dr. A.M. Versluis 
$\begin{array}{lll}1 & \text { Introduction } & 1\end{array}$

1.1 Piezo inkjet printing . . . . . . . . . . . . . . . . 1

1.2 Bubbles and drops in piezo inkjet printing . . . . . . . . . 2

1.3 Guide through the chapters . . . . . . . . . . . . . . . . 4

2 Acoustic sizing of a bubble in an ink channel 7

2.1 Introduction . . . . . . . . . . . . . . . . . . . 7

2.2 Geometry of the inkjet printhead . . . . . . . . . . . . 8

2.3 Experimental parameters . . . . . . . . . . . . . . . . . . . . . . 9

2.4 Modeling the printhead . . . . . . . . . . . . . . . . . . 10

2.5 Comparing the model with experiments . . . . . . . . . 18

2.6 Conclusion . . . . . . . . . . . . . . . . . . . . . . . . 22

3 Acoustic sizing of a bubble in a MEMS ink channel 23

3.1 Introduction . . . . . . . . . . . . . . . 23

3.2 Geometry of the MEMS channel . . . . . . . . . . . . . 26

3.3 Visualizing in the infrared regime . . . . . . . . . . . 26

3.4 Experimental parameters . . . . . . . . . . . . . . . . . . . 30

3.5 Modeling the print head . . . . . . . . . . . . . . . . . . . 33

3.6 Results . . . . . . . . . . . . . . . . . . . . . . . . . . . . . . . . . 37

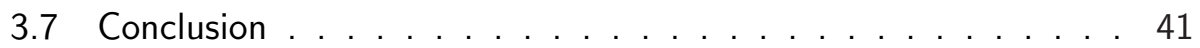

4 Illumination by Laser Induced Fluorescence 43

4.1 Introduction . . . . . . . . . . . . . . . . . . . . . . . . 43

4.2 Criteria for high speed flash-photography . . . . . . . . . . 45

4.3 Illumination by laser induced fluorescence . . . . . . . . . 47

4.4 Comparison with other light sources . . . . . . . . . . . 50

4.5 Examples . . . . . . . . . . . . . . . . . . . . . . . . . . . . 54

4.6 Discussion and conclusion . . . . . . . . . . . . . . . . . . . 56

5 Drop formation visualization $\quad 59$

5.1 Introduction . . . . . . . . . . . . . . . . . . . . 59

5.2 Geometry of the inkjet printhead . . . . . . . . . . . . 61

5.3 Experimental parameters . . . . . . . . . . . . . . . 61

5.3 .1 High speed recordings . . . . . . . . . . . . . 63

5.3 .2 Single flash recordings. . . . . . . . . . . . . . . . 64

5.4 Data analysis $\ldots \ldots \ldots \ldots . \ldots \ldots 7$

5.5 Spatial and temporal resolution . . . . . . . . . . . 71 
5.5 .1 Reproducibility . . . . . . . . . . . . . . . 72

5.6 Velocity comparison . . . . . . . . . . . . . . . . . . . . . 74

5.7 Numerical model . . . . . . . . . . . . . . . . . . . . 75

$5.7 .1 \quad$ Governing equations . . . . . . . . . . . . . . . 76

5.7 .2 Numerical implementation . . . . . . . . . . . . . . . 79

5.8 Comparison . . . . . . . . . . . . . . . . . . . . . . . . . 79

5.9 Discussion and outlook . . . . . . . . . . . . . . . . . 82

$\begin{array}{lll}6 & \text { Controlled air entrapment } & 83\end{array}$

6.1 Introduction . . . . . . . . . . . . . . . . . . . . . . . . 83

6.2 Experimental parameters . . . . . . . . . . . . . . 85

6.3 Characterization of the bubble entrapment pulse . . . . . . . . . 86

6.4 Acoustical characterization . . . . . . . . . . . . . . . . 91

6.5 Summary \& Outlook . . . . . . . . . . . . . . . . . . . 93

$\begin{array}{lll}7 & \text { Conclusions and outlook } & 95\end{array}$

\begin{tabular}{ll}
\hline References & 98
\end{tabular}

\begin{tabular}{ll}
\hline Summary & 107
\end{tabular}

$\begin{array}{ll}\text { Samenvatting } & 110\end{array}$

\begin{tabular}{ll}
\hline Dankwoord & 115
\end{tabular}

\begin{tabular}{ll}
\hline About the author & 119
\end{tabular} 


\section{1}

\section{Introduction}

\subsection{Piezo inkjet printing}

Inkjet printing is the most widely spread application in microfluidics and, since the first inkjet device was patented by William Thompson in 1858 (The Siphon recorder, UK Patent 2147/1867), it has developed into a versatile and major drop deposition technique. In inkjet printing various methods are applied to create controlled droplets, but there are two distinct classes in which inkjet printing is commonly divided, continuous inkjet printing and drop-on-demand inkjet printing.

In continuous inkjet printing droplets are formed by the Rayleigh breakup of a continuous stream of liquid [1]. These droplets are charged by an electric field and, by applying an additional electric field downstream of the jet, these droplets can be deflected on demand. Continuous inkjet printing is one of the fastest inkjet technologies, where drop repetition rates in the order of $100 \mathrm{kHz}$ can be achieved. However, continuous inkjet printing comes with certain disadvantages; it requires complicated hardware to synchronize breakup, charging electrodes and deflection electrodes. An additional disadvantage is that the droplets which are not printed have to be recycled continuously, which severely complicated this technique.

The inkjet counterpart to continuous inkjet printing is drop-on-demand inkjet printing. A typical drop-on-demand printhead consists of several hundreds of channels, where each channel is equipped with an actuator to generate pressure waves. By precise timing of the actuation, the drop-on-demand printer generates drops with repetition frequencies in the order of $20 \mathrm{kHz}$. The two most common types of drop-on-demand printers are thermal and piezo inkjet printers. In thermal inkjet printing the pressure is generated by a vapor bubble, which is created by local heating of the ink. This limits both the diversity of liquids that can be used, and the durability of the printhead.

Piezo inkjet printing does not have these limitations, and has proven itself a 
very reliable drop deposition technique. As a piezo is used as actuator, all kind of liquids can be printed, with droplet sizes ranging from nanoliters down to a few picoliters [2]. By far the best known application is the production of press related materials, such as books, photos and posters. But the broad range of printable liquids, the high drop repetition rates and the constant quality of the drop formation have made it the preferred drop deposition technique for dozens of applications [3]. Examples include the printing of three dimensional structures for rapid prototyping [4], the printing of etch resist and semiconductors [5], the printing of solar panels [6], the deposition of thin layers of nanoparticles such as carbon nanotubes [7], or the printing of LED displays [8]. Also bioprinting is an entire area of research, focusing on the printing of biological materials [9]. And it is even common to print edible images onto birthday cakes.

The basic principles of the drop-on-demand devices are similar and independent of the application. Reliability is crucial, especially in applications such as the printing of electronics and bioprinting, where the omittance of a single droplet is unacceptable. Hence considerable research is performed in the optimization of drop formation and the stability in drop production. The complexity in the fluid dynamics of the drop formation, where inertia, surface tension and viscosity are equally important, make it a fascinating subject for scientists throughout the last century [10, 11].

The subject of inkjet printing is more versatile than drop formation itself and for example also treats the consistency of the drop formation, structural mechanics involved in the channel design, the chemical composition of the liquids, and the impact and splashing of drops [12]. This thesis treats a part of the elaborate subject; the subject of channel acoustics, air entrapment and drop formation.

\subsection{Bubbles and drops in piezo inkjet printing}

The research done in this thesis is part of a long lasting cooperation between Océ technologies B.V. and the Physics of Fluids group of the University of Twente. This collaboration on the research of piezo inkjet printing started at the time the R\&D department at Océ technologies B.V. developed an acoustic sensing technology [13]. With acoustic sensing it is possible to monitor the acoustic pressure inside the inkjet channel during the drop formation. This new technique proved very useful for detecting abnormalities in the print process. In the study of these abnormalities it was found that microbubbles inside the channel disrupt the print process. The acoustic sensing could be used to detect the presence of microbubbles, but it was unclear where the microbubbles were originating from. By measuring the recovery time of a channel after air entrapment, predictions 


\subsection{BUBBLES AND DROPS IN PIEZO INKJET PRINTING}

could be made on the size of the bubble.

In 2003 De Jong et al. showed that, moments before the microbubble disturbance was detected, a small flip-flop is present in the acoustic signal [14]. By using this flip-flop as a trigger for a high speed camera, it was observed that the disturbance in the acoustics is accompanied with a disrupted drop formation (Figure 1.1). By physically capturing the droplets during the disrupted drop formation, Van den Berg was able to show that small dust particles caused the disrupted drop formation [14]. The study also confirmed that the bubble only originates from air entrapment at the meniscus. To induce air entrapment the meniscus had to be disturbed, and dust particles or the presence of an ink layer around the nozzle would be the underlying causes [14]. Not only can the presence of an ink layer directly disturb the meniscus, but it was shown that it can transport dirt particles. There were event two different flow mechanisms found that transport ink and dirt. Firstly, the drop formation induces an air flow strong enough to displace the ink [15]. Secondly, Marangoni stresses, caused by local changes in the surface tension, also resulted in a transport of ink [16].

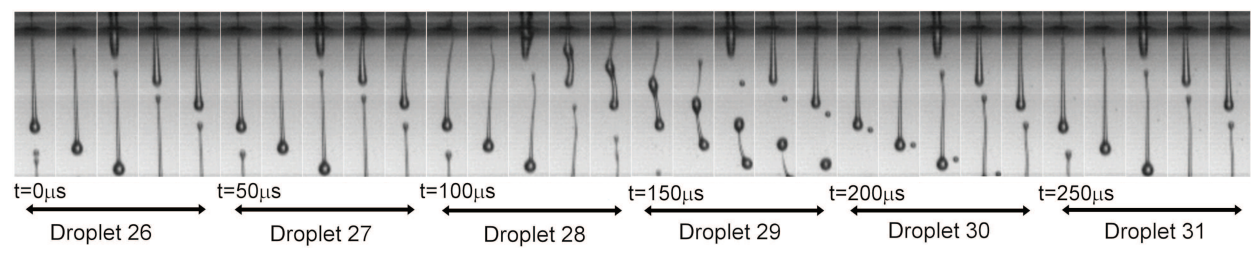

Figure 1.1: Droplet formation recorded at $100 \mathrm{kfps}$ showing the disturbance that can result in air entrapment. Droplet 27 displays a slight deviation in the tail. Droplet 28 shows a large disturbance being jetted out. Droplet 29 and 30 display regular droplet formation again. Recording taken from [14].

In 2005 an acoustic model was developed to calculate the channel pressure and the influence of a microbubble inside the channel. The model was used to predict how the velocity of the droplets change due to the presence of a microbubble. The model and the experimental validation were treated in [17, 18]. A glass insert was added to a printhead, which made it possible to visualize the presence and size of microbubbles inside the channel [17] but, due the modifications, the acoustic sensing could not be applied. Most of these results are also treated in the extensive review on the dynamics of piezo inkjet printing $(\mathrm{H}$. Wijshoff [2]).

In 2006 the research in this thesis started, and the research questions were 
stated. Although the channel acoustics showed sensitive to air bubbles and disturbances, still no quantitative validation was made of the effect of a microbubble on the channel acoustics. There was also the question of air entrapment itself; what mechanism causes air entrapment and how is this related to external disturbances? Is it possible to create a method to study air entrapment controllably, such that fast detection methods can be developed? How applicable is the available acoustic model and can it be used for improving the acoustics design of the channel?

In 2008 Océ Technologies B.V. launched the the ColorWave 600, which contained the first generation drop-on-demand printheads. The elaborate knowledge on acoustic sensing was applied in this printer, making it a very fast printer and very reliable printer. At the same time Océ Technologies B.V. was developing a new class of printheads, based on Micro-Electro-Mechanical-Systems (MEMS). With the MEMS technology the channel size was reduced by one order of magnitude, while increasing the productivity. During the ongoing development of the MEMS printhead, old questions were revisited, e.g. does air entrapment occur, and if so, can the bubble be visualized.

\subsection{Guide through the chapters}

In chapter 2 the effect of an air bubble on the acoustics of an inkjet printhead is further studied. This was done experimentally, by visualizing the bubble inside the channel, while simultaneously measuring the channel acoustics. A onedimensional acoustic model was applied to correlate optical experiments with acoustical measurements. Chapter 3 treats the new Micro-Electro-MechanicalSystem (MEMS) printhead. In this chapter infrared light is utilized to visualize air bubbles inside the MEMS printhead without modifying the channel. With this new method the presence, size and position of air bubbles could be confirmed.

The new generation printheads creates smaller droplets, which gives rise to the formation of satellite drops. To visualize the formation of these smaller droplets and the satellite formation a novel illumination technique is introduced in chapter 4. The illumination technique is elaborately tested and compared with modern high-end light sources. With the new illumination technique it is possible to capture the drop formation in extreme detail, which is treated in chapter 5 . Besides the experimental research on drop formation, chapter 5 also treats a fast one-dimensional drop model.

Chapter 6 combines the study on air entrapment, acoustic measurement and drop visualization altogether into a single chapter. Here we introduce an acoustic pulse that can be used to entrap microbubbles in a controlled way. The 


\subsection{GUIDE THROUGH THE CHAPTERS}

possible mechanism causing air entrapment is explored by visualizing the drop formation comparing the measurements with a Computational Fluid Dynamics simulation.

tn the conclusions of this thesis an overview of the results from are presented and the contribution of the research to inkjet printing. 
1. INTRODUCTION 


\section{2}

\section{Acoustic measurement of bubble size in an inkjet printhead ${ }^{1}$}

The volume of a bubble in a piezo inkjet printhead is measured acoustically. The method is based on a numerical model of the investigated system. The piezo not only drives the system, but it is also used as a sensor by measuring the current it generates. The numerical model is used to predict this current for a given bubble volume. The inverse problem is to infer the bubble volume from an experimentally obtained piezo current. By solving this inverse problem, the size and position of the bubble can thus be measured acoustically. The method is experimentally validated with an inkjet printhead that is augmented with a glass connection channel, through which the bubble was observed optically, while at the same time the piezo current was measured. The results from the acoustical measurement method correspond closely to the results from the optical measurement.

\subsection{Introduction}

The dynamics of a sound driven free bubble in an infinite volume are well described by the Rayleigh-Plesset equation [19--21], whose validity, even under the extreme conditions of single bubble sonoluminescence, has been thoroughly established [22]. However, many important cases of bubble dynamics occur under constraint conditions, in finite volumes of liquid, rather than infinite volumes, such as in confined spaces and near a wall [23--26]. Examples include the behavior of gas bubbles in blood vessels, aiming at improving ultrasound diagnostics and treatment [27], or thermal inkjet printing and other microfluidic

\footnotetext{
${ }^{1}$ Published as: Roger Jeurissen, Arjan van der Bos, Hans Reinten, Marc van den Berg, Herman Wijshoff, Jos de Jong, Michel Versluis, and Detlef Lohse, Acoustic measurement of bubble size in an inkjet printhead, Journal of the Acoustical Society of America 126, pp. 2184-2190 (2009).
} 
applications, where bubbles are used as actuators [28, 29]. However, bubbles can also disrupt the operation of the printhead as was shown in earlier research [14, 17, 18]. Although inkjet printing is a robust process and billions of droplets can be printed without problems, there is a small chance that during actuation a small air bubble is entrapped at the nozzle of an ink channel. The bubble influences the channel acoustics, reducing the pressure buildup at the nozzle. The bubble grows by rectified diffusion until it reaches a diffusive equilibrium [14, 17, 18]. At this size, the pressure buildup at the nozzle is insufficient for droplet production, so that the channel stops jetting. This malfunctioning can be detected acoustically [14], but until now the relation between bubble size and channel acoustics has not been shown quantitatively. In fact in many studies the bubble was assumed to behave as if it were in an unbounded liquid [30, 31].

The dynamics of a bubble in confined space is fundamentally different from that in an infinite volume of liquid where the far field is three dimensional. In contrast, in a compressible inviscid liquid, the far field of a bubble between two parallel infinite walls is two dimensional [32], and the far field of a bubble in an infinitely long pipe is one dimensional [33-35]. An incompressible liquid does not allow bubble volume fluctuations in either confined space, while the volume fluctuations in an unbounded volume of liquid are possible and governed by the Rayleigh-Plesset equation. Models that assume an unbounded volume of liquid are therefore inappropriate for a bubble in a confined space.

In this study, a model is used that captures the effect that a bubble has on the channel acoustics and vice versa. To validate the model, experimental results are presented which correlate the acoustic change inside the channel with optical measurements of an entrained air bubble.

\subsection{Geometry of the inkjet printhead}

The inkjet printhead that is used in this research is developed by Océ Technologies B.V. This experimental printhead consist of 256 similar ink channels. Each channel has an actuator section with a rectangular cross section of $118 \mu \mathrm{m}$ by $218 \mu \mathrm{m}$ and a length of $8 \mathrm{~mm}$. A cylindrical channel section with a radius of $125 \mu \mathrm{m}$ and a length of $1.5 \mathrm{~mm}$ connects the actuator section to the nozzle. A piezo is placed onto the actuator section. When a trapezoidal pulse of $13 \mu \mathrm{s}$ (4 $\mu$ s rise time, $5 \mu$ s plateau, $4 \mu$ s fall time) [36] is applied to this piezo, it generates acoustic pressure waves inside the channel. The generated waves are reflected at both outer ends of the channel; the ink reservoir at one side, and nozzle plate at the other side. The result is a velocity and pressure build up at the nozzle which leads to a droplet being ejected [37, 38]. Typically for this 


\subsection{EXPERIMENTAL PARAMETERS}

specific printhead, droplets of $30 \mathrm{pl}$ are generated at a rate of $20 \mathrm{kHz}$ with a velocity of $6 \mathrm{~m} / \mathrm{s}$.

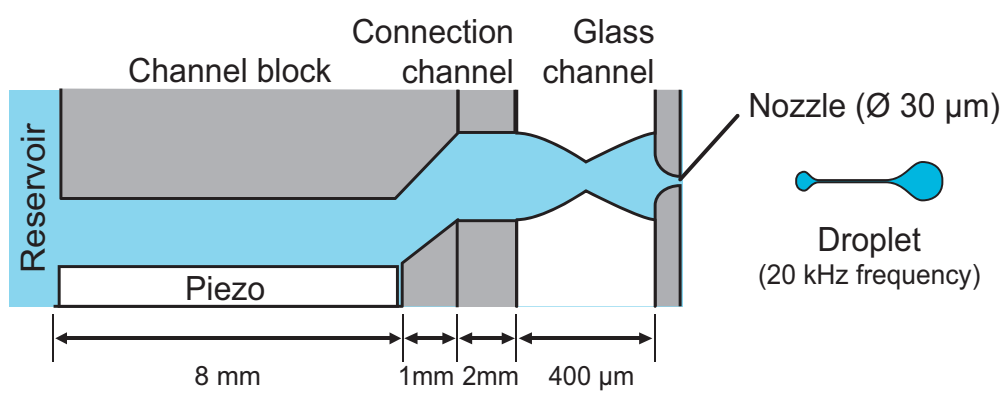

Figure 2.1: The channel inside the printhead is about $10 \mathrm{~mm}$ long and is actuated by a $8 \mathrm{~mm}$ long piezo. In between the channel block and the nozzle plate a $400 \mu \mathrm{m}$ long glass connection channel is placed through which the bubble dynamics can be observed.

To visualize the dynamics of the entrained air bubble, a $400 \mu \mathrm{m}$ long glass connection channel [39] was interposed between the ink channel and the nozzle plate (Figure 2.1), similarly as done in reference [14]. This channel was made by powder blasting which resulted in an hourglass shape with a waist diameter of $220 \mu \mathrm{m}$ and a maximum diameter of $300 \mu \mathrm{m}$ at the ends. An extra $2 \mathrm{~mm}$ connection channel was required to interpose the glass connection channel. In Figure 2.2 shows the connection channel with an air bubble inside. A $100 \mu \mathrm{m}$ thick nickel nozzle plate is glued on top of the connection channel. The nozzles inside the nozzle plate have a trumpet shape with a diameter of $30 \mu \mathrm{m}$ at the exit and $130 \mu \mathrm{m}$ at the inlet.

\subsection{Experimental parameters}

Besides visualizing the bubble dynamics, also the pressure variations inside the channel were measured. This was done by measuring the piezo current in between the actuation pulses [13]. This technique has earlier been applied in reference [14]. Even small pressure fluctuations in the channel result in measurable current fluctuations from the piezo. As this signal is only measured in between the actuation pulses, the time window in which the current is measured at a droplet production rate of $20 \mathrm{kHz}$ is $37 \mu \mathrm{s}$. An example of the measured piezo current is shown in Figure 2.3. This figure illustrates the change in the acoustic signal after an air bubble is entrapped inside the channel. 


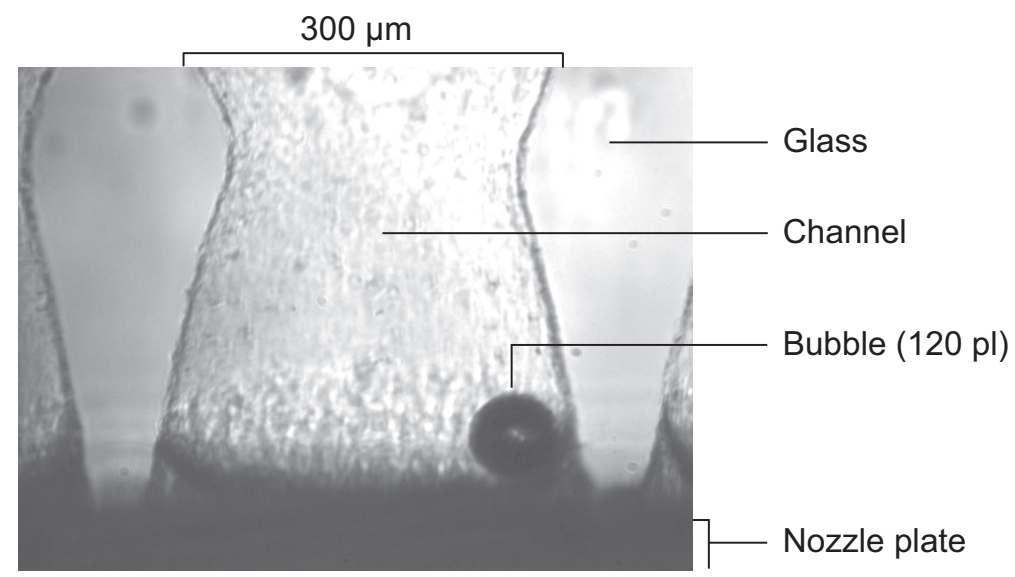

Figure 2.2: A microscope image showing an entrapped air bubble in the glass connection channel. While actuating, the fully grown air bubble will just remain oscillating in the channel indefinitely. Note the position of the air bubble: due to the secondary Bjerknes force it is pushed against the glass wall where it stays fixed even after the actuation is stopped. On the left and right sides of the channel the neighboring channels can also be seen.

The piezo current was measured at a range of bubble volumes. To accomplish this, air entrapment was induced by physically blocking a channel while actuating. The actuation was continued until the entrapped bubble reached a diffusive equilibrium size which, in this specific setup, is about $120 \mathrm{pl}$. Then the actuation was stopped allowing the bubble to dissolve. The bubble dissolves at a rate of approximately $0.5 \mathrm{pl} / \mathrm{s}$, so it takes about 4 minutes for a $120 \mathrm{pl}$ bubble to fully dissolve. During the dissolution of the bubble, piezo current data were gathered by actuating at a frequency of $1 \mathrm{~Hz}$. At this reduced actuation rate, rectified diffusion is not strong enough to sustain the bubble, so it dissolves. One microsecond before every actuation pulse, an image of the bubble was captured. In this way motion blur due to volume oscillations was prevented.

\subsection{Modeling the printhead}

Deformation of a piezo gives rise to a current $I$ from the actuator. Such a deformation can be induced by varying the voltage over the electrodes. Thanks to this effect, the piezo can be used as an actuator. Another way in which the piezo can be deformed is caused by acoustic waves in the channel, making it possible to use the piezo element also as a sensor. Here a model is used 


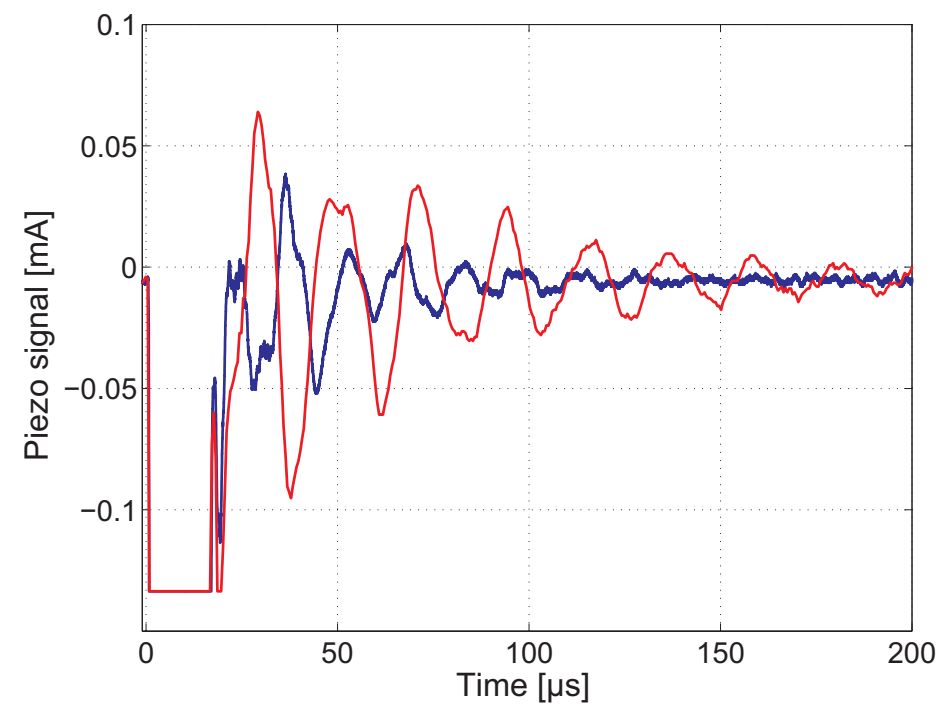

Figure 2.3: Piezo current of a normal operating nozzle (blue), and with an entrained air bubble with a volume of $V_{b}=80 \mathrm{pl}$ (red) close to the nozzle plate. It can be seen in this figure that the volume oscillations of the entrapped bubble modify the piezo current significantly; the piezo current amplitude is less damped and the main frequency decreases.

to calculate the piezo current [18], which links the Rayleigh-Plesset equation to the equations that govern the propagation of acoustic waves in a viscous medium in a flexible pipe and the response of the piezo and channel to the actuator voltage.

Acoustically, the print head consists of four linked sections of pipes as shown in Figure 2.4. The properties of the channel are constant over each section. The relevant properties are the piezo electric expansion coefficient $\alpha_{j}$, the wall flexibility $\beta_{j}$, the cross sectional area $A_{j}$, the velocity of sound in the liquid $c$, the liquid density $\rho$, the viscosity $\mu$, and the length $L_{j}$ of the channel section. The piezo electric expansion coefficient is defined as

$$
\alpha \equiv \frac{1}{A}\left(\frac{\partial A}{\partial U}\right)_{P}
$$

where $U$ is the voltage over the electrodes of the piezo element and $P$ is the pressure in the channel. The wall flexibility is defined as

$$
\beta \equiv \frac{1}{A}\left(\frac{\partial A}{\partial P}\right)_{U}
$$


These two quantities can either be determined with a solid mechanics calculation, provided that the geometry and material parameters are accurately known, or they can be determined by measuring the piezo current in the absence of a bubble.

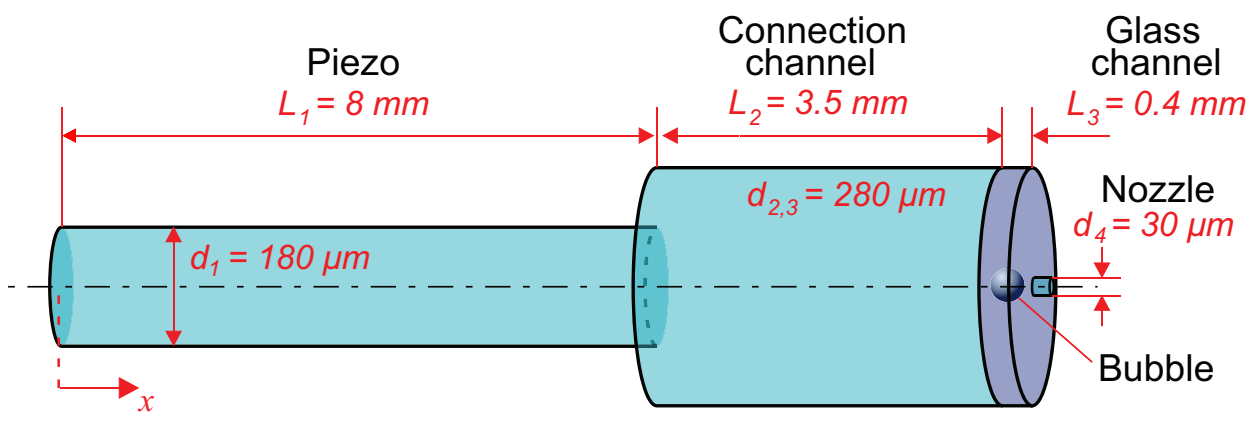

Figure 2.4: The print head as it is implemented in the model. From left to right: actuator channel, connection channel, glass connection channel and nozzle.

In the model the pressure calculation is performed in the frequency domain, using the discrete Fourier transform defined through

$$
f(t)=\sum_{j} F\left(\omega_{j}\right) e^{i \omega_{j} t}
$$

Here $f(t)$ is the relevant quantity in the time domain, and $F(\omega)$ is the corresponding quantity in the frequency domain. The explicit dependence on frequency is dropped in the remainder of the paper for the sake of brevity. The pressure $P$ is decomposed into the waves propagating to the left $P_{l}$ and right $P_{r}$. For each channel section, the amplitudes of the left and right propagating waves are calculated per frequency,

$$
P=\sum_{j} P_{r} e^{i\left(\omega_{j} t-k x\right)}+P_{l} e^{i\left(\omega_{j} t+k x\right)}+P_{s}
$$

Here the pressure $P_{S}$ is caused by the actuator, hence only depends on the imposed actuator voltage. The wave number $k$ is a complex quantity due to viscous dissipation. For a cylindrical pipe a closed form expression was obtained 
analytically in reference [40], namely

$$
k=\frac{\omega}{c_{e f f}} \sqrt{\frac{1}{1+\frac{2 \sqrt{i J_{1}(}\left(\mathrm{Wo}^{\frac{3}{2}}\right)}{\mathrm{Wo}_{0}\left(\mathrm{Wo}^{\frac{3}{2}}\right)}} .}
$$

The functions $J_{0}$ and $J_{1}$ are the ordinary Bessel functions of the first kind, of zeroth and first order, respectively. The Womersley number Wo is the ratio of the inertia of the oscillating velocity field over the viscosity,

$$
W o_{j}=\frac{1}{2} d_{j} \sqrt{\frac{\omega \rho}{\mu}},
$$

where $d_{j}$ is the diameter of the section. The effective wave velocity differs from the velocity of sound due to wall flexibility and is given by the inviscid phase velocity of acoustic waves. It was derived by Young [41] and is given by

$$
c_{e f f}=\sqrt{\frac{c^{2}}{1+\beta c^{2} \rho}} .
$$

If the wall flexibility $\beta$ vanishes, the effective wave velocity is equal to the velocity of sound $c$. If the walls are flexible the effective wave velocity is smaller. The wave number (Equation 2.5) has been the main result of the acoustical model [40]. The boundary conditions are continuity of pressure and volume flow rate. Equation 2.4 for the pressure, Equation 2.5 for the wave number, and the boundary conditions describe the propagation of acoustic waves in a flexible channel filled with a viscous liquid. The effect of the bubble is included in the volume flow rate balance between the nozzle and the glass connection channel by explicitly considering the flux $q_{b}$ from the bubble,

$$
A_{c} u_{c}=A_{n} u_{n}+q_{b} .
$$

Here $A_{c}$ and $A_{n}$ are the cross sectional areas of the glass connection channel and the area of the nozzle respectively and $u_{c}$ and $u_{n}$ are fluid velocities in these sections. The volume flux from the bubble is calculated with the RayleighPlesset equation

$$
r \ddot{r}+\frac{3}{2} \dot{r}^{2}=\frac{1}{\rho}\left(P_{g}(r)+P_{v}-\frac{2 \sigma}{r}-\frac{4 \mu \dot{r}}{r}-P_{\infty}(t)\right) .
$$

In the Rayleigh-Plesset equation, $r$ is the bubble radius, $P_{g}(r)$ is the gas pressure in the bubble, $P_{v}$ is the saturated vapor pressure of the ink, and $\sigma$ is the surface 
tension of the ink. The gas pressure is obtained from the polytropic relation assuming an isothermal bubble. The saturated vapor pressure is $P_{v}=2400 \mathrm{Nm}^{-2}$ and the surface tension is $\sigma=0.028 \mathrm{Nm}^{-1}$. Through the ambient pressure $P_{\infty}$, which is obtained from the channel acoustics calculation, the channel acoustics are coupled to the bubble dynamics. A more extensive treatment of this model can be found in reference [18].

Electrically, the piezo actuator is a capacitor in parallel with a variable current source. The piezo current depends on the capacitance of the actuator $C_{a}$, the coupling coefficient $\alpha$, and the pressure in the channel. The coupling coefficient relates the voltage over the piezo to the deformation of the channel and has also been used in the calculation of the channel acoustics. The time derivative of the charge expresses the relation between the actuator voltage and the piezo current in the time domain $I_{t}$,

$$
I_{t}=\frac{\mathrm{d} Q}{\mathrm{~d} t}=\left(\frac{\partial Q}{\partial U}\right)_{P} \frac{\mathrm{d} U}{\mathrm{~d} t}+\left(\frac{\partial Q}{\partial P}\right)_{U} \frac{\mathrm{d} P}{\mathrm{~d} t} .
$$

Here $Q$ is the total charge on the piezo actuator and $U$ the voltage over the piezo actuator. To calculate or interpret the piezo current, the isobaric capacitance and the relation between the channel pressure and current have to be determined. The isobaric capacitance of the piezo actuator is measured directly. The piezo current due to pressure fluctuations can be calculated from the thermodynamic fundamental equation of the actuator channel. The differential of the energy per unit length of channel is given by,

$$
\mathrm{d} e=P \mathrm{~d} A+U \mathrm{~d} q,
$$

where $q$ is the charge per unit length and $e$ is the energy of the channel per unit length.

The analysis is simplified when the Legendre transform [42] with respect to pressure and actuator voltage is used, because the mechanical properties of the channel are known in terms of the pressure and actuator voltage as independent parameters. The differential of the Legendre transform $g$ (Gibbs the free energy per unit length) is

$$
\mathrm{d} g=\mathrm{d} e-\mathrm{d}(A P)-\mathrm{d}(U q)=-A \mathrm{~d} P-q \mathrm{~d} U .
$$

The isobaric capacitance is defined as the second derivative,

$$
C_{P} \equiv\left(\frac{\partial Q}{\partial U}\right)_{P}=L_{a}\left(\frac{\partial q}{\partial U}\right)_{P}=-L_{a}\left(\frac{\partial^{2} g}{\partial U^{2}}\right)_{P},
$$


where $L_{a}$ is the actuator channel length and $q$ is assumed to be constant. The coupling coefficient $\left(\frac{\partial Q}{\partial P}\right)_{U}$ is

$$
\left(\frac{\partial Q}{\partial P}\right)_{U}=-L_{a}\left(\frac{\partial}{\partial P}\right)_{U}\left(\frac{\partial g}{\partial U}\right)_{P}=-L_{a}\left(\frac{\partial}{\partial U}\right)_{P}\left(\frac{\partial g}{\partial P}\right)_{U}=L_{a}\left(\frac{\partial A}{\partial U}\right)_{P} .
$$

Combining equations 2.1 and 2.14 yields the coupling coefficient

$$
\alpha A L_{a}=\left(\frac{\partial Q}{\partial P}\right)_{U} .
$$

Combining equations 2.10, 2.13, and 2.15 yields the piezo current

$$
I_{t}=C_{p} \frac{\mathrm{d} U}{\mathrm{~d} t}+\alpha A L_{a} \frac{\mathrm{d} P}{\mathrm{~d} t} .
$$

In general, the pressure is a function of position. When the fluctuations are sufficiently slow for the system to come to rest locally, the piezo current can be obtained by integrating over the length of the actuator,

$$
I_{t}=C_{p} \frac{\mathrm{d} U}{\mathrm{~d} t}+\alpha A \int_{0}^{L_{a}} \frac{\mathrm{d} P}{\mathrm{~d} t} \mathrm{~d} x
$$

This approximation is valid here, since the wavelength is much larger than the channel radius, ensuring that the system is in local equilibrium. The piezo current is now known in terms of the actuator voltage and the channel pressure.

From the Fourier transform of the pressure, the Fourier transform of the piezo current $I_{f}$ can be calculated. Inserting the expression of the pressure into Equation 2.17, applying the Fourier transform defined in Equation 2.3, and dividing by $e^{i \omega t}$ yields an expression for the piezo current,

$$
I_{f}=i \omega C_{p} U+\alpha A_{j} \frac{\omega}{k_{j}}\left(-P_{r, j} e^{-i k L_{a}}+P_{l, j} e^{i k_{j} L_{a}}\right)+\alpha_{j} A_{j} L_{a} i \omega P_{s} .
$$

If the electric signal source were an ideal voltage source, the voltage over the actuator would now be prescribed and the electrical resistance would vanish. The piezo current would be determined and measured as an indication of the acoustics in the channel. In reality however, the signal generator is not an ideal voltage source but has an output impedance $R_{p}$. Therefore the voltage over the piezo actuator is not imposed, but obtained as a part of the solution. The symbols that refer to electric properties of the measurement system are clarified in Figure 2.5. The piezo voltage is the sum of the actuation pulse $U_{a}$ and the voltage over the output impedance of the signal generator and the connections,

$$
U=U_{a}-I_{f} R_{p}
$$




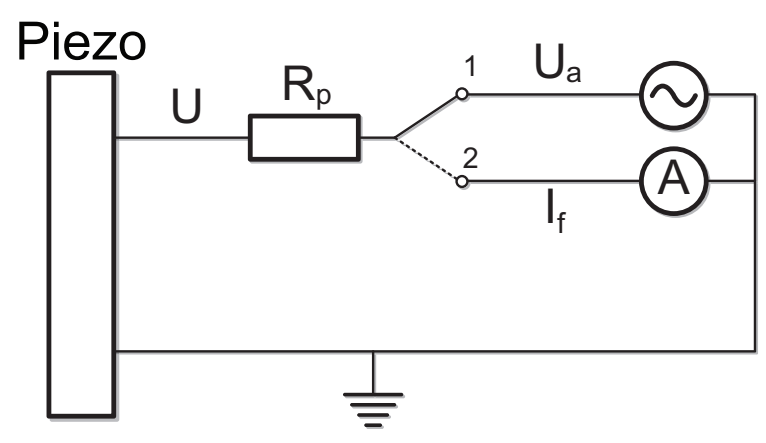

Figure 2.5: The simplified measurement circuit: The switch changes between 1, actuation and 2 , when the piezo is used as hydrophone. The output impedance, $R_{p}$, is in reality distributed throughout the system. It consists of resistance at connections, in wires, in the amperemeter, and in the voltage source. The jet pulse $U_{a}$ differs from the voltage $U$ over the piezo electrodes due to this resistance. In reality, the voltage source consists of a number of linked devices: an arbitrary waveform generator, a switchboard, and amplifiers.

When Equation 2.19 is inserted into Equation 2.18, an expression for the piezo current with a nonideal voltage source is obtained,

$$
I_{f}=i \omega C_{p}\left(U_{a}-I_{f} R_{p}\right)+\alpha A_{j} \frac{\omega}{k_{j}}\left(-P_{r, j} e^{-i k_{j} L_{a}}+P_{l, j} e^{i k_{j} L_{a}}\right)+\alpha A_{j} L_{a} i \omega P_{s} .
$$

Upon rearranging, the piezo current for a finite output resistance is obtained as

$$
I_{f}=\frac{1}{1+i \omega C_{p} R_{p}}\left(i \omega C_{p} U+\alpha_{j} A_{j} \frac{\omega}{k_{j}}\left(-P_{r, j} e^{-i k_{j} L_{a}}+P_{l, j} e^{i k_{j} L_{a}}\right)+\alpha_{j} A_{j} L_{a} i \omega P_{s}\right) .
$$

This expression shows that a finite output resistance acts as a low-pass filter with a cutoff frequency of $\omega_{c}=\frac{1}{C_{p} R_{p}}$. Since the order of magnitude of the output impedance is typically $R_{p}=100 \Omega$ and the capacitance of the piezo actuator is about $1 n F$, the cutoff frequency is typically $\omega_{c}=10 \mathrm{MHz}$. The order of magnitude of the resonance frequencies of the printhead is $100 \mathrm{kHz}$, which is much smaller. Therefore, the output impedance can be neglected.

The coupling coefficient $\alpha_{j}$ and the wall flexibility $\beta_{j}$ can be determined by comparison of the measured and calculated piezo current. Modifying the coupling coefficient changes the magnitude of the measured signal, but not its shape. So when the correct value of $\alpha_{j}$ is used in the model, the amplitudes of the measured and calculated piezo currents are equal. The wall flexibility 
changes the resonance frequencies of the channel. Thus, when the correct value of $\beta_{j}$ is used, the frequencies that are present in the calculated piezo current match those in the measured signal. These conditions were used to determine both parameters. Now that these parameters have been determined, the current from a printhead with a bubble can be modeled and compared with the experiment (see Figure 2.6).

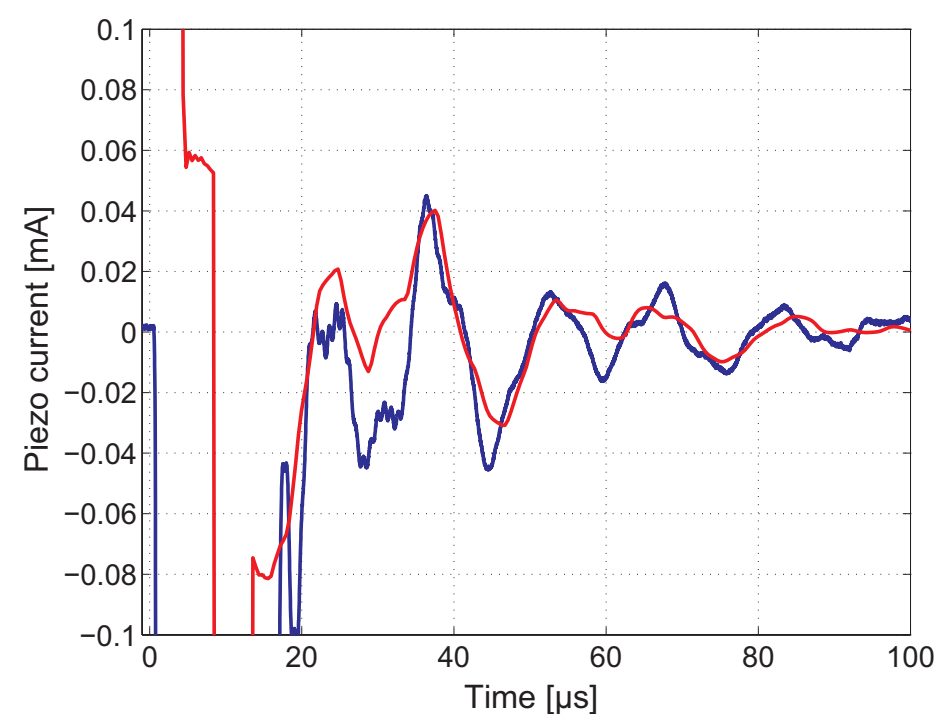

Figure 2.6: The measured (blue line) and calculated piezo currents (red line). Both amplitude and frequency match which indicates that both the wall flexibility and the piezo electric coupling coefficient are chosen correctly. The amplitude deviation in the beginning of the signal is probably caused by the dielectric relaxation of the piezo. 


\subsection{Comparing the model with experiments}

In order to compare the model with the experiment, it is convenient to single out the change in the piezo current due to the bubble. Therefore, the piezo current of the undisturbed nozzle $I_{0}$ is subtracted from the piezo current obtained when a bubble is entrapped $I\left(V_{b}\right)$. This gives the differential piezo current

$$
\tilde{I}\left(V_{b}\right)=I\left(V_{b}\right)-I_{0} .
$$

We will distinguish between the experimental differential current $\tilde{I}_{e}$, with a corresponding optical measured bubble volume $V_{e}$, and the differential current resulting from the model $\tilde{I}_{m}\left(V_{m}\right)$, where $V_{m}$ is the volume of the bubble assumed in the calculation. The undisturbed piezo current is obtained experimentally by measuring the piezo current in the absence of an entrained bubble. With the model, the undisturbed current can be obtained by setting the bubble volume to zero. Figure 2.7 shows examples of experimentally obtained differential currents $\tilde{I}_{e}$. This figure illustrates again the pronounced change in the piezo current when

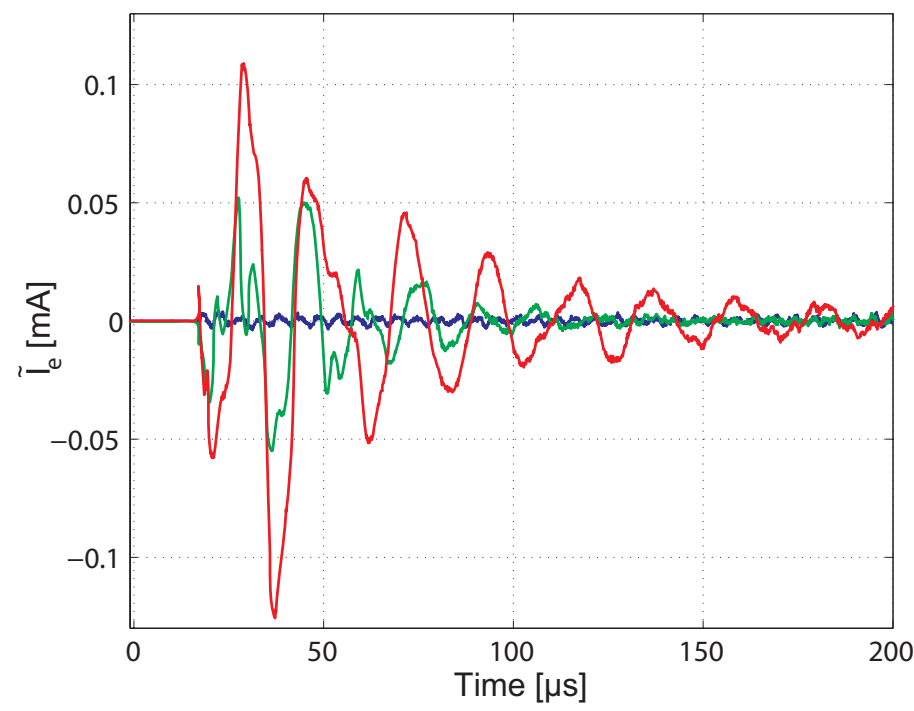

Figure 2.7: Experimentally obtained differential piezo currents $\tilde{I}_{e}=I_{e}-I_{0}$. The blue line shows the signal of an undisturbed channel, the green line shows the signal when a bubble of $5 \mathrm{pl}$ is entrapped and the red line shows the signal when a bubble of $81 \mathrm{pl}$ is entrapped. The signal from the undisturbed channel shows the magnitude of noise in the measurements. Obviously, in the absence of noise, the differential piezo current of the undisturbed channel would have vanished throughout.

an air bubble is present, compared to the current of an undisturbed channel. 


\subsection{COMPARING THE MODEL WITH EXPERIMENTS}

Moreover, it shows that even for very small bubbles, the change in the piezo current is still significant.

The difference between the measured and calculated piezo current can be expressed as $\delta_{i}\left(V_{m}\right)$, the relative norm of the difference, defined as

$$
\delta_{i}\left(V_{m}\right)=\frac{\left\|\tilde{I}_{e}-\tilde{I}_{m}\left(V_{m}\right)\right\|}{\left\|\tilde{I}_{e}\right\|} .
$$

Here the $L_{2}$ norm is used, which is defined as

$$
\|f(t)\|_{2} \equiv \sqrt{\frac{1}{T} \int_{0}^{T}|f(t)|^{2} \mathrm{~d} t} .
$$

The norm of the difference is nondimensionalized using the norm of the measured differential current. In case of a bubble inside the channel, the value of $\delta_{i}\left(V_{m}\right)$ depends on the bubble volume $V_{m}$ that is assumed in the calculation. The value of $\delta_{i}\left(V_{m}\right)$ is close to zero when the differential current of the

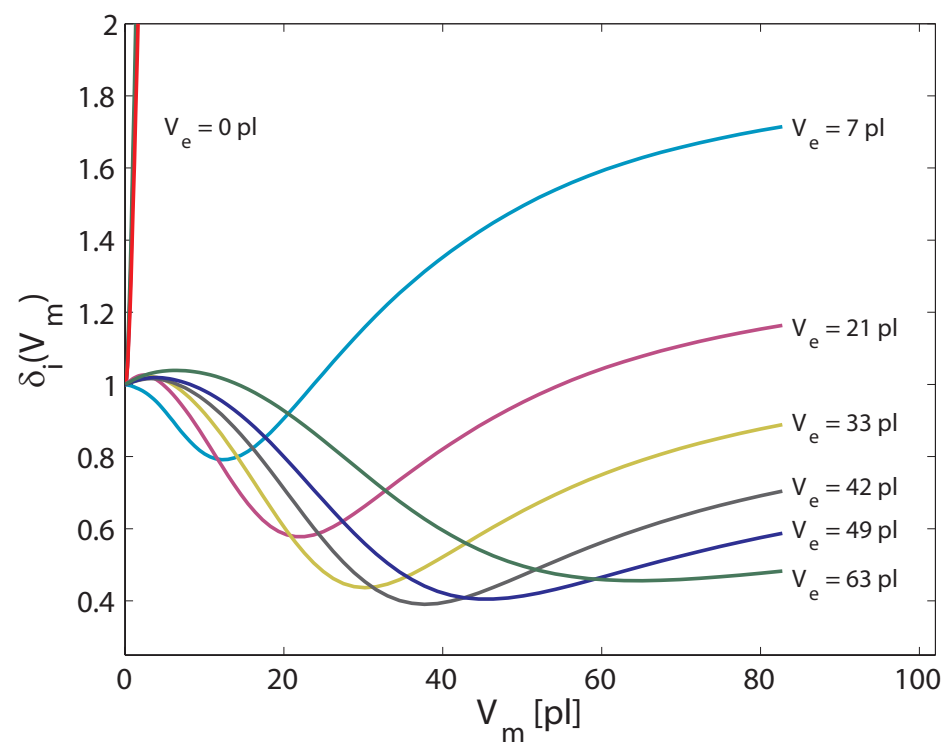

Figure 2.8: Norm of the difference between the measured and calculated disturbances. This function of the bubble volume has a distinct minimum where the agreement between the model and the experiment is the highest. The graphs where no bubble is present rise sharply from a value of $\delta_{i}\left(V_{m}\right)=1$ at zero bubble volume. The optically found bubble volumes are shown on the right of the curves; it agrees with the position of the minimum, revealing the success of the employed model. 
model matches the differential current of the experiment. Note that $\delta_{i}\left(V_{m}\right)$ is a positive definite function of the bubble volume that is assumed in the calculation. Therefore, when $\delta_{i}\left(V_{m}\right)$ reaches a minimum, the match between model and experiment should be optimal. The value $V_{m}$ for which this minimum is reached should then correspond to the measured bubble volume. In Figure 2.8 the relative norm of the difference is shown for eight measured piezo currents as a function of the assumed bubble volume. The functions are smooth and well behaved, which facilitates the search for their minimum. In the domain used in the calculation only a single minimum is found for $\delta_{i}\left(V_{m}\right)$. To illustrate the agreement between the model and experiment at this minimum, Figure 2.9 shows the differential piezo current of a measurement with its modeled counterpart. In this example, the optically obtained bubble volume was $81 \mathrm{pl}$. By inserting the corresponding piezo current into the model the minimum in $\delta_{i}\left(V_{m}\right)$ was found for a bubble of $86 \mathrm{pl}$. As can be seen in Figure 2.9, the calculated piezo current closely resembles the measured piezo current in both frequency and amplitude.

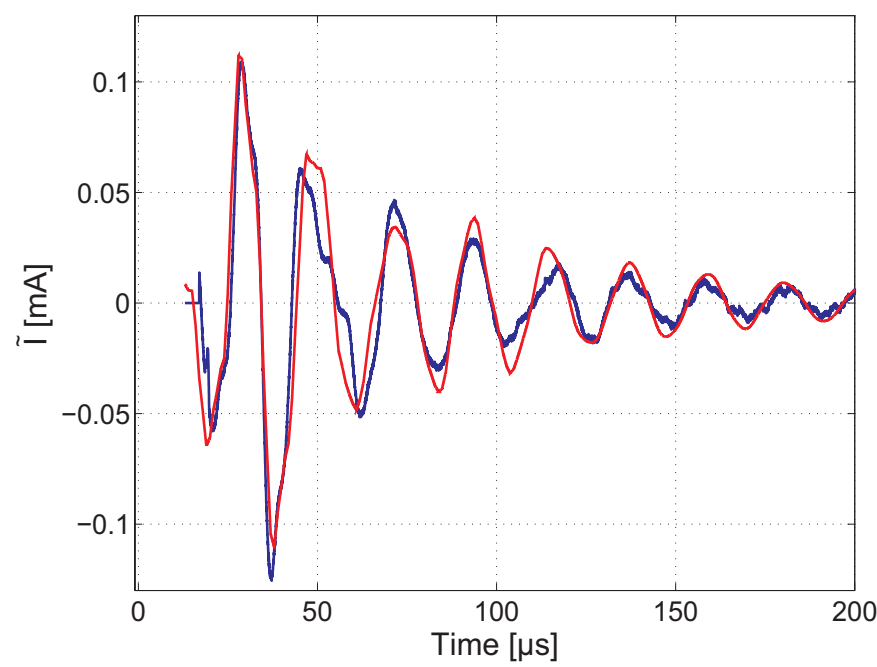

Figure 2.9: The calculated differential piezo current $\tilde{I}_{m}\left(V_{m}\right)$ (red) is compared with the experimentally obtained differential piezo current $\tilde{I}_{e}\left(V_{e}\right)$ (blue). For these currents the model finds a bubble volume of $86 \mathrm{pl}$, which is close to the value of $81 \mathrm{pl}$ that was measured optically.

The quality of the model becomes even more convincing in Figure 2.10, where $V_{e}$, gathered during the bubble dissolution process, is compared with $V_{m}$ calcu- 


\subsection{COMPARING THE MODEL WITH EXPERIMENTS}

lated by the model. For both methods, the absolute error is given by the colored area. The absolute error in the optically obtained bubble volume increases with the bubble volume. This originates from the measurement method, where the radius is extracted from the images with an accuracy of a few pixels. The absolute error is about $0.9 \mu \mathrm{m}$, independent of the bubble size itself. As the bubble volume is $V_{e}=\frac{4}{3} \pi r_{e}^{3}$, where $r_{e}$ is the bubble radius, the relative error in the bubble volume is three times the relative error in the radius; $\frac{\Delta V_{e}}{\left|V_{e}\right|}=3 \frac{\Delta r_{e}}{\left|r_{e}\right|}$. Correspondingly, the absolute error $\Delta V_{e}=\left(4 \pi r_{e}^{2}\right) \Delta r_{e}$, is quadratic in the bubble radius. Note that the error in the optical bubble volume does not affect the error in the calculated result, as $V_{e}$ is not a parameter of $\delta_{i}\left(V_{m}\right)$, but only the current $I_{e}$ which was measured simultaneously with $V_{e}$.

The error in the acoustic measurement $\Delta V_{m}$ is calculated from the minimum value in Figure 2.8 by using

$$
\Delta V_{m}=\frac{\left\|\tilde{I}_{e}-\tilde{I}_{m}\left(V_{m}\right)\right\|_{2}}{\frac{\partial}{\partial V_{m}}\left\|\tilde{I}_{m}\left(V_{m}\right)\right\|_{1}} .
$$

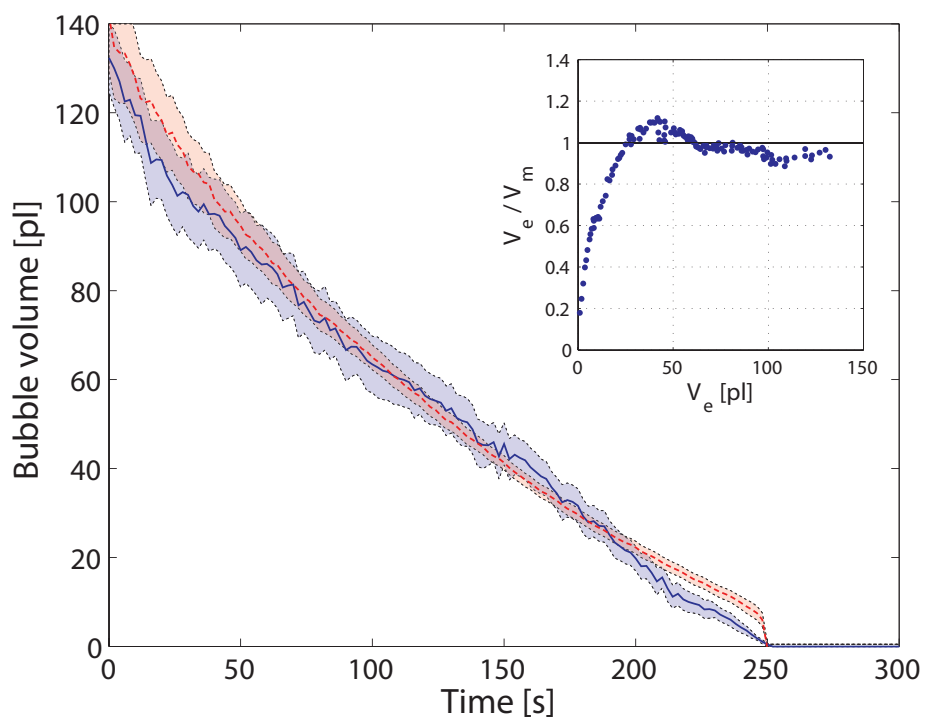

Figure 2.10: Acoustically measured bubble volume $\left(V_{m}\right)$ is shown as a red line and the optically measured bubble volume $\left(V_{e}\right)$ is shown as a blue line. The areas around the lines give the error margins in the results. In the inset, the ratio of the optically measured bubble volume over the acoustically measured bubble volume is shown. This illustrates that the relative error diverges for small bubbles. For larger bubbles, the relative error is less then 12 percent. 
Here the difference between the calculated piezo current and the measured piezo current is assumed to be Gaussian white noise. The derivative is evaluated by a finite difference approximation.

In the inset of Figure 2.10, the ratio of the acoustically measured bubble volume over the optically measured bubble volume is shown. This illustrates that for bubbles above $20 \mathrm{pl}$, the relative error is less than 12 percent. For small bubble the relative error diverges, and the acoustic measurement method becomes less accurate. This is attributed to nonlinear volume oscillations of the air bubble, which this linearized model cannot capture.

\subsection{Conclusion}

A linear model was used to estimate the volume of a bubble in an inkjet channel. With this model it was shown how a bubble influences the channel acoustics of an inkjet printhead. The linear approximation in this model is valid for bubbles that are larger than $20 \mathrm{pl}$. Small bubbles exhibit nonlinear behavior, which are not captured by the model, resulting in a less accurate volume predictions in this regime. To overcome this problem, the method can be extended by solving the full nonlinear equations. The two-way coupling with the channel acoustics turns the Rayleigh-Plesset equation into a delay differential equation. This nonlinear equation can be solved numerically [43] at the cost of increased calculation time.

The model calculates the current through the actuator. By comparing this current with experimentally obtained currents, the model is able to accurately determine the bubble volume. In this way an acoustic measurement method for the volume of entrapped air bubbles is obtained. This method was validated by optically imaging the bubble volume. Additionally, the result shows that the linear regime of volume oscillations of an air bubble inside an inkjet channel and the corresponding channel acoustics is well understood. 


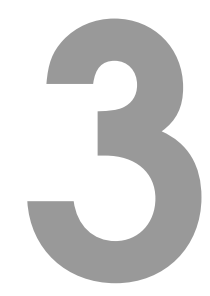

\section{Infrared imaging and acoustic sizing of a bubble inside a MEMS piezo ink channel $^{2}$}

Here we study a Micro-Electro-Mechanical Systems (MEMS)-based print head. By using the actuating piezo transducer in receive mode, the acoustical field inside the channel was monitored, clearly identifying the presence of an air microbubble inside the channel during failure of the jetting process. The infrared visualization technique allowed for an accurate measuring of the bubble size and the bubble dynamics inside the intact print head. A model was developed to calculate the mutual interaction between the channel acoustics and the bubble dynamics. The model was validated by simultaneous acoustical and infrared detection of the bubble. The model can predict the presence and the size of entrapped air bubbles inside an operating ink channel, purely from the acoustic response.

\subsection{Introduction}

Inkjet printing is the most wide spread technological application of microfluidics. It is becoming increasingly popular for applications that require precise material deposition, such as printing of electronics, displays, medical chips, solar panel printing and even for creating 3D structures [6]. There are several techniques for reliable drop generation and new techniques are still being developed, for example the E-jet which can be used to produce droplets smaller than a picoliter [44]. The two most common techniques are thermal inkjet printing, used for printing water based liquids, and piezo inkjet printing, which is used

\footnotetext{
${ }^{2}$ Submitted as: Arjan van der Bos, Tim Segers, Roger Jeurissen, Hans Reinten, Marc van den Berg, Herman Wijshoff, Michel Versluis, and Detlef Lohse, Infrared imaging and acoustic sizing of a bubble inside a MEMS piezo ink channel, Journal of Applied Physics
} 
for printing various liquids. Because a piezo is used as an actuator, liquids with a broad range of viscosities and temperatures can be printed, making it widely applicable [2]. All applications require $100 \%$ reliability, well defined small droplets and, at the same time, demand increasingly higher productivity.

Micro-Electro-Mechanical-System (MEMS) technology is widely applied in the chip industry. MEMS technology is becoming increasingly important for future generations of piezo-driven print heads. With print heads on wafer scale, complex designs with sub-micron details can be produced at large quantities, while decreasing the overall cost per nozzle. This technique has already been applied for the development of thermal inkjet printing [45] and more recently MEMS-based piezo inkjet print heads have been developed [46]. Here we study a prototype print head from Océ Technologies B.V. with an integration density of four channels per square millimeter, and a drop production rate up to 100.000 droplets per channel.

Reproducibility and reliability of an ink channel do not only rely on the design of the print head, but also on the properties of the ink, the driving waveform that actuates the channel, and the environment in which the print head is operated. One reliability issue in piezo inkjet printing is when an air bubble gets entrapped inside the nozzle. Entrapment can occur due to an ink film on the nozzle plate or dust particles around the nozzle [14]. Also the printing process is more susceptible to air entrapment when the drop frequency increases. If the actuation is continued after the bubble entrapment, the bubble will grow due to rectified diffusion [19, 20, 22, 47]. The acoustic driving field inside the print head channel exerts a force on the bubble. The dominating forces are the primary Bjerknes force, which pulls the bubble into the channel, and the secondary Bjerknes force [19, 20, 22, 47, 48], which pushes the bubble against the channel wall. After several thousands of actuations the bubble has grown to a size, such that it pulsation contributes to the overall acoustic field. This results in a disturbed drop formation and, in some cases, to the stopping of the jetting process [14, 17]. The only method to restore the nozzle performance is either to flush ink including the bubble, or to stop the actuation for the bubble to dissolve due to capillary forces. Both of these methods consume both ink and time and are therefore highly undesirable.

To increase the reliability of the channel Océ Technologies B.V. has invented a technique to monitor the channel acoustics while printing [13], comparable to the technique disclosed in Kwon et al. [36, 49]. A similar technique was also applied in chapter 2 and in reference [17, 18, 50], and has proven to be a reliable technique to monitor the onset and growth of disturbances. To investigate the applicability of this technique in a order of magnitude smaller print head channel, in this paper the complex relations between acoustics and 


\subsection{INTRODUCTION}

the bubble dynamics are studied. This is done by measuring the acoustic signal, while simultaneously visualizing the air bubble. As silicon becomes transparent for wavelengths between $1.1 \mu \mathrm{m}$ and $6 \mu \mathrm{m}$ (near-infrared light), it is possible to visualize the inner channel. The principle of visualizing flows inside silicon devices was already demonstrated in earlier research where PIV was performed inside a MEMS-based fluidic device [51-53]. In the following, two situations are studied. First a bubble dissolving inside the channel, secondly a stable bubble oscillating in the acoustic field. The experiments are compared with a one-dimensional acoustic model, which has proven to be fast and reliable for calculating the channel pressure and the flow rate, as was shown in chapter 2. Two-way coupling between the channel acoustics and the bubble dynamics is included in the model. A comparison of the modeled and measured acoustic signal leads to a prediction of the bubble size. The infrared images are then used to verify the results from the acoustic model. Finally, the model is used to predict the effect of the presence of a bubble on the ink velocity inside the nozzle.

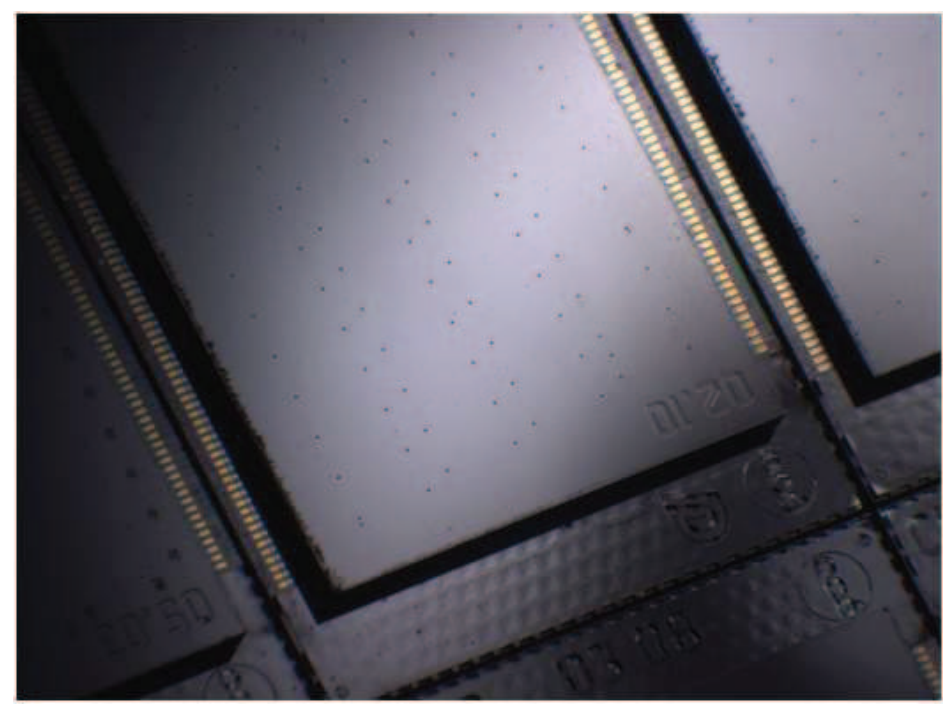

Figure 3.1: Partial view of a MEMS inkjet print head on a wafer. The single chip contains eight rows of nozzles and on the sides of the chip the connections for the electronics are shown. Next to the chip the edges of the neighboring chips are visible. The chip used in this research contains 320 individually controllable nozzles. 


\subsection{Geometry of the MEMS channel}

The print head used for this research is designed and developed by Océ Technologies B.V. in the Netherlands and is a MEMS (Micro-Electro-Mechanical System) based design containing 320 individual channels integrated into a single chip (Figure 3.1). A schematic overview of a single channel is shown in Figure 3.2. The ink is supplied from a reservoir, which is placed on top of the chip. From the reservoir the ink flows through a restriction into the actuation chamber, $400 \mu \mathrm{m} \times 400 \mu \mathrm{m} \times 75 \mu \mathrm{m}$ in size. Below the actuation chamber the ink flows into a $300 \mu \mathrm{m}$ long feed-through, with a diameter of $175 \mu \mathrm{m}$. A $75 \mu \mathrm{m}$ thick nozzle plate is positioned at the end of the feed-through. The nozzle plate consists of a pyramid shaped funnel and a cylindrical pipe with a radius of about $11 \mu \mathrm{m}$. To create the funnel the nozzle wafer is etched with a $\mathrm{KOH}$ solution. This dissolves the silicon preferential in the $<100>$ planes [54], resulting in a smooth surface with an angle of $54.7^{\circ}$.

The acoustic field is generated by a piezo element placed on top of the actuation chamber. The piezo is actuated with a trapezial pulse of $4 \mu \mathrm{s}(1 \mu \mathrm{s}$ rise, $2 \mu \mathrm{s} \mathrm{high} \mathrm{and} 1 \mu \mathrm{s}$ fall time), driving the channel at its resonant frequency. The channel is designed such that its resonance frequency is approximately $150 \mathrm{kHz}$, allowing for each individual channel to print droplets with frequencies up to $100 \mathrm{kHz}$. Applying the actuation pulse with an amplitude of $35 \mathrm{~V}$ results in droplets of $4 \mathrm{pl}$ and a velocity of approximately $6 \mathrm{~m} / \mathrm{s}$. The ink used is not water based, but a non-colored version of the CrystalPoint technology [55]. The ink, instead of drying, crystalizes on the paper, resulting into very rapid solidification. To liquify the ink the print head is operated at a temperature of $130^{\circ} \mathrm{C}$. At this temperature the viscosity of the ink is $10 \mathrm{mPas}$, with the density and surface tension of the ink $1080 \mathrm{~kg} / \mathrm{m}^{3}$ and $28 \mathrm{mN} / \mathrm{m}$, respectively.

\subsection{Visualizing in the infrared regime}

The challenge here was to visualize the air bubble inside the silicon channel. In the work presented in chapter 2 this was done by adding a glass insert to the channel and combine this with index-matching ink [17, 50]. Adding a glass insert to the MEMS print head, which is an order of magnitude smaller, would involve major modifications of the channel geometry, resulting in a complete different acoustic behavior. The channel is made predominantly of silicon which is transparent for near-infrared light at wavelengths of $1.1 \mu \mathrm{m}$ up to $6 \mu \mathrm{m}$, which may facilitate infrared imaging of the bubble inside the MEMS print head. This approach comes with quite an optical challenge, namely the large difference in refractive index between silicon, the ink in the channel, and the air 


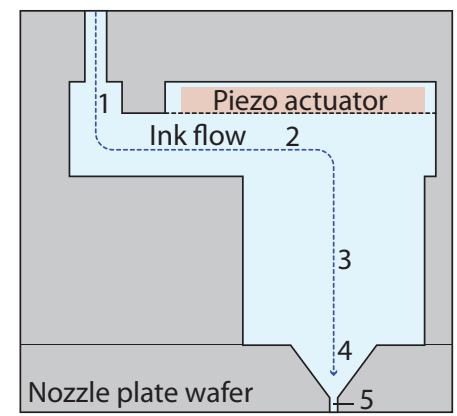

Side view

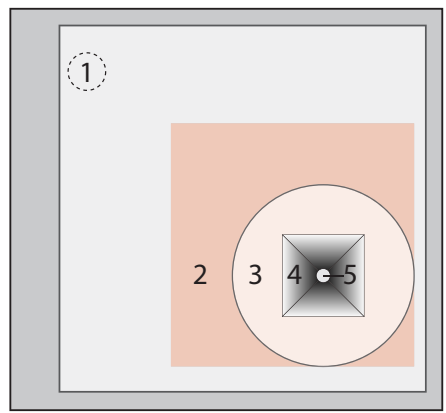

Bottom view

Figure 3.2: A schematic overview of the MEMS piezo inkjet channel. The left part shows a side view of the channel, and the right part a bottom view. The blue line depicts the ink-flow; the ink, coming from the reservoir, enters through a restriction (1), from where it flows into the actuation chamber (2). Below the actuation chamber a $300 \mu \mathrm{m}$ long feed-through is placed (3), after which the nozzle plate is reached. The nozzle plate is $75 \mu \mathrm{m}$ thick and consists of a pyramid shaped funnel(4) and a nozzle(5) with a radius of $11 \mu \mathrm{m}$.

surrounding the print head. The refractive index $n$ of silicon is approximately 3.5 at $1.2 \mu \mathrm{m}$. The ink used here is transparent for infrared light, but has a much lower refractive index of $n=1.5$. The consequences resulting from this difference becomes clear when the transmittance and reflectance of a light ray, passing a boundary between two media, is described. Light can be represented by two orthogonal linearly polarized waves, one parallel, and one orthogonal to the plane of incidence. These two polarizations are treated separately by the Fresnel equations [56],

$$
T_{\perp}=\frac{n_{t} \cos \theta_{t}}{n_{i} \cos \theta_{i}}\left(\frac{2 \sin \theta_{t} \cos \theta_{i}}{\sin \left(\theta_{i}+\theta_{t}\right)}\right)^{2},
$$


and

$$
T_{\|}=\frac{n_{t} \cos \theta_{t}}{n_{i} \cos \theta_{i}}\left(\frac{2 \sin \theta_{t} \cos \theta_{i}}{\sin \left(\theta_{i}+\theta_{t}\right) \cos \left(\theta_{i}-\theta_{t}\right)}\right)^{2} .
$$

Here $\theta_{i}$ gives the incident angle and $n_{i}$ the refractive index of the incident media, and $\theta_{t}$ the angle of refraction at the transmissive media with refractive index $n_{t}$. If the light source is unpolarized the transmittance is given by

$$
T=\frac{T_{\perp}+T_{\|}}{2} .
$$

When the incident light ray is perpendicular to the incident surface, $\theta_{i}=0$ equations 3.1 and 3.2 simplify to

$$
T=T_{\perp}=T_{\|}=\frac{4 n_{t} n_{i}}{\left(n_{t}+n_{i}\right)^{2}} .
$$

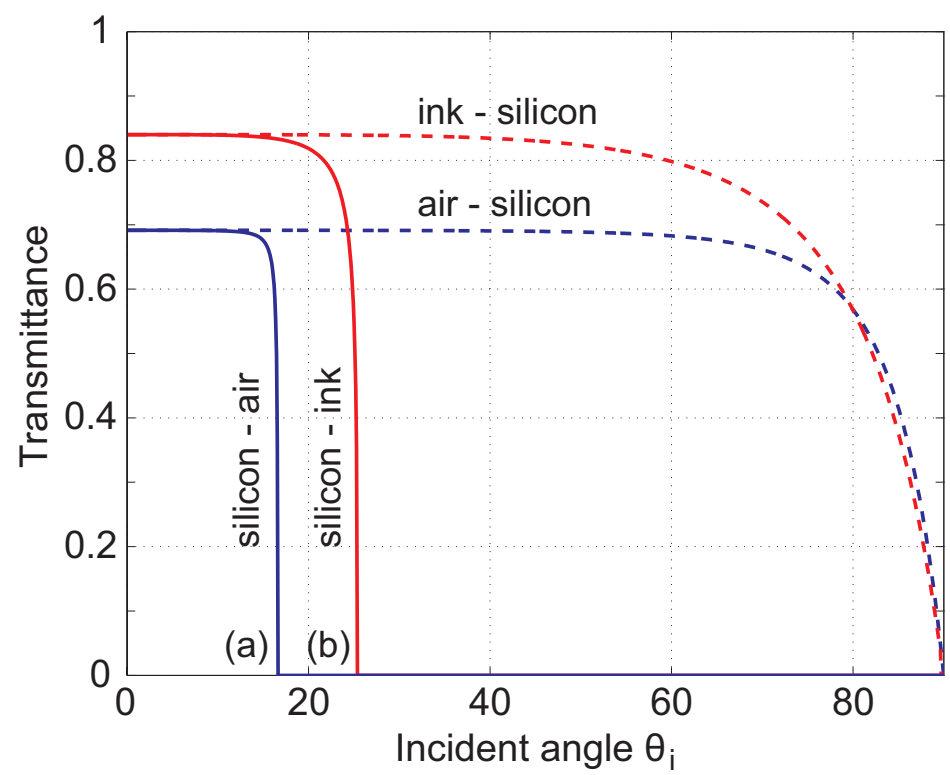

Figure 3.3: Unpolarized transmission curves for the silicon-ink, and silicon-air interfaces at a wavelength of $1.2 \mu \mathrm{m}$. The solid blue line gives the transmittance between silicon and air, the dotted blue line for the air-silicon interface, the solid red line for the ink-silicon interface, and the dotted line for the silicon-ink interface. As the light travels from the ink through the silicon $15 \%$ is reflected, and another $30 \%$ is lost at the silicon-air interface. Also the incident angles above which total internal reflection occurs can be seen. These are $16.6^{\circ}$ (a) for a silicon air interface and $25.4^{\circ}$ (b) for a silicon-ink interface. 
Using these equations the transmission curves for the silicon-ink and silicon-air interfaces can be calculated (Figure 3.3). This shows that at the ink-silicon interface at most $85 \%$ of the incoming light will be transmitted, and for the airsilicon interface only $70 \%$ of light is transmitted. Figure 3.3 also shows a critical angle of incidence above which all the light is reflected, termed total internal reflection [56]. For the silicon-air and the silicon-ink interface the critical angles are $16.6^{\circ}$ and $25.4^{\circ}$, respectively. To understand the consequence of the critical angle for visualizing the inkjet channel, a ray trace of the last section of the channel was performed (Figure 3.4). Figure 3.4. shows that all the rays that pass from the feed through to the funnel will be reflected at the silicon-air interface. Even rays that enter the funnel surface with an angle of $89^{\circ}$, still impinges the nozzle plate with an angle of $25.4^{\circ}$, resulting in total reflection. The only possible way to visualize the inner channel is if the rays pass through parallel planes, as is shown in Figure 3.4b.

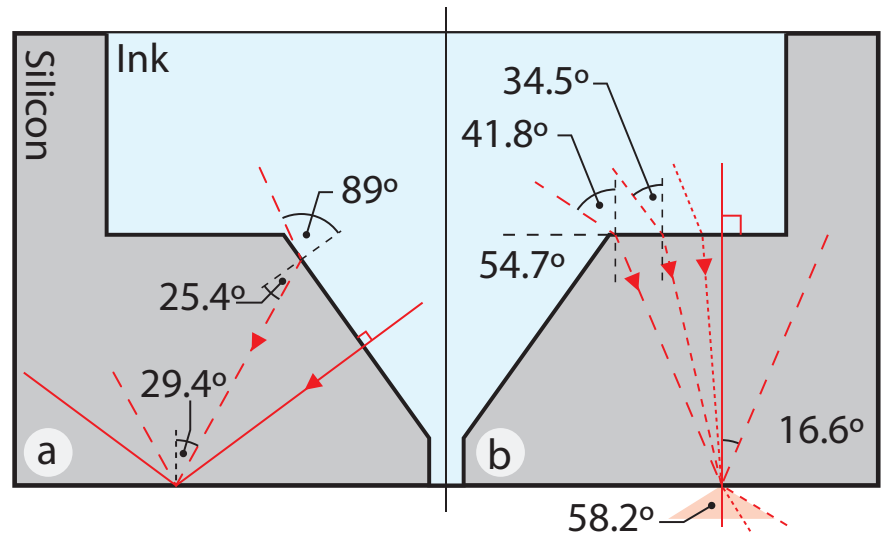

Figure 3.4: Ray trace of the light passing from the ink $(n=1.5)$ through the silicon nozzle plate $(n=3.5)$ to air $(n=1.0)$. In the left $(a)$ it is shown that all the light that falls onto the funnel area is refracted such that at the nozzle plate all the rays are reflected. In the right (b) it can be seen that the light passing through parallel planes can only be captured partly with the camera. The NA of the objective of 0.85 has an opening angle of $58.2^{\circ}$, light incidents the silicon surface with an angle of $34.5^{\circ}$ will be captured by the objective. The light that incidents under an angle of $41.8^{\circ}$ is fully reflected at the nozzle plate.

Illuminating the channel gives a similar challenge. As the channel is closely surrounded by neighboring channels, it is not possible to illuminate from the sides. Also illumination from above is not possible, as the upper part of the channel is covered by a piezo ceramic material. To overcome this problem 
the channel was illuminated from below, but again, only the light traveling perpendicular to the nozzle plate will be able to reach the inner part of the channel. This results in significant intensity loss, which was compensated by using a high-power infrared light source.

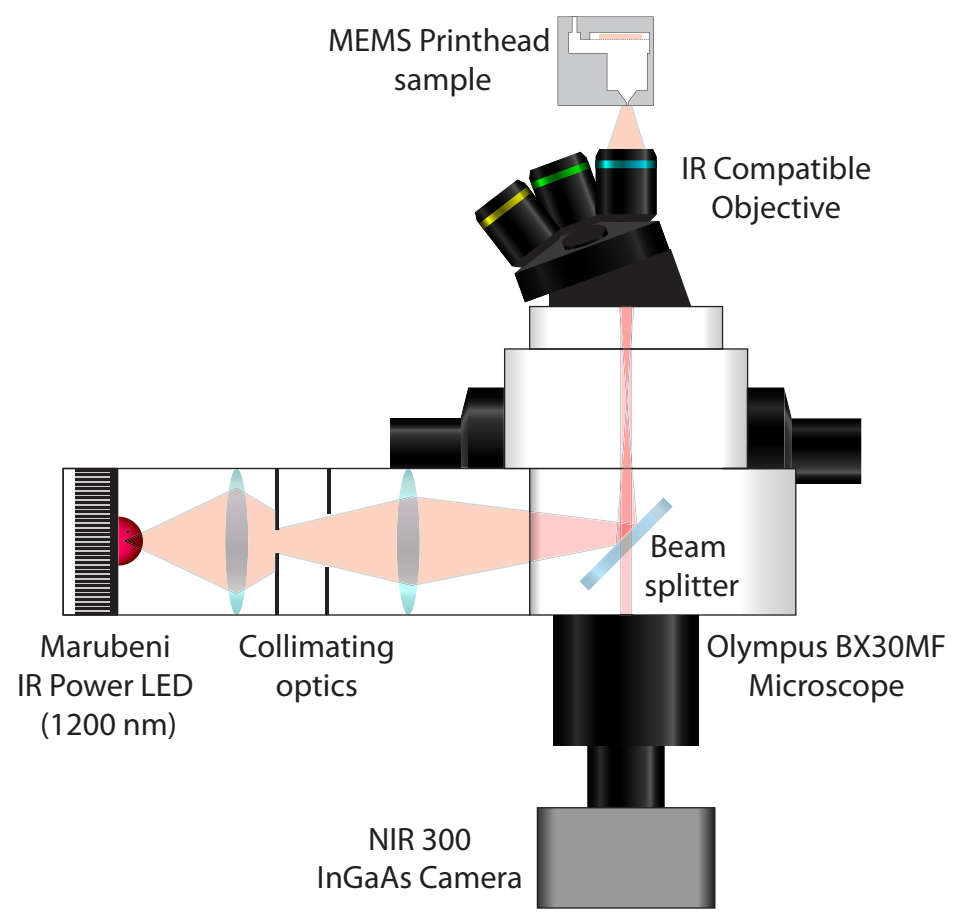

Figure 3.5: The reflected light setup that is used to for infrared visualization of the MEMS inkjet channel. As a light source a high intensity IR-LED with a wavelength of $1200 \mathrm{~nm}$ is used. A beam splitter is employed to reflect the light onto the objective. The light returning from the sample is gathered by the same objective and, after passing the beam splitter again, captured by the infra-red camera.

\subsection{Experimental parameters}

Reflected light microscopy allows for both the outgoing and the incoming light to be transmitted perpendicular onto the sample [57]. We use an Olympus $B X 30 M F$ microscope with an axial illumination unit(Olympus $U-R L A)$ as shown in Figure 3.5. The light source was a high intensity IR-LED (Marubeni, L1200-66-60), with a radiant power of $60 \mathrm{mWatt}$ and an intensity peak at a wavelength of $1.2 \mu \mathrm{m}$. By using a LED, illumination can be performed contin- 


\subsection{EXPERIMENTAL PARAMETERS}

uously as well as stroboscopically. An additional advantage of the LED is that, due to its narrow spectral bandwidth, chromatic abberation is minimized. The light from the LED is collimated, after which it passes through a beam splitter, then through the microscope objective, and finally onto the sample. The microscope objective has a magnification of 63 times and a numerical aperture of 0.85 . The reflected light from the sample is collected through the same microscope objective, passes through the beam splitter, and reaches the camera. The camera is a CCD camera (VDS Vosskühler, NIR-300), sensitive for wavelengths between $0.9 \mu \mathrm{m}$ and $1.7 \mu \mathrm{m}$, with a pixel size of $30 \mu \mathrm{m}$, and a maximum frame rate of $50 \mathrm{fps}$.

A typical visualization is shown in Figure 3.6 and shows a recording of a prototype MEMS print head. In the figure two channels next to each other are shown, also two neighboring channel pairs can be seen above and below. Also, at the top and bottom of the image, the edges the neighboring channels can be seen. The print head sample was not filled with ink.

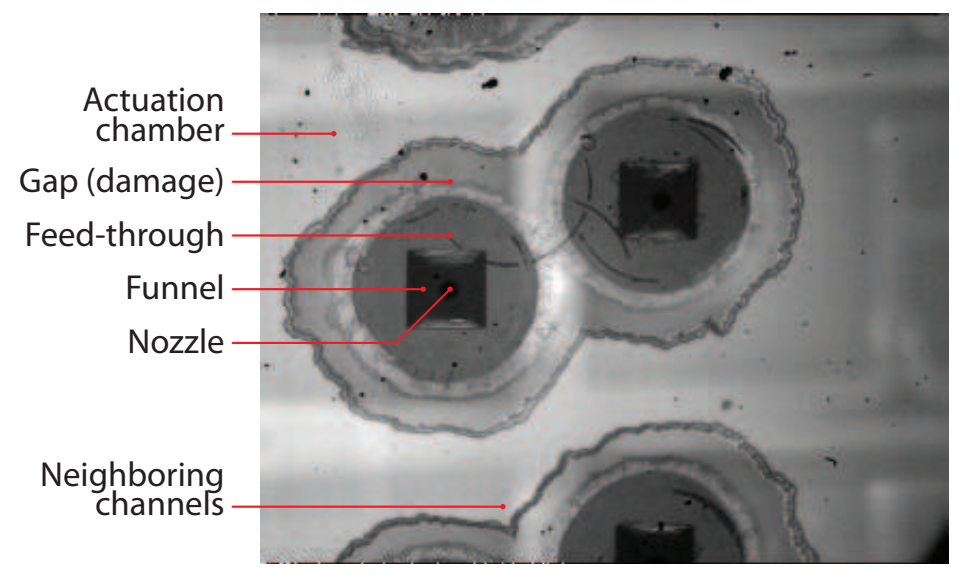

Figure 3.6: An infrared microscope image of one of the MEMS print head prototypes. The bottom view shows two channels facing each other. This image clearly shows the funnel, the feed-through section, and also the actuation chamber is just visible. Although the funnel seems to be slightly transparent, this is actually the light reflecting from the bottom side. There is also too little light passing through the nozzle area to illuminate this part. The gray area around the nozzle shows lack of glue in this prototype.

The acoustics were measured by using the piezo not only as actuator, but also in receive mode. The electronic circuit measured a relative change of the acoustics, with respect to normal operating conditions of the channel. Figure 3.7 shows both the acoustic signal of a normal operating channel and that 
of a disrupted channel.

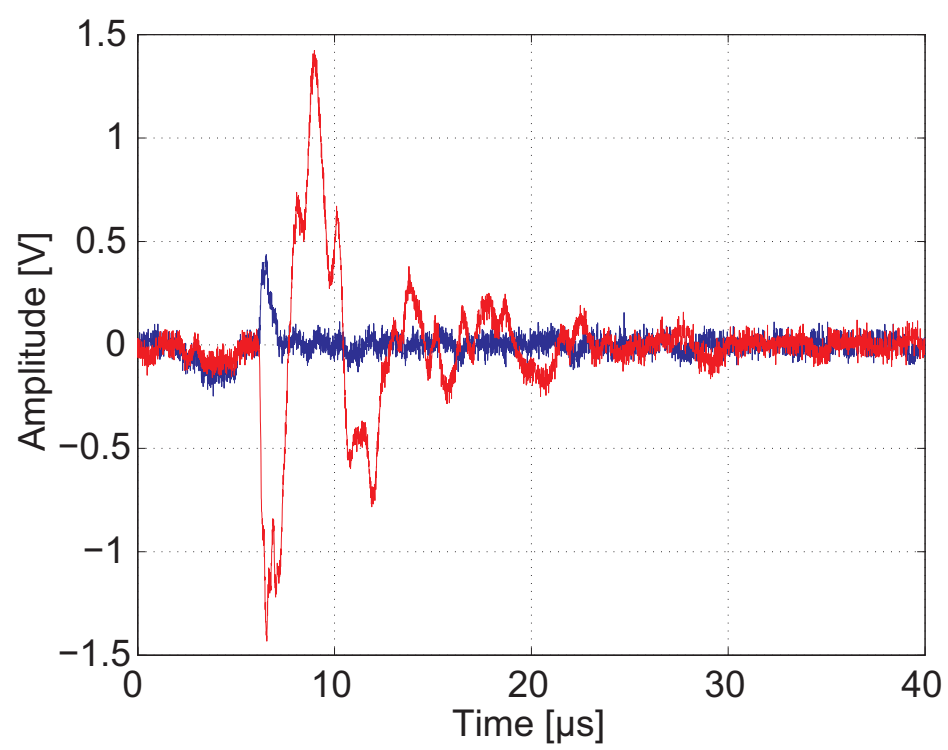

Figure 3.7: The acoustic signal of a normal operating channel (blue) is almost zero when the channel is functioning normally. If the acoustics are disrupted due to an air bubble the signal detection method deviates, showing high frequency components (red). With this measurement technique even small bubbles, of only a few picoliter, can be detected.

To capture the effect that an air bubble has on the channel acoustics, both the acoustic signal and visual recording have to be acquired simultaneously. As the process of air entrapment is a transient process, it is difficult to study the entrapment event itself. Moreover the size of the entrapped air bubble is below the optical resolution. Here we study a bubble already entrapped in the channel. The bubble was entrapped by actuating the channel at a very high frequency, which is known to enlarge the possibility of air entrapment. After the bubble is entrapped it grows due to rectified diffusion and changes position due to the Bjerknes forces [19, 20, 22, 47, 48]. It takes only milliseconds before the bubble reaches an equilibrium size and position, favoring a corner between the feed-through and the nozzle plate of the channel.

Two systems are studied here. To study a dissolving bubble first the bubble was entrapped, then the actuation frequency was lowered to $2 \mathrm{~Hz}$ only to probe the bubble size. At this very low frequency the growth caused by rectified diffusion is negligible. The channel was imaged just before the probing pulse, to prevent motion blur due to bubble oscillations. For each image the LED 
was set to illuminate the channel for a typical length of $10 \mathrm{~ms}$. A schematic illustration of the experiment is shown in Figure 3.8.

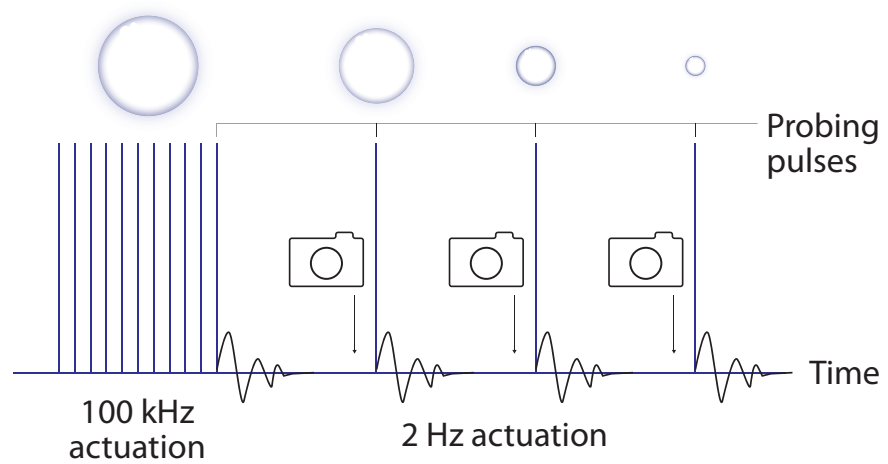

Figure 3.8: Overview of the experimental approach to capture both acoustic and optical response simultaneously. After a bubble is entrapped, the actuation frequency is lowered from $100 \mathrm{kHz}$ to $2 \mathrm{~Hz}$, consequently the bubble will dissolve. The low actuation frequency is required to measure the channel acoustics corresponding to a certain bubble size. Just before the channel is actuated, a microscope image of the channel is made.

An oscillating bubble inside the channel was also studied. After the bubble was entrapped the actuation frequency was lowered to $20 \mathrm{kHz}$. The bubble moves to a fixed position and reaches an equilibrium size. If the actuation parameters remain constant the bubble will stay at this position for minutes without an effective change in volume. The bubble oscillation was extremely stable which allowed us to create an image by multiple illuminations at a fixed time in the oscillation. The single image required 400 flashes of 300 ns. By changing the time delay between the actuation and the illumination with steps of $0.5 \mu \mathrm{s}$, a stroboscopic movie of the bubble oscillation could be recorded.

\subsection{Modeling the print head}

To understand how the bubble affects the channel acoustics a one-dimensional acoustic model was developed. This model was also applied in chapter 2 to predict the size of an air bubble inside the channel of a print head [50]. It models the propagation of acoustic waves in a viscous medium in a flexible pipe. Also the piezo transmit transfer function is included in the model, and the channel acoustics at the piezo section are calculated to recover the electric response of the piezo. The model includes the two way coupling between the 
air bubble inside the channel and the channel acoustics. In the model the print head channel is treated as a number of axisymmetric coupled sections, as shown in Figure 3.9. Within an individual section the fluid properties and the material parameters are kept constant. The relevant parameters of each section $(j)$ are the piezo electric expansion coefficient $\alpha_{j}$, the wall flexibility $\beta_{j}$, the cross sectional area $A_{j}$, and the length $L_{j}$. The piezo electric expansion coefficient is defined as the volume displacement due to the actuation voltage,

$$
\alpha \equiv\left(\frac{\partial V}{\partial U}\right)_{P}
$$

where $U$ is the voltage over the electrodes of the piezo element and $P$ is the pressure in the channel. The wall flexibility can be defined as the change of volume due to the pressure given by

$$
\beta \equiv\left(\frac{\partial V}{\partial P}\right)_{U}
$$

These two quantities can either be determined with a structural mechanics calculation, provided that the geometry and material parameters are accurately known, or they can be determined by measuring the piezo current in the absence of a bubble. The pressure $P$ is decomposed in the waves propagating to the left $P_{l}$ and to the right $P_{r}$. For each channel section, the amplitudes of the left and right propagating waves are calculated per frequency,

$$
P=\sum_{j} P_{r} e^{i\left(\omega_{j} t-k x\right)}+P_{l} e^{i\left(\omega_{j} t+k x\right)}+P_{s} .
$$

The actuator pressure $P_{s}$ depends only on the imposed actuator voltage. The wave number $k$ is a complex quantity due to viscous dissipation. The boundary conditions are continuity of pressure and volume flow rate. The overall parameters are the velocity of sound in the liquid $c$, the liquid density $\rho$, the viscosity $\mu$.

The effect of the bubble is included in the volume flow rate boundary condition at a channel crossing by explicitly considering the flux $q_{b}$ from the bubble,

$$
A_{j-1} u_{j-1}=A_{j} u_{j}+q_{b} .
$$

Here $A_{j}$ is the cross-sectional area of the corresponding channel section and $u_{j}$ is the fluid velocity in this section, where $j \in\{1,2,3,4\}$ corresponds to the restriction channel, the actuation channel, the feed-through, and the funnel, respectively. If the bubble is not positioned at a channel crossings, a virtual channel crossing is added to the model. In this way the bubble can move freely 


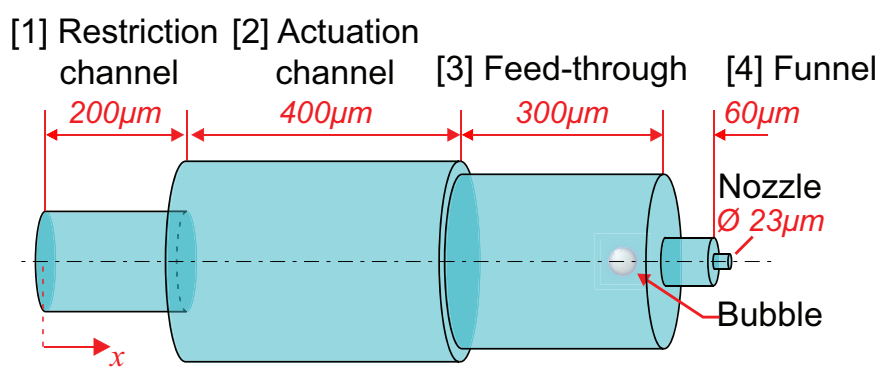

Figure 3.9: The ink channel as it is implemented in the model. The ink flow is directed from left to right and passes the restriction (1), actuation channel (2), feed-through (3) and finally the funnel (4) and nozzle section.

through the entire geometry. The volume flux from the bubble is calculated with the Rayleigh-Plesset equation [19, 20]

$$
R \ddot{R}+\frac{3}{2} \dot{R}^{2}=\frac{1}{\rho}\left(P_{g}(R)+P_{v}-\frac{2 \sigma}{R}-\frac{4 \mu \dot{R}}{R}-P_{\infty}(t)\right) .
$$

In the Rayleigh-Plesset equation, $R$ is the bubble radius, $P_{g}(R)$ is the gas pressure in the bubble, $P_{v}$ is the saturated vapor pressure of the ink, and $\sigma$ is the surface tension of the ink. The gas pressure is obtained from the polytropic relation, assuming an isothermal bubble. The saturated vapor pressure is $P_{v}=2.4 \mathrm{mNm}^{-2}$ and the surface tension is $\sigma=28 \mathrm{mNm}^{-1}$. Through the ambient pressure $P_{\infty}$, which is obtained from the channel acoustics calculation, the channel acoustics are coupled to the bubble dynamics. A more extensive treatment of this model can be found in references [18, 50].

The dimensions of the model geometry, shown in Figure 3.9. were calculated by maintaining the same length and area for each section as in the MEMS print head. The two remaining parameters, the electric expansion coefficient $\alpha$ and the wall flexibility $\beta$, were determined with ANSYS 12 [58], giving $\alpha=0.2 \mathrm{pl} / \mathrm{V}$ and $\beta=1.2 \mathrm{pl} / \mathrm{bar}$. With the geometry, $\alpha$, and $\beta$ defined, the piezo response can be calculated. Figure 3.10 shows the calculated acoustic signal and that of the experiment. Here the acoustic signal was calculated for a bubble with a radius of $11 \mu \mathrm{m}$, which corresponds to the optically measured value of $11 \pm 1 \mu \mathrm{m}$. Thus we find excellent agreement between measured and modeled acoustic pressure. 


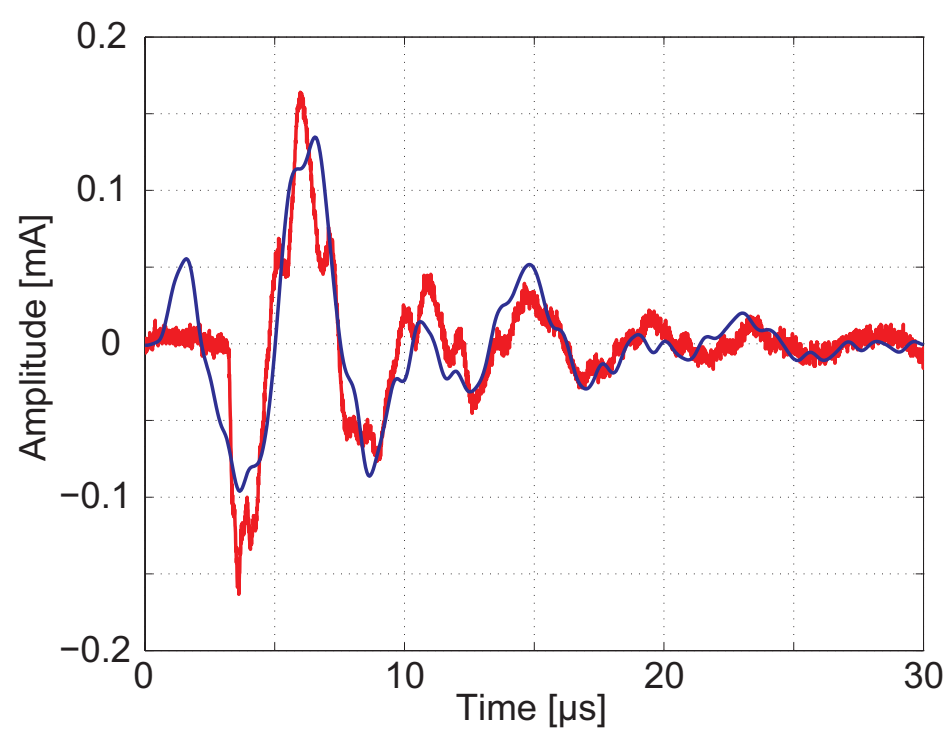

Figure 3.10: The acoustic signal calculated by the model (blue) compared with the acoustic signal from the experiment (red). In both the model and the experiment an air bubble of $11 \mu \mathrm{m}$ was present at the feed-through-funnel crossing. 


\subsection{Results}

The model can be used to calculate the pressure and the flow rate in the individual channel sections and to calculate how the presence of the bubble influences these quantities. The validity of the model was tested by comparing the calculated results with the experimental results of a dissolving bubble and of an oscillating bubble.

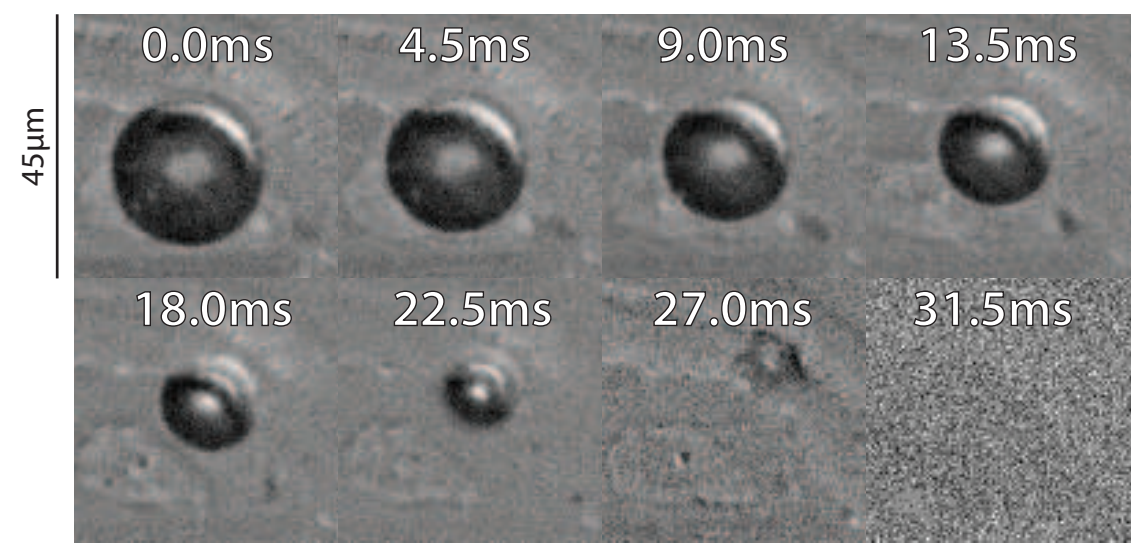

Figure 3.11: A sequence of a bubble dissolving inside the ink channel. The initial bubble has a radius of $12 \mu \mathrm{m}$, which fully dissolves in 30 seconds with an approximate dissolution rate of $0.3 \mathrm{pl} / \mathrm{s}$.

\section{Dissolving bubble}

We recorded the dynamics of air bubbles entrapped inside the channel. Figure 3.11 shows a selection taken for a non-actuating case where the bubble dissolves. This sequence was used to determine the radius $R_{\exp }$ of the bubble, as shown in Figure 3.12. From these experiments it was found that a bubble with radius $R_{\exp }=12 \mu \mathrm{m}$ dissolves in approximately 30 seconds, corresponding to the volume of $0.3 \mathrm{pl} / \mathrm{s}$ which is the same order of magnitude as was found in [50]. The error analysis shown in Figure 3.12 is derived from the image processing, the error due to possible deformations of the bubble is averaged out.

We also model the bubble radius that corresponds to the acoustics signals acquired from the measurement $\left(I_{\text {exp }}\right)$. For that purpose the model was set to calculate an acoustic signal $\left(I_{\text {mod }}\right)$ for a certain bubble size $\left(R_{\text {mod }}\right)$. The calculated signal was then compared with the experimentally obtained acoustic 
signal by calculating the relative norm of the difference $\left(\delta_{i}\left(R_{\text {mod }}\right)\right)$ given by

$$
\delta_{i}\left(R_{\mathrm{mod}}\right)=\frac{\left\|I_{\exp }-I_{\bmod }\left(R_{\bmod }\right)\right\|}{\left\|I_{\exp }\right\|}
$$

Equation 3.10 is calculated by iteration over a range of bubble radii until $\delta_{i}$ reaches a minimum. The value of $\delta_{i}$ at this minimum and the sensitivity of $\delta_{i}$ to $R_{\text {mod }}$ is used to determine the error in the calculation as explained in chapter 2. The calculated bubble radius from this comparison are also shown in Figure 3.12, where good agreement is found between the model and the experiments. It can be seen in the figure that the modeled radius decreases significantly after 20 seconds. This coincides with the bubble moving into a slit between the nozzle plate and the feed-through. The model is no longer applicable here, as the geometry at this position strongly deviates from the modeled geometry.

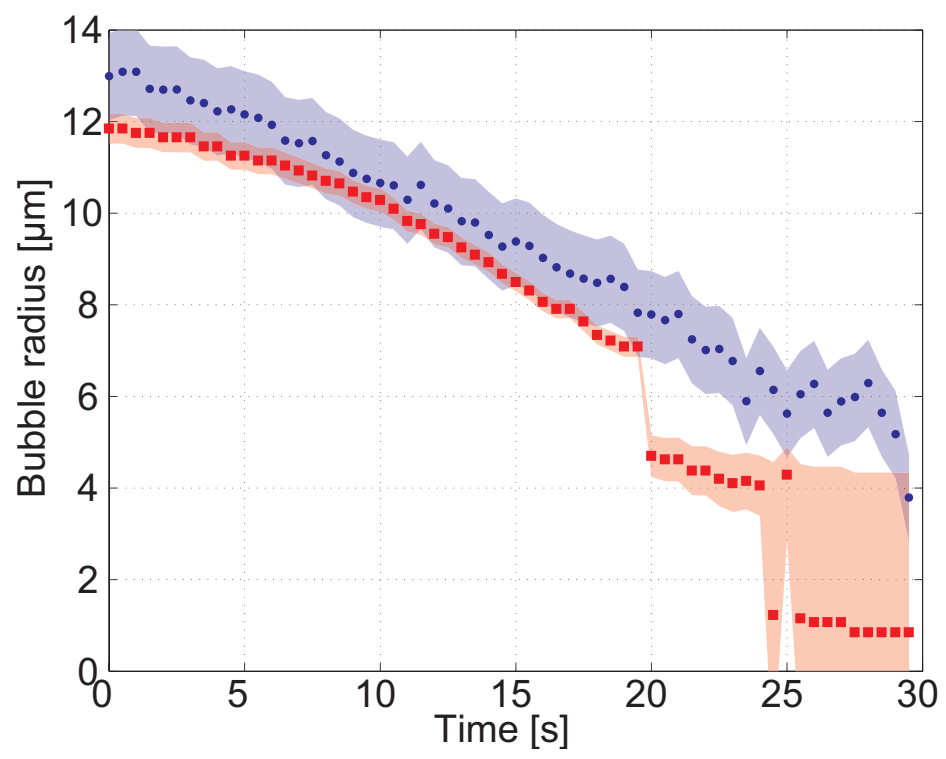

Figure 3.12: Using the infrared images the bubble radii could be measured as a function of time (blue dots). The model was also used to predict the bubble radii which is shown in red squares. The experimentally measured bubble radii agree with the calculated radii. After 22 seconds the bubble is pushed into a slit which could cause the deviation in the model at this point. The colored area around the point depicts the error in both these methods. 


\subsection{RESULTS}

\section{Oscillating bubble}

The infrared experiments were also used to capture the radius as a function of time of an oscillating bubble, $R_{\exp }(t)$. The pressure $P_{\bmod }(t)$ in the channel close to the bubble was calculated with the acoustic model using the initial bubble radius $R_{\exp }(0)$ as an input parameter. The expected radius as a function of time $R_{\mathrm{RP}}(t)$ is then calculated with the Rayleigh-Plesset equation, using the calculated channel pressure $P_{\bmod }(t)$ and the experimentally measured $R_{\exp }(0)$ as input parameters. The radius calculated from the Rayleigh-Plesset equation $R_{\mathrm{RP}}(t)$ is compared with the experimentally measured radius $R_{\exp }(t)$ in Figure 3.13 and so the model is validated. The agreement is very good, considering that the error in the radius of the bubble is in the order of three microns. This error is a result of the asymmetrical shape of the bubble as it is pushed into a corner of the channel.

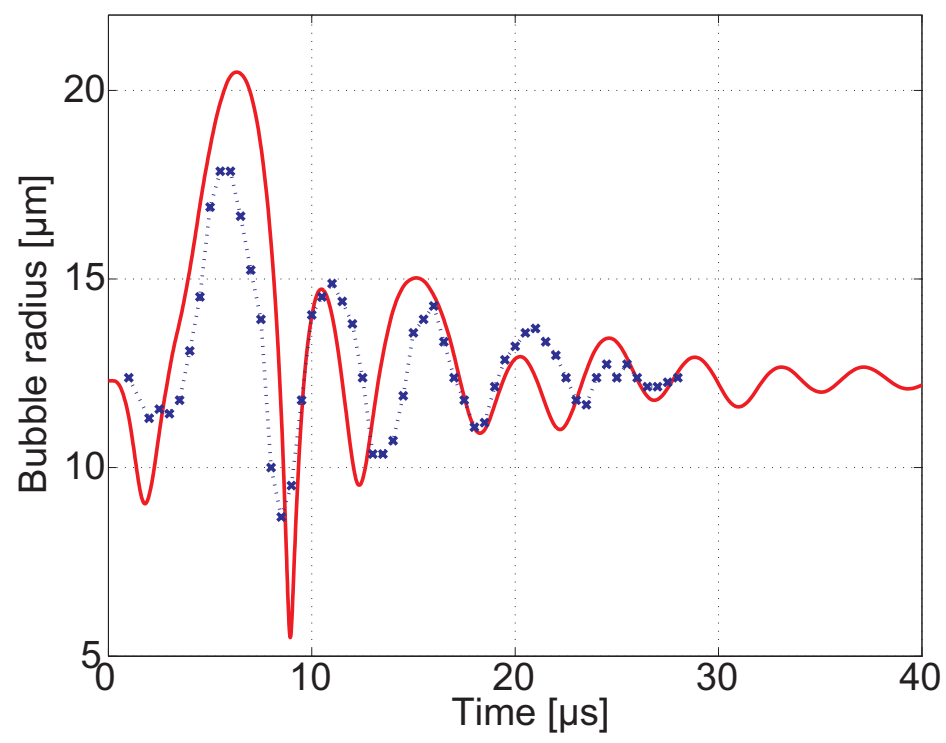

Figure 3.13: The oscillation of the bubble measured from the experiment (blue dots) compared with the calculated oscillation (red solid line). The oscillation is calculated with the full Rayleigh-Plesset equation for a bubble of $12 \mu \mathrm{m}$ and the channel pressure close to the bubble calculated by the model.

\section{Velocity inside the nozzle}

To illustrate the applicability of the model we now calculate the velocity of the fluid inside the nozzle after actuation. Figure 3.14 shows the velocity, as a 
function of time, inside the nozzle for different bubble radii. In this example the bubble is located at $75 \mu \mathrm{m}$ from the nozzle. It can be seen that, as the bubble radius increases, the velocity in the nozzle decreases. The effect the position of the bubble has on the velocity inside the nozzle is illustrated in Figure 3.15 where the maximum value of the velocity $\left(U_{\max }\right)$ during an actuation period inside the nozzle, are displayed for different bubble radii. This figure also shows the root mean square value of the nozzle velocity $\left(U_{\mathrm{rms}}\right)$ during the first $30 \mu \mathrm{s}$ of the actuation period. When a bubble is located far enough from the nozzle, the velocity steadily decreases for increasing bubble size. If a relative small bubble, $R_{\text {mod }} \approx 5 \mu \mathrm{m}$, is located close to the nozzle, the velocity in the nozzle even increases. In reality the entrapped bubble starts close to the nozzle opening and travels into the channel while steadily growing. Therefore an increase in the drop velocity could be expected just before the nozzle stops jetting, as was also observed in [17].

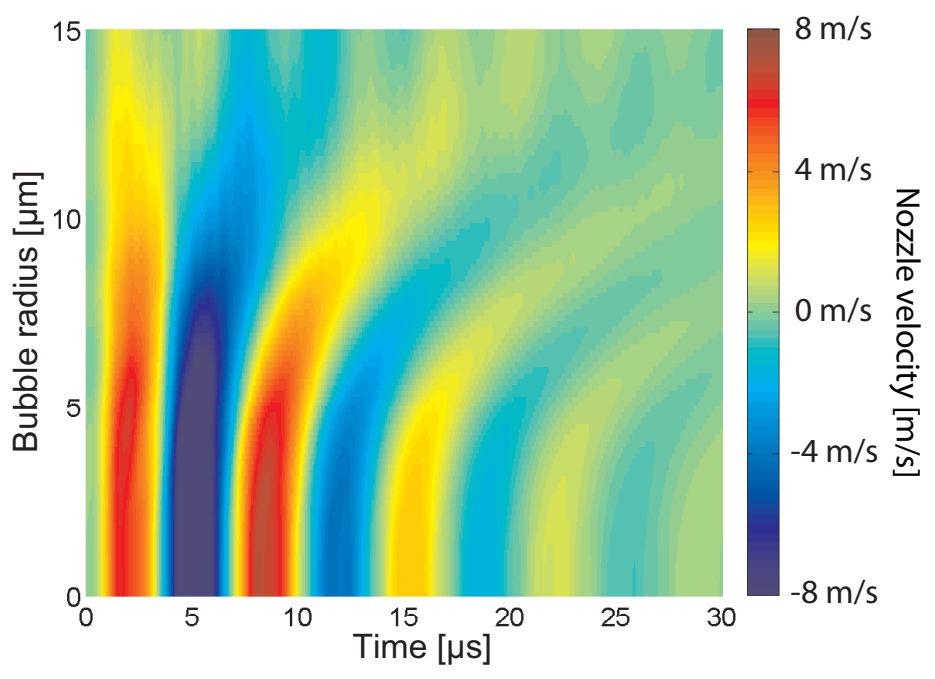

Figure 3.14: The model is applied to calculate the effect of an air bubble on the velocity dynamics inside the nozzle. Here the model was used to calculate the velocity amplitude during the first $30 \mu \mathrm{s}$ after the actuation. The bubble was positioned at $75 \mu \mathrm{m}$ from the nozzle opening. A bubble smaller than $3 \mu \mathrm{m}$ seems to have small influence on the velocity amplitude. As the bubble size increases the velocity amplitude in the no when the bubble grows beyond $5 \mu \mathrm{m}$ the velocity in the nozzle decreases rapidly. 


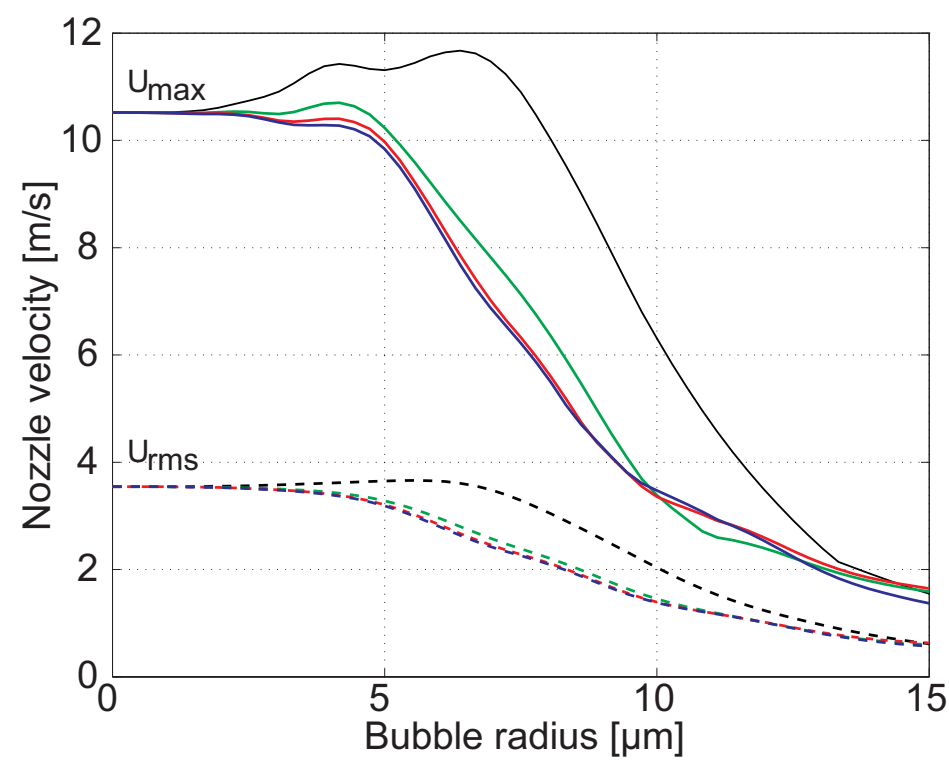

Figure 3.15: The effect of the bubble on the velocity in the nozzle for different bubble positions. The solid lines represent the maximum velocity $\left(U_{\max }\right)$ in the nozzle during an actuation. The dotted lines represent the root mean square of the velocity $\left(U_{\mathrm{rms}}\right)$ during the first $30 \mu \mathrm{s}$. The black line represents a bubble positioned at $25 \mu \mathrm{m}$ from the nozzle, the green line a bubble at $40 \mu \mathrm{m}$, the red line a bubble at $75 \mu \mathrm{m}$, and the blue line a bubble at $125 \mu \mathrm{m}$ from the nozzle. Once the bubble passes beyond the nozzle, the overall effect is a decrease in the nozzle velocity. However a small bubble inside the nozzle causes an increase in nozzle velocity.

\subsection{Conclusion}

In this research a new method for visualizing an air bubble inside a MEMS inkjet print head was measured by using infrared light. The difficulties that arise when visualizing the dynamics inside an operating inkjet channel were treated and solved. By using a high intensity infrared LED continuously a dissolving bubble could be visualized. The LED was also applied stroboscopically, which made it possible to visualize an oscillating bubble. Simultaneously with the visual recordings the acoustics were measured and compared with a linear acoustic model. The model was used to calculate the effect of a bubble on the channel. The pressure close to the bubble was calculated to predict the radial bubble dynamics, which corresponded very well with experiment. In addition the model was used to predict the presence and the size of a bubble from the measured acoustic signal. A good agreement was found between the calculated bubble 
size and the optically measured bubble size. It can therefore be concluded that the effect of the bubble is also correctly incorporated in the model. Therefore the model was applied to calculate how the velocity dynamics in the nozzle change due to the presence of a bubble.

The short calculation time of the model gives a wide range of possibilities, such as optimizing the acoustic design of the ink channel. Accurate and fast models will remain necessary to increase knowledge of bubbles disrupting inkjet channels, and can be used to further improve the reliability of inkjet print heads. 


\section{4}

\section{iLIF: High intensity laser-induced fluorescence illumination for single flash imaging on a nanoseconds timescale}

The challenge in visualizing fast microscale fluid motion phenomena is to record high quality images free of motion blur. Here we present an illumination technique based on laser-induced fluorescence which delivers high intensity light pulses of $7 \mathrm{~ns}$. The light source consists of a Q-switched Nd:YAG laser and a laser-dye solution incorporated into a total internal reflection lens, resulting in a uni-directional light beam with a millimeter-sized circular aperture and $3^{\circ}$ divergence. The laser coherence, considered undesirable for imaging purposes, is reduced whilst maintaining a nanoseconds pulse duration. The properties of the illumination system are quantified and a comparison is made with other high intensity pulsed and continuous light sources.

\subsection{Introduction}

It has been a challenge throughout the last century to freeze fast fluid motion phenomena onto a single image and, in such a way, distinguish the finest details at the smallest length scales. One of the first to address this challenge was A.M. Worthington [59] in 1895 when he used a spark to visualize a splash of milk. Worthington already predicted that flash recording would become of great importance in scientific research, but it wasn't until the work of Edgerton [60] that the scientific utilization of flash photography became widely accepted. In the last decade digital camera technology has evolved rapidly, and high speed visualization has become a valuable experimental method [61]. At the same time, illumination techniques continued to develop, from high intensity Xenon 


\section{ILLUMINATION BY LASER INDUCED FLUORESCENCE}

flashes to low cost high intensity LEDs, both of which can be used for pulsed as well as continuous illumination.

In microfluidics a wide range of phenomena are studied, which primarily involve the dynamics of droplets, bubbles and particles. Despite the small sizes of these objects the associated velocities are usually in the order of meters per second. Hence, to achieve accurate visualization not only high spatial resolution but also high temporal resolution are required. For this purpose one can either employ a camera with a short exposure time, or a light source capable of emitting flashes of short duration. The first option generally requires fast and expensive high-speed cameras which are often limited in their resolution [61]. Therefore flash photography is the preferred method for experiments where high-resolution single images are required, since the method does not require a fast shutter and can in principle be performed with any type of camera. Furthermore the pulse duration of flash illumination sources can easily be shorter than the shortest exposure time of a high-speed camera. On the other hand, the maximum repetition rate of flash light sources with sufficient intensity is often limited to several kilohertz, making these sources unsuitable for recording multiple consecutive frames.

Nowadays, several types of nanosecond light sources are available that can deliver considerable amounts of light within a few nanoseconds. There are, for example, affordable solutions with high intensity LEDs [62-64], or high intensity spark plugs [65, 66]. However, when it comes to emitting ultrashort ${ }^{1}$ high intensity light flashes, a pulsed laser is clearly the most effective. Lasers can be used directly for flash illumination, as was done for example in [68] and [69], but there are some major drawbacks to consider. The light emitted by a laser has a very narrow bandwidth and is fully coherent, resulting in diffraction fringes and laser speckle patterns in the recorded images. Additionally, refocusing of the laser beam has the potential risk of causing permanent damage to the camera sensor.

Methods to suppress these effects are predominantly based on reducing the spatial coherence of the light, for example by applying rotating or vibrating optical elements like fibers and diffusors [71]. For a laser pulse however, a more effective method is to decrease its temporal coherence. One intersting approach to achieve this is through excitation of a fluorescent laser dye. Here the pulse duration is practically unaltered, but the energy of the pulse is redistributed into a broader optical bandwidth at higher wavelengths. This technique has proven to be very effective and was already applied in shadowgraph experiments [70], and is closely related to fluorescent flow visualization described in [72, 73]. A disadvantage is that the cuvette containing the dye can act as a secondary

\footnotetext{
${ }^{1}$ Currently, the shortest achievable laser pulse durations are measured in attoseconds [67.
} 


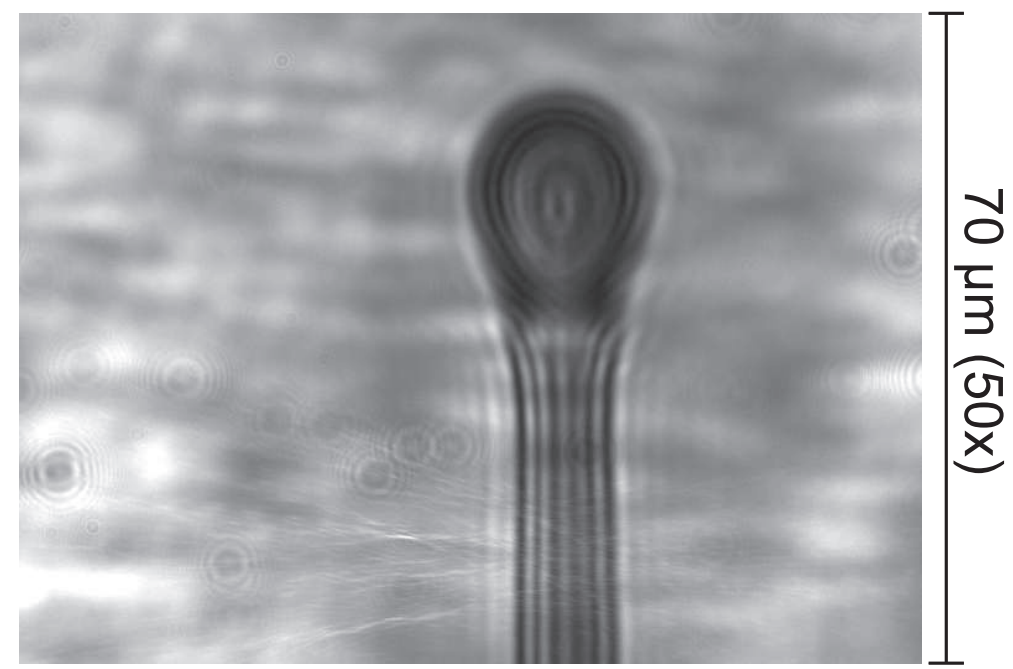

Figure 4.1: The head of an inkjet droplet[2] imaged using the illumination where the laser dye is contained in a cuvette as described in [70]. The image shows a speckle pattern in the background and interference patterns of the light passing through and around the droplet.

laser cavity [74], thereby partially restoring the coherent nature of the pulse (see Figure 4.1). Additionally, relatively high laser energies were required to obtain acceptable illumination intensities, as a result of high losses due to the omni-directionality of the fluorescence emission.

Here we address these issues using a modified single flash illumination technique based on laser-induced fluorescence. The obtained illumination is ideally suited for flash-photography in experiments involving very small time- and length scales. To validate the technique its performance is compared in a standard imaging setup with a range of high-end commercially available lightsources, both pulsed and continuous.

\subsection{Criteria for high speed flash-photography}

The application of flash-photography in experiments is primarily aimed at obtaining precise information about the position and dimensions of the studied object at a certain instant in time. It is therefore of prime importance to capture the smallest details in both temporal- and spatial resolution at high contrast. To define this more quantitatively three criteria are stated here. First, assuming that a microscope objective with the highest possible numerical aper- 


\section{ILLUMINATION BY LASER INDUCED FLUORESCENCE}

ture is chosen for the experiment, the effective optical magnification $M_{\text {eff }}$ must be sufficient to avoid undersampling of the image with respect to the spatial resolution $r$ as defined by the Rayleigh-criterion [57]. The spatial Nyquist criterion requires that at least 2 pixels lay within $r M_{e f f}$. Hence it follows that the magnification must be such that

$$
M_{\text {eff }}>\frac{2 d}{r}
$$

where $d$ is the pixel size. Larger magnifications allow denser spatial sampling (known as oversampling) but also result in a smaller field-of-view and lower image brightness. The magnification is therefore limited by the optimum size of the object-image and the available illumination intensity.

Secondly, to ensure maximum image contrast the intensity of the illumination should be adjusted to cover the full dynamic range of the camera sensor. The extent to which the intensity can be varied is, however, limited due to the reciprocal relationship between illumination intensity and exposure time. To clarify, an image with a certain fixed brightness can be obtained with either low light conditions and longer exposure times, or vice versa. In the situation where an object is motionless both settings result in identical images. However if the object of interest is moving, the image becomes susceptible to motion-blur. This undesired effect causes a smeared appearance of the image of the object due to its displacement during the time the image is recorded.

Minimizing motion-blur constitutes the third criterion which is required to accurately capture a single high resolution image of a moving object and this can be achieved by adjusting the temporal resolution of the imaging system. As discussed, this temporal resolution is determined either by the duration of the illumination pulse (indicated by $\tau_{p}$ ) or by the camera exposure time $\tau_{c}$, which is the time duration during which the mechanical or electronic shutter of the camera is opened to expose the sensor to an illuminated object. Evidently, the actual temporal resolution $\tau$ will be the shortest of both durations, hence

$$
\tau=\min \left(\tau_{p}, \tau_{c}\right) .
$$

If we now define $\varepsilon$ as being the displacement in pixels of the object moving with velocity $U$ during time $\tau$ :

$$
\varepsilon=\tau \frac{M_{\mathrm{eff}} U}{d}
$$

motion-blur will be minimal if $\varepsilon \leq 1$. In most experiments the object velocity, magnification and pixel-size are pre-determined and motion-blur is minimized 


\subsection{ILLUMINATION BY LASER INDUCED FLUORESCENCE}

by choosing an illumination- or exposure time such that

$$
\tau \leq \frac{d}{M_{\mathrm{eff}} U}
$$

\subsection{Illumination by laser induced fluorescence}

To obtain maximum fluorescence efficiency while minimizing coherence we constructed a laser-dye lens. The core of a total internal reflection lens (TIR-lens) where normally a high power LED can be placed was filled with a laser-dye (Figure 4.2). This dye consisted of a fully saturated solution of LDS 698 (Exciton Inc., Dayton, U.S.) in ethanol. The TIR-lens (L2-Optics) is an acrylic collimator with a total beam divergence of $3^{\circ}$. The dye was excited by a Nd:YAG laser (Solo PIV, New Wave) emitting a 6.5 ns pulse (full width at half maximum, see Figure 4.3) with a maximum energy of $100 \mathrm{~mJ}$ at $532 \mathrm{~nm}$. This configuration allows the greater part of the laser pulse to be absorbed, re-emitted and subsequently reflected in the forward direction thus promoting the reduction of the temporal coherence of the pulse.

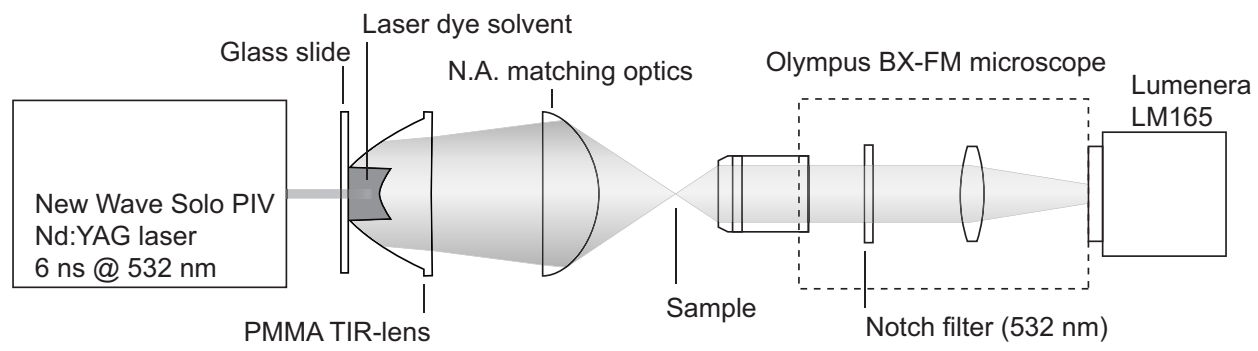

Figure 4.2: Typical application of illumination with laser dye fluorescence. In the illumination setup a laser excites the dye after which the fluorescent light from the cavity is collected and focused through a collimation lens onto a microscope. To filter out any remaining laser light a notch-filter (Semrock NF01-532U-25) is used.

To confirm the applicability of this setup for illumination by laser induced fluorescence (iLIF), the pulse length and spectrum were measured. To measure the pulse length a light sensor (Thorlabs-DET 210) was mounted directly after the TIR-lens and connected to an oscilloscope (Tektronix TDS5034B), resulting in a typical rise time of the measuring system of $1.2 \mathrm{~ns}$. The laser and oscilloscope were triggered with a delay/pulse generator (Berkely Nucleonics model 565) with an accuracy of $250 \mathrm{ps}$. The measurement was carried out with- and without a notch filter in between the lens and photodiode. As shown in Figure 4.3 the iLIF does not result in a noticeable difference in pulse length 


\section{ILLUMINATION BY LASER INDUCED FLUORESCENCE}

with respect to the laser. The influence of the notch-filter on the iLIF-pulse shape was also found to be negligible (data not shown).

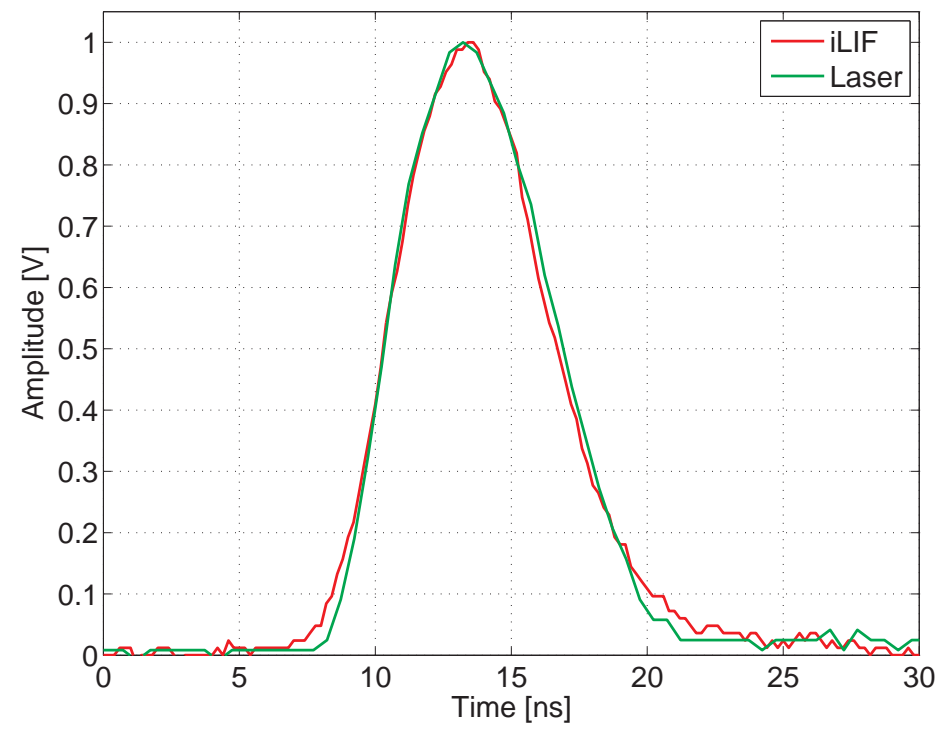

Figure 4.3: The normalized average of 16 measurements of the pulse shape of both the laser- and the iLIF pulse.

The spectral characteristics of the iLIF were determined using a high resolution fiber optic spectrometer (AVASPEC 3648, FWHM resolution: $0.32 \mathrm{~nm}$ ). Figure 4.4 shows the broad spectrum of the fluorescence light. The spectrum was recorded with the notch filter in front of the spectrometer. However, measurements without the notch filter also showed no energy at $532 \mathrm{~nm}$ above the noise level, indicating that most of the laser energy is absorbed by the laser dye. 


\subsection{ILLUMINATION BY LASER INDUCED FLUORESCENCE}

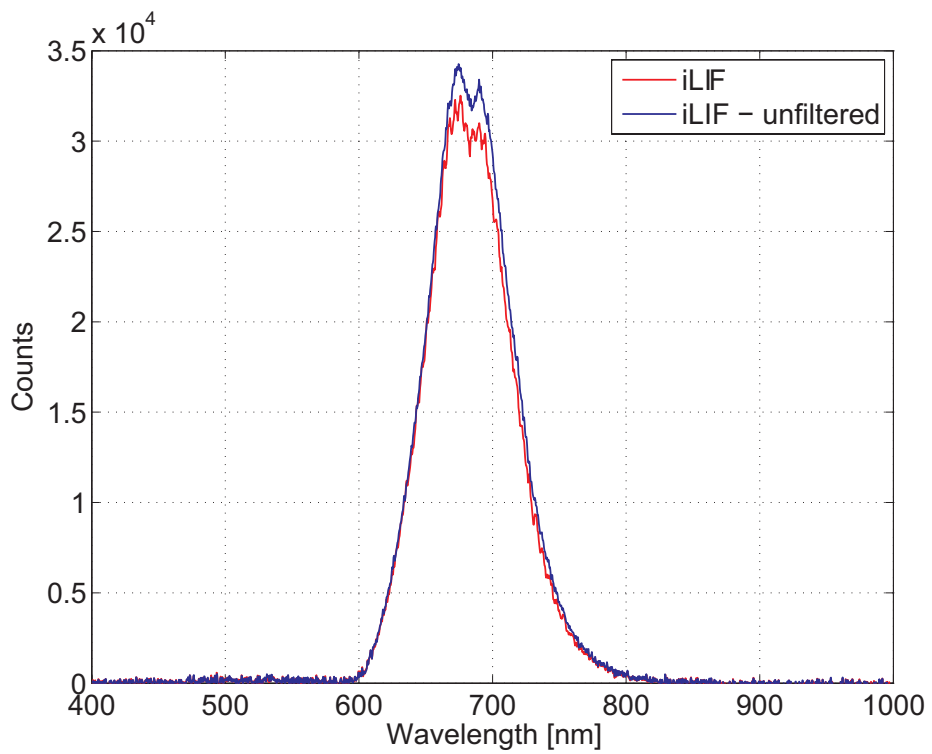

Figure 4.4: Spectra of the iLIF pulse with- and without the notch-filter. 


\section{ILLUMINATION BY LASER INDUCED FLUORESCENCE}

\subsection{Comparison with other light sources}

To quantify the performance of the laser-induced fluorescence illumination a comparison was made with several high intensity light sources, typically used for high speed imaging of microscopic events. An overview of the light sources, both pulsed and continuous, is given in table 4.1. All continuous light sources have an optical fibre, glass or liquid core with a diameter of 4 to $8 \mathrm{~mm}$, to deliver the light to the sample, except for the LED's and the continuous Xenon light source. The LED's are mounted in a TIR-lens with a divergence of $3^{\circ}$, comparable to the TIR-lens used for iLIF. The continuous Xenon light source (Hella B.V.) has a clear aperture with a radius of approximately $10 \mathrm{~cm}$. It can serve as a light source for experiments on scales ranging from several micrometers to one meter.

Table 4.1: Characteristics of the light sources

\begin{tabular}{|c|c|c|c|}
\hline Light source & Type & $\begin{array}{l}\text { Pulse } \\
\text { length } \\
\text { (fwhm) }\end{array}$ & $\begin{array}{l}\text { Pulse } \\
\text { rate } \\
\text { (max) }\end{array}$ \\
\hline Laser Dye TIR lens & pulsed & $7 \mathrm{~ns}$ & $20 \mathrm{~Hz}$ \\
\hline Laser Dye cuvette & pulsed & $7 \mathrm{~ns}$ & $20 \mathrm{~Hz}$ \\
\hline HSPS Nanolite KL-L & pulsed & $16 \mathrm{~ns}$ & $\begin{array}{l}20 \\
\mathrm{kHz}\end{array}$ \\
\hline Seoul Semicon P7 ${ }^{1}$ & \multicolumn{2}{|c|}{ pulsed/CW1 1 s } & $\begin{array}{l}1 \\
\mathrm{MHz}\end{array}$ \\
\hline Lumiled Luxeon Star ${ }^{2}$ & \multicolumn{2}{|c|}{ pulsed/CW1 1 s } & $\begin{array}{l}1 \\
\mathrm{MHz}\end{array}$ \\
\hline $\begin{array}{l}\text { Perkin Elmer MVS- } \\
7010\end{array}$ & \multicolumn{2}{|c|}{ pulsed/CW200 $\mu \mathrm{s}$} & $10 \mathrm{~Hz}$ \\
\hline Olympus ILP-1 & $\mathrm{CW}$ & - & - \\
\hline Sumita LS-M352 & $\mathrm{CW}$ & - & - \\
\hline Schott KL1500LCD & $\mathrm{CW}$ & - & - \\
\hline Schott Ace & $\mathrm{CW}$ & - & - \\
\hline $\begin{array}{l}\text { Hella Mega Beam } \\
\text { Xenon }\end{array}$ & $\mathrm{CW}$ & - & - \\
\hline
\end{tabular}

The test setup schematically depicted in Figure 4.5 was designed to measure the relative intensity of all the light sources. Since light source properties such as beam profile, beam divergence and spectral intensity profile differ from 


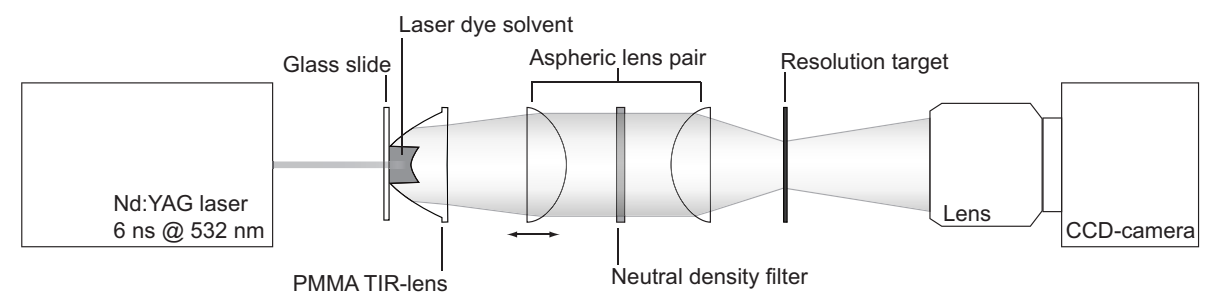

Figure 4.5: Setup used for the comparison of the various light sources. The location of the first aspheric lens is adjusted to collect and collimate the light from the lightsource.

one light source to the other, the setup was chosen to resemble a typical but simplified experimental setup for high speed flow visualization. An aspheric lens pair collimated the light from the source onto a USAF 1951 resolution test chart (Edmund Optics). A telecentric lens (Jenoptik) was used to form a 1:1 image of a $500 \times 500 \mu \mathrm{m}$ square from the target onto a CCD-camera (Lumenera, LM165M, 8 bit monochrome). Neutral density filters with optical densities ranging from 2.5 to 5.0 were used to avoid overexposure of the CCD. Except for the first aspheric lens, all elements of the setup and the position of the light source were fixed in place. To optimize the light intensity and to ensure even illumination of the target, the position of the movable lens was adjusted for each light source.

For the continuous light sources the exposure time of the camera was adjusted to get an average pixel value of the square of approximately 200 counts. This procedure was repeated for several ND-filters per light source. The recorded images were analyzed and the results were scaled with the exposure times, number of pulses and optical density of the ND-filters used.

Figure 4.6 shows the comparison of the single pulse intensities of the pulsed light sources. Saturation behavior of the fluorescent laser-dye is visible in the graph as the maximum light intensity peaks at a laser energy of $5.7 \mathrm{~mJ}$. Compared to the LED's the iLIF shows a sixfold higher light intensity at a pulse length which is 2 orders of magnitude shorter. The Nanolite has an light intensity comparable to the LED's but at the same timescale as the iLIF. However, the location of the spark from the Nanolite varies per shot, causing large variations in illumination intensity and homogenity between images.

The results of the continuous light sources were scaled to an illumination time of 7 ns to match the pulse length of the iLIF and compared in Figure 4.7. From the graph the potential of the iLIF becomes clear; the semi-continuous Xenon flash is outperformed by two orders of magnitude and the continuous light sources are even a factor of one thousand less intense than the iLIF. 


\section{ILLUMINATION BY LASER INDUCED FLUORESCENCE}

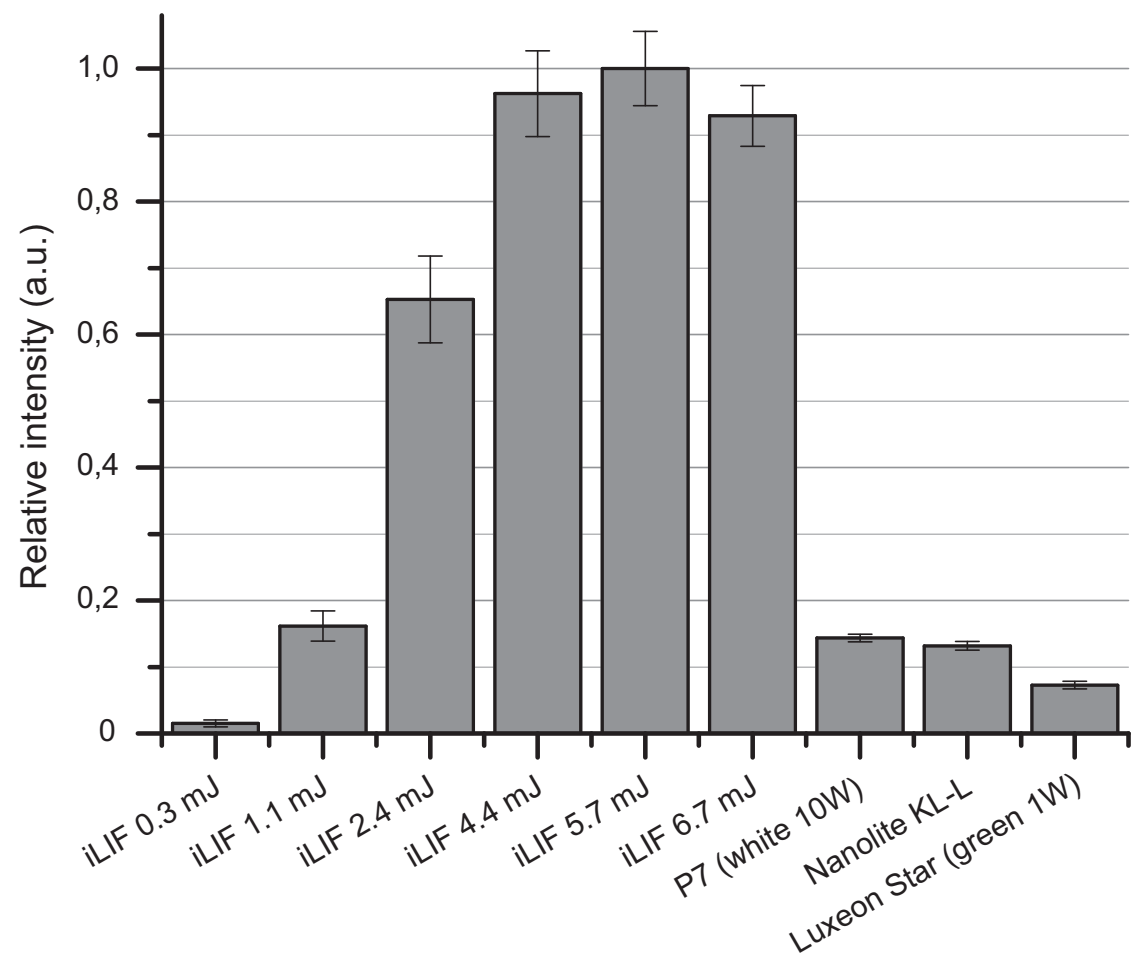

Figure 4.6: Relative intensity of the pulsed lightsources. The energy values indicate the laser pulse energy used to excite the laser-dye. 


\subsection{COMPARISON WITH OTHER LIGHT SOURCES}

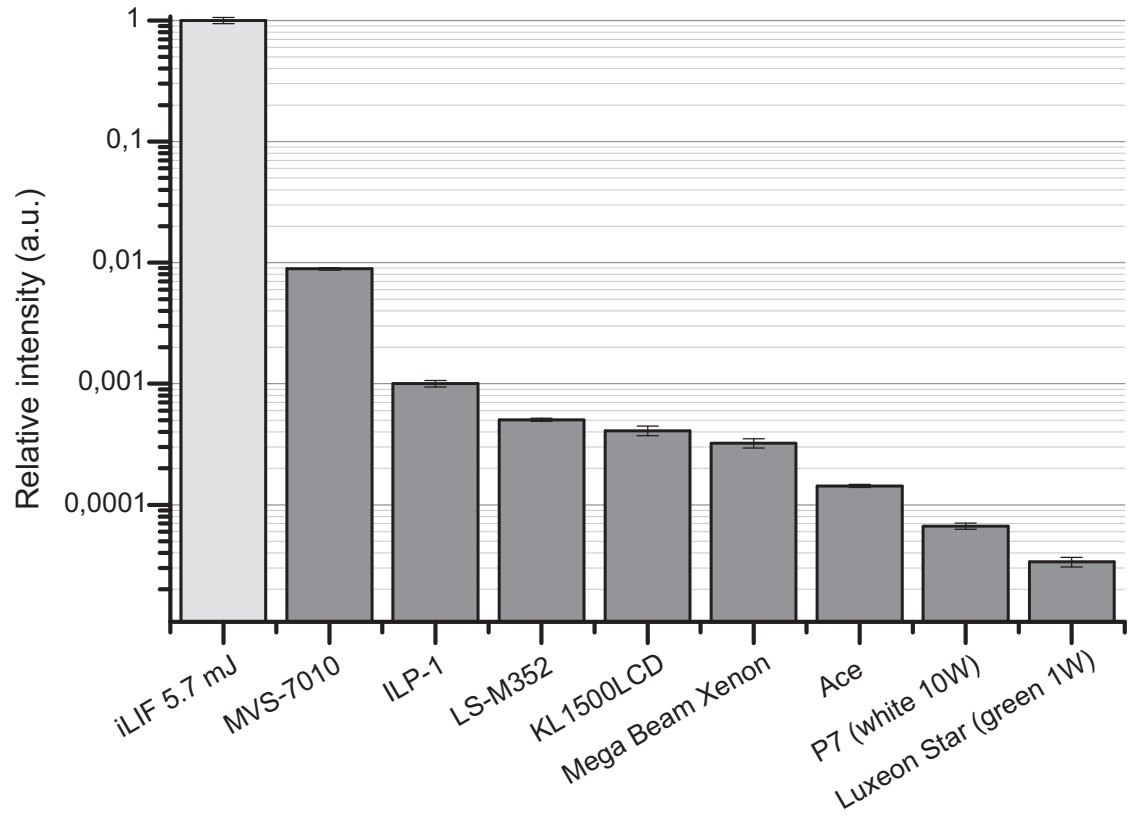

Figure 4.7: Relative illumination intensities for the continuous lightsources normalized to the maximum obtainable intensity of the iLIF and scaled to $7 \mathrm{~ns}$ illumination time. Note the logarithmic scale. 


\section{ILLUMINATION BY LASER INDUCED FLUORESCENCE}

\subsection{Examples}

As drop formation in inkjet printing is an almost perfectly reproducible process, single flash photography is frequently applied for its visualisation [68, 75]. Here we use this reproducible quality to demonstrate the effectiveness of the iLIF compared to other flash illumination sources. The experimental setup used was equivalent to Figure 4.2, where the inkjet print head is placed in the sample location. The light emitted from the TIR-lens is focussed through a collimation lens onto the region of interest. The collimation lens was chosen such that the numerical aperture (N.A.) matches with that of the microscope objective ensuring maximal optical resolution and intensity [57]. The microscope (Olympus BX$30 M F)$ is equipped with three long distance objectives, the LMPLFLN $10 \times$, (WD $21 \mathrm{~mm} / \mathrm{NA}=0.25)$, the SMPLFLN $20 \times(\mathrm{WD} 25 \mathrm{~mm} / \mathrm{NA}=0.25)$, and the SMPLFLN 50×, (WD $18 \mathrm{~mm} / \mathrm{NA}=0.35)$. A notch filter (Semrock (NF01$532 \mathrm{U}-25)$ ) is placed before the camera to filter out any remaining laser light. The camera is a Lumenera LM165 with a sensitive Sony EXview HAD CCD sensor with pixel size of $6.45 \mu \mathrm{m}$, and a resolution of $1392 \times 1040$. The scale factor resulting from the camera and the microscope is for the $10 \times, 20 \times$ and $50 \times$ objective respectively, $640 \mathrm{~nm} /$ pixel, $320 \mathrm{~nm} /$ pixel, and $129 \mathrm{~nm} /$ pixel.

The printhead is an experimental prototype developed by Océ Technologies B.V., similar to the printheads used in references [2, 14]. The printhead ejects droplets with a diameter of $30 \mu \mathrm{m}$, and a terminal velocity of $6 \mathrm{~m} / \mathrm{s}$. The typical velocity during the drop formation is in the order of $20 \mathrm{~m} / \mathrm{s}$. Using Equation 4.4 for the indicated magnifications we find that the droplet can be imaged without the motion-blur effect if the illumination times are smaller than $\tau_{10}=32 \mathrm{~ns}, \tau_{20}=16 \mathrm{~ns}$ and $\tau_{50}=6 \mathrm{~ns}$.

For comparison, two alternative light sources were used for imaging of the inkjet drop formation. These were the high intensity Luxeon LED flash with an illumination time of $\tau_{p}=400 \mathrm{~ns}$ and a Nano Lite with an illumination time of $\tau_{p}=16 \mathrm{~ns}$. As shown in table 4.2 the displacement $\varepsilon$ of the image of the droplet for $10 x$ or $20 x$ magnifications is less than one pixel for both the iLIF and the Nanolite.

The LED is clearly unsuited for detailed imaging of the drop formation, motion blur due to the long pulse and noise due to the high intensity are clearly visible. This is also confirmed with by calculating $\varepsilon$ where, assuming $U=20 \mathrm{~m} / \mathrm{s}$. Equation 4.3 gives $\varepsilon$ equal to 12,25 and 62 for a $10 \times, 20 \times$ and $50 \times$ magnification, respectively.

The Nanolite proves a very usable illumination and Equation 4.3 gives $\varepsilon$ equal to $0.5,1$ and 2.5 , for a $10 \times, 20 \times$ and $50 \times$ magnification, respectively. Nevertheless the intensity is too low to create the desired contrast at higher 


\subsection{EXAMPLES}

magnifications and, additionally, the intensity varies significantly for different images due to the spark illumination.

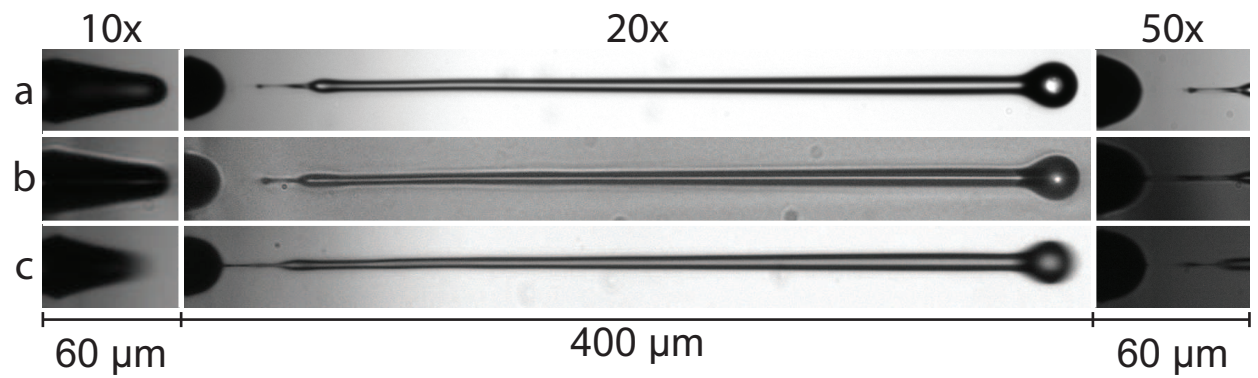

Figure 4.8: Inkjet drop formation imaged using 3 different flash illumination sources. The image illuminated with the iLIF is shown in (a), (b) shows the recording with the Nanolite, and (c) shows the recording with the LED. On the left the drop formation is shown at $11 \mu$ s with $10 \times$ magnification, in the middle the drop formation is shown at $44 \mu$ with $20 \times$ magnification, and on the right the image the area of the pinch-off at the meniscus is shown with $50 \times$ magnification. The camera gain is increased for the Nanolite and the LED to create enough contrast. For the Nanolite the gain is set at 3.5, 20 and 24(max), respectively. For the LED this is 2.5, 10 and 24( $\max )$, respectively. For the iLIF no gain was necessary.

Table 4.2: Comparison of the amount of motion-blur indicated by $\varepsilon$ for the imaging of a $20 \mathrm{~m} / \mathrm{s}$ inkjet droplet using 3 pulsed light sources.

\begin{tabular}{l|l|l} 
Light source & $M_{\text {eff }}$ & $\varepsilon$ \\
\hline \multirow{3}{*}{ Laser Dye TIR lens $\left(\tau_{p}=7 \mathrm{~ns}\right)$} & 10 & 0.22 \\
& 20 & 0.43 \\
& 50 & 1.1 \\
\hline \multirow{3}{*}{ HSPS Nanolite KL-L $\left(\tau_{p}=16 \mathrm{~ns}\right)$} & 10 & 0.47 \\
& 20 & 0.93 \\
Lumiled Luxeon Star $\left(\tau_{p}=400 \mathrm{~ns}\right)$ & 50 & 2.3 \\
\hline & 10 & 12 \\
& 50 & 25 \\
\hline
\end{tabular}


As another demonstration, Figure 4.9 shows the evolution of the inkjet droplet recorded with the iLIF. The images reveal the size of the thin secondary tail between the drop and meniscus (also seen in Figure 4.8). The improved quality of the recordings, both in spatial and temporal resolution, give way to novel analysis of the drop formation, as is elaborately discussed in chapter 5 .

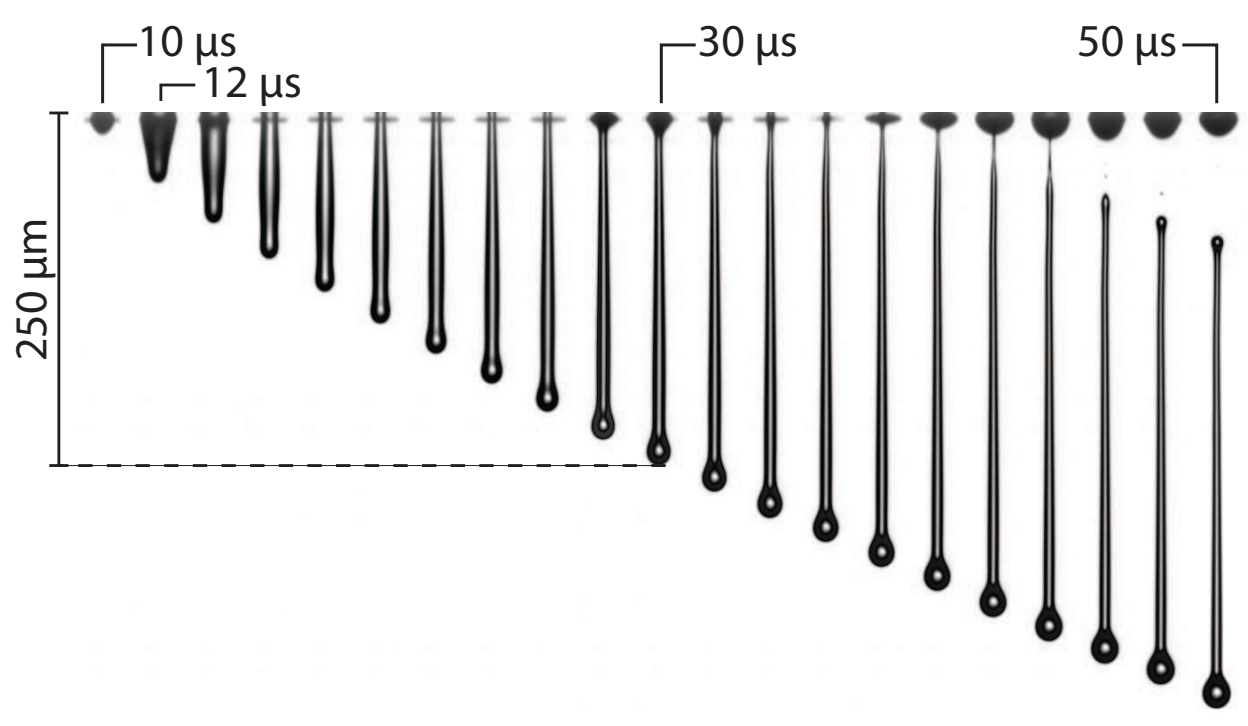

Figure 4.9: The drop formation of inkjet channel as a function of time. The background has been subtracted to create a higher contrast. The figure shows 21 individual droplets and illustrates the reproducibility of the experiment and the quality of the iLIF light source.

\subsection{Discussion and conclusion}

The fluorescence illumination method presented here research proves to be a very promising technique for flash photograpy of fast and small scale phenomena. The illumination technique was evolved from an earlier applied technique were a fluorescent dye in a cuvette was used to reduce the coherence of the laser illumination. The use of a TIR-lens instead of a cuvette results in reduced coherence and uniform and unidirectional emittance of the light. The iLIF system delivers $7 \mathrm{~ns}$ light pulses without suffering from spatial or temporal coherence image artifacts. It is a relatively simple system to obtain high intensity flash illumination for fast microscopic events. Compared to other high intensity pulsed and continuous light sources it shows significantly higher intensity levels with a 


\subsection{DISCUSSION AND CONCLUSION}

short pulse duration, uniform illumination and low jitter.

Further investigations should verify if any degradation of the dye solution can be observed and if other, lower energy pulsed lasers can be used. It has been shown here that less than 1 millijoule of energy in six nanoseconds is enough to surpass all other tested light sources, thus implying that similar energy in a slightly longer pulse could give similar results, making the application more affordable. The efficiency can also be optimized, by testing if the dye used is the most efficient or if laser dyes with a higher quantum yield are available. Another aspect that could still be improved is the design of the TIR-lens, where the shape can be optimized for different applications.

We plan to upscale the $i L I F$, and as such make it applicable for macroscale experiments for the visualizion of impact phenomena and shock-waves in fluids. 
4. ILLUMINATION BY LASER INDUCED FLUORESCENCE 


\section{5 \\ Velocity profile inside a piezo-acoustic inkjet droplet: Experimental and theoretical results}

Droplets with a well-controlled and narrow size distribution are required in many industrial and medical applications. In this work we study droplet formation from an inkjet printhead by using ultra high-speed imaging at 15 million frames per second. A second technique was also applied where a series of single flashes of 7 ns was used to illuminate the drop formation. The acquired recordings are used to calculate the flow rate and velocity inside the droplet. The results are compared with a one-dimensional model based on the lubrication approximation. In the model the equations are solved on an Eulerian grid with a second order accurate scheme.

\subsection{Introduction}

The evolution of a drop is a battle for dominance between inertia, surface tension, and viscosity, making it a long-lasting challenge to describe all aspects. This makes it a subject that has fascinated scientists throughout history, involving great pioneers of the modern fluid dynamics [10]. In the last decades both experimental and computational techniques developed very fast, resulting in numerous innovate theoretical, experimental and numerical research [11, 17, 18, 50]. Also industry shows high interest in research on the subject of drop formation, as drop dispensers are used in a wide range of applications. Examples are sprays which can be applied in car engines [76], drug inhalers [77], and coming to the subject of this research, inkjet printing.

Inkjet printing is well known for the impressive reproducibility of the drop formation. This has made inkjet technology a reliable technique for drop deposition of all kinds of liquids and various applications [3]. The drop volumes 
produced with inkjet technology range from nanoliters down to a few picoliter. The field is continuously searching for new methods to produce even smaller droplets, while retaining velocities in the order of meter per seconds [78]. One aspect that limits the production of small droplets at high velocities, is the formation of satellite droplets. When a fast viscous jet is ejected from a nozzle, a long slender tail is formed behind the tip of the drop. If the timescale at which the tail is pulled towards the main drop is longer than the timescale of the Rayleigh breakup, unwanted satellites are formed [68, 79]. The smaller satellite droplets have a low velocity, hence their movement is susceptible to surrounding air flows, potentially resulting in undesired deposition. By optimizing the actuation pulse the time span at which the drop contracts can be reduced, thus minimizing the formation of satellite droplets.

Measuring the effect of different actuation pulses on the velocity of the drop is a challenging study, especially because the length scale at which the drop is formed is in the order of a micrometer, while the velocity is in the order of meters per second. Therefore ultra high-speed imaging [77] is required to accurately visualize the drop formation. Another possibility is, provided that the drop formation is fully repeatable, to use stroboscopic techniques [68, 75]. In this study both techniques are used to study the drop formation, both giving a very high temporal and spatial resolution. The first technique uses the Brandaris 128 ultra high speed camera [80], which can record up to 25 million frames per second. The second technique is a stroboscopic single flash visualization, that uses a novel illumination technique. The illumination with a flash time of $7 \mathrm{~ns}$ was specially developed for the drop formation and is discussed in chapter 4 To verify the improved quality of these two methods, they are compared on both spatial and temporal resolution. In this research it is investigated whether it is possible to extract the flow rate and the velocity within the droplet using the reproducibility of the drop formation.

Beside the experimental research on the drop formation we also employ a theoretical model, based on the one-dimensional lubrication approximation of the Navier-Stokes equation. Similar models have already been used for simulating drop formation [20] and sprays [77]. A novel numerical implementation applied in this research is the regularizing of the surface tension at very small radius. This prevents the singularity at pinch-off and simplifies how to deal with the coalescence of the drops [81]. Due to the simplified equations the calculation time of the lubrication model is in the order of minutes. This makes the model well suited to explore a large range of parameters in a relative short time. 


\subsection{Geometry of the inkjet printhead}

The inkjet printhead that is used here was developed by Océ Technologies B.V. This printhead consist of 256 similar ink channels, where each channel has a $5 \mathrm{~mm}$ long actuation section, and a $50 \mu \mathrm{m}$ thick nozzle plate. The nozzle has a trumpet shape with an outer radius of $15 \mu \mathrm{m}$. The acoustic pressure is generated by a piezo element, placed in the actuation chamber. The piezo is actuated with a trapezoid pulse of $7 \mu \mathrm{s}(2 \mu \mathrm{s}$ rise, $3 \mu \mathrm{s} \mathrm{high,} \mathrm{and} 2 \mu \mathrm{s}$ fall time), driving the channel close to its resonant frequency. Applying an actuation pulse of approximately $80 \mathrm{~V}$ results in $20 \mathrm{pl}$ droplets. Although the typical velocity of the drop is approximately $10 \mathrm{~m} / \mathrm{s}$, the maximum velocity during the drop formation can reach up to $20 \mathrm{~m} / \mathrm{s}$. More details on the acoustics and stability of this printhead can be found in chapter 2 and references [2, 14].

The liquid used is a non-colored version of the CrystalPoint technology toner pearls [55] which, instead of drying, crystalizes on the paper, resulting into very rapid solidification. To liquify the ink the printhead is operated at a temperature of $130^{\circ} \mathrm{C}$. At this temperature the viscosity of the ink is $10 \mathrm{mPas}$. To ensure a constant viscosity the temperature of the ink is controlled with two Eurotherm 2408 PID controllers. At this temperature the density and surface tension are $1080 \mathrm{~kg} / \mathrm{m}^{3}$ and $28 \mathrm{mN} / \mathrm{m}$, respectively. A benefit of the CrystalPoint technology is that the ink does not suffer from degradation or dehydration at the nozzle, which is a common problem in water based inks [82].

\subsection{Experimental parameters}

The drop formation was imaged with two different experimental techniques, namely high speed imaging and stroboscopic single flash imaging. Where high speed imaging can be applied to study the evolution of a single droplet, stroboscopic imaging is used to visualize thousands of reproducible droplets [61]. In contrast with most stroboscopic imaging techniques, where multiple flashes are used to create a single high contrast image, in a single flash recording only one image per drop is acquired. By changing the delay between the flash and the drop for the next image, a sequence of images is captured. The sequence of multiple droplets is treated as if it is a single evolving droplet. This method of time-delay imaging is only possible when the drop formation is highly reproducible, hence the experimental settings have to be controlled with utmost precision. The advantage of the single flash recording is that the images are more detailed in both optical and temporal resolution compared to high speed recordings. In addition, we also use high speed recordings are made, which are used in order to verify the results from stroboscopic recordings. 


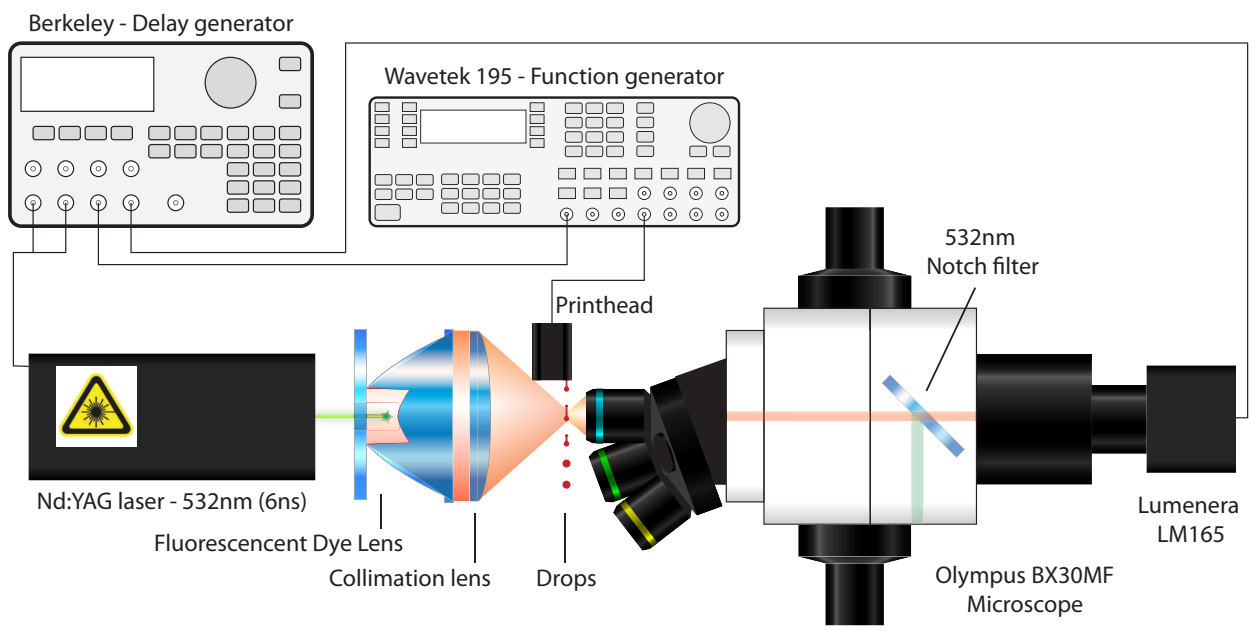

Figure 5.1: In the single flash setup a laser illuminates a fluorescent dye that is contained within the cavity of a hollow lens. The dye emits a light pulse of 7 ns with very high intensity. The emitted light is collimated onto the droplets using an aspherical lens. A notch filter inside the microscope prevents that laser light reaches the CCD camera. A computer controlled delay generator is used to control the laser, the function generator, and the camera.

Figure 5.1 shows the setup used for single flash recordings. The setup was placed onto a damped optical breadboard to prevent external vibrations. The microscope is an Olympus $B X-30 M F$ microscope, equipped with three long distance objectives, the LMPLFLN $10 \times,(\mathrm{WD}=21 \mathrm{~mm} / \mathrm{NA}=0.25)$, the $S M$ $P L F L N 20 \times(\mathrm{WD}=25 \mathrm{~mm} / \mathrm{NA}=0.25)$, and the SMPLFLN 50×, (WD $=18 \mathrm{~mm}$ $/ N A=0.35)$. For visible light the resolving power of these objectives is approximately $600 \mathrm{~nm}$. Though this limits the focus of imaged details, the imaged displacements are only limited by the pixel size and illumination time. To ensure that the full optical resolution is utilized the light from the light-source is converged with an aspherical lens, such that the numerical aperture (NA) matches that of the objective [57].

The spatial resolution of the recording depends on the magnification $\left(M_{\text {eff }}\right)$ and the resolution of the camera. Here the spatial resolution is in the order of $100 \mathrm{~nm} /$ pixel and, in combination with a drop velocities in the order of $10 \mathrm{~m} / \mathrm{s}$, motion blur can easily occur. To prevent motion blur in the images the drops have to be imaged at a small imaging time scale. For the high speed imaging 


\subsection{EXPERIMENTAL PARAMETERS}

this time scale depends on the exposure time, and for single flash imaging it depends on the illumination time (chapter 4). The optimal imaging time scale at which no motion blur occurs can be calculated as

$$
\tau_{M}<\frac{\text { pixel size }}{u \cdot M_{\text {eff }}} .
$$

Here $\tau_{M}$ gives the imaging time corresponding with a magnification $M$. The pixel size is a camera dependant parameter, and $u$ gives the velocity of the drop. When imaging inkjet droplet with large magnifications it is expected that the actual imaging time scale is larger then $\tau_{M}$, thus resulting in motion blur. If the actual imaging time scale $\tau$ is known, the amount of motion blur in pixels $\varepsilon$ that is expected can be calculated by

$$
\varepsilon=\tau \frac{u \cdot M_{\mathrm{eff}}}{\text { pixel size }}
$$

In this research we make a distinction between $\tau_{b}$ for the exposure time of the high speed camera, and $\tau_{f}$ for the illumination time of the single flash recording. Equation 5.2 can also be used to estimate whether the different experimental aspects are balanced. For $\varepsilon$ order 1 the experiment is well defined, while recordings for which $\varepsilon>1$ suffer from motion blur. For $\varepsilon<1$ the experiment is over-sampled which, for a high speed camera experiment, results in no observable displacement between consecutive frames.

\subsubsection{High speed recordings}

The high speed recordings were done with the Brandaris 128 high speed camera [80]. The Brandaris 128 uses a fast rotating mirror (max 20.000 rps) to sweep the image across 128 highly sensitive CCDs, giving a maximum frame rate of $25 \mathrm{Mfps}$. Each CCD has a resolution of $320 \times 296$ pixels and an effective pixel size of $10.9 \mu \mathrm{m} \times 10.9 \mu \mathrm{m}$. To illuminate the drop formation, a high intensity Xenon light source (Perkin Elmer Xenon flash) is used. The nature of the experiment limited the maximum frame rate to $16 \mathrm{Mfps}$, corresponding to an imaging time scale $\tau_{b}$ of $63 \mathrm{~ns}$. Table 5.1 shows the required time scale $\tau_{M}$, next to the amount of motion blur $\varepsilon$ expected due to the actual time scale. The table also shows the resolution per pixel, and the total field of view (FoV) for the high speed camera.

Due to the small field of view and the limited amount of frames, multiple movies are required to visualize the entire drop formation. The total time of the drop formation is approximately $60 \mu \mathrm{s}$. As in a single recording session the Brandaris 128 acquires 128 frames $(8 \mu \mathrm{s})$, approximately twelve sequential movies must be used to record the drop formation. The twelve movies were 
subsequently stitched together into a single continuous movie. Here the reproducibility of the drop formation and precise timing allow for a smooth transition between the sequential movies. Additionally, the small field of view required that, to visualize the drop formation with a $20 \times$ magnification, two series of movies were recorded at different distances from the nozzle. Figure 5.2. 3 shows a typical recoding for a $20 \times$ magnification.

\begin{tabular}{|c|c|c|c|c|}
\hline \multicolumn{5}{|c|}{ Brandaris 128} \\
\hline$M_{e f f}$ & resolution & FoV & $\tau_{M}$ & $\varepsilon$ \\
\hline 10 & $1.09 \mu \mathrm{m} / \mathrm{pixel}$ & $349 \mu \mathrm{m}$ & $55 \mathrm{~ns}$ & 1.14 \\
\hline 20 & $0.55 \mu \mathrm{m} / \mathrm{pixel}$ & $174 \mu \mathrm{m}$ & 27 ns & 2.3 \\
\hline 50 & $0.22 \mu \mathrm{m} /$ pixel & $70 \mu \mathrm{m}$ & $11 \mathrm{~ns}$ & 5.7 \\
\hline \multicolumn{5}{|c|}{ Single flash recording } \\
\hline$M_{e f f}$ & resolution & FoV & $\tau_{M}$ & $\varepsilon$ \\
\hline 10 & $0.65 \mu \mathrm{m} / \mathrm{pixel}$ & $898 \mu \mathrm{m}$ & $32 \mathrm{~ns}$ & 0.22 \\
\hline 20 & $0.32 \mu \mathrm{m} /$ pixel & $449 \mu \mathrm{m}$ & $16 \mathrm{~ns}$ & 0.43 \\
\hline 50 & $0.13 \mu \mathrm{m} / \mathrm{pixel}$ & $180 \mu \mathrm{m}$ & $7 \mathrm{~ns}$ & 1.08 \\
\hline
\end{tabular}

Table 5.1: The experimental parameters for the high speed imaging and those for the flash recordings. The expected motion blur in the experiments was calculated for a velocity of $20 \mathrm{~m} / \mathrm{s}$ and an imaging time scale $\tau_{b}=63 \mathrm{~ns}$ for the Brandaris 128 , and $\tau_{f}$ $=7 \mathrm{~ns}$ for the single flash recording. The table illustrates the advantage of the flash recording compared to the high speed recordings; the resolution is higher, the field of view larger, and the actual imaging time scale matches the required one.

\subsubsection{Single flash recordings}

The flash visualization was done with the setup already shown in Figure 5.1. The short flash was created by exciting a laser dye solution with a pulsed laser. The resulting fluorescent light has a very high intensity, while the undesired coherence of the laser is removed. The illumination time of this light source (iLIF) is only $7 \mathrm{~ns}$ (chapter (4). To record the images a sensitive CCD camera (Lumenera LM165) with a resolution of $1392 \times 1040$ pixels and a pixel size of $6.45 \mu \mathrm{m} \times 6.45 \mu \mathrm{m}$ was used. Table 5.1 shows the desired imaging time scales $\tau_{M}$, next to expected motion blur due to the actual time scale $\tau_{f}$. The combination of the light source with the camera and microscope gives $\varepsilon<1$ for the $10 \times$ and $20 \times$ magnification, and $\varepsilon \approx 1$ for the $50 \times$ magnification, hence no motion blur is expected. Table 5.1 illustrates the advantage of the single flash light source, compared to the high speed recording. 


\subsection{EXPERIMENTAL PARAMETERS}

The short illumination time gives the possibility to choose a very small temporal resolution, corresponding to the smallest timescale in the experiment (chapter (4.2). Here a step time of $10 \mathrm{~ns}$ was used and, to confirm reproducibility, five images were recorded at each step. To control the delays between the drop, the illumination and the camera, a Berkely Nucleonics pulse generator (model 565) with a $250 \mathrm{ps}$ precision was used. Additionally a fully automated procedure was programmed with Matlab (The MathWorks) to control the hardware and gather the images from the camera. In the experiments the initial phase of the drop was studied, recording only the first $60 \mu$ s of the drop formation. This resulted in a total of 30.000 images for a single experiment, taking about six hours to record. Figure $5.2 \mathrm{~b}$ shows 21 images of the drop evolution as a time sequence below a similar sequence recorded with the Brandaris 128 ultra high speed camera. 


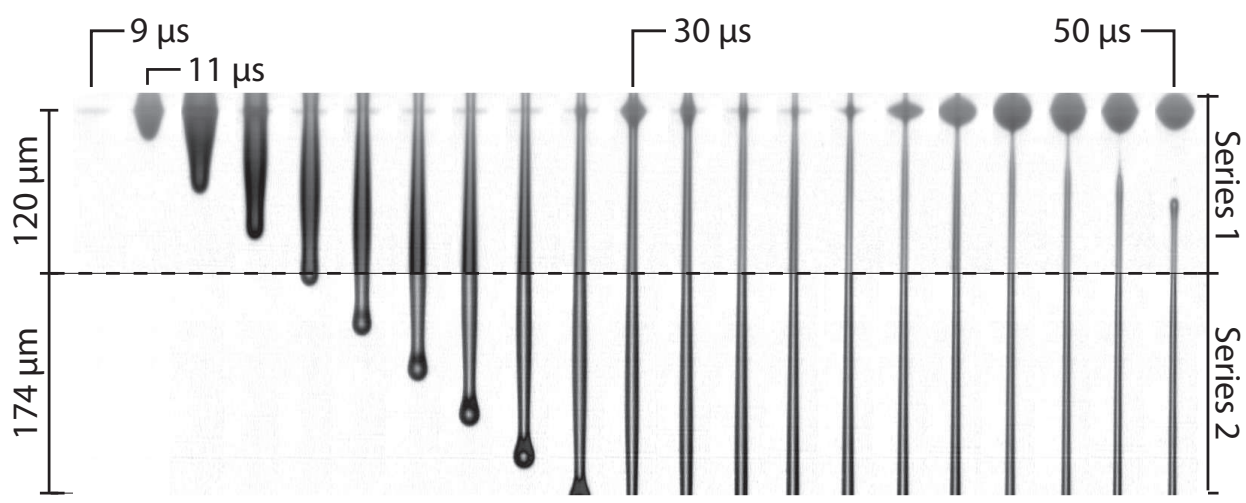

(a) - Brandaris 128

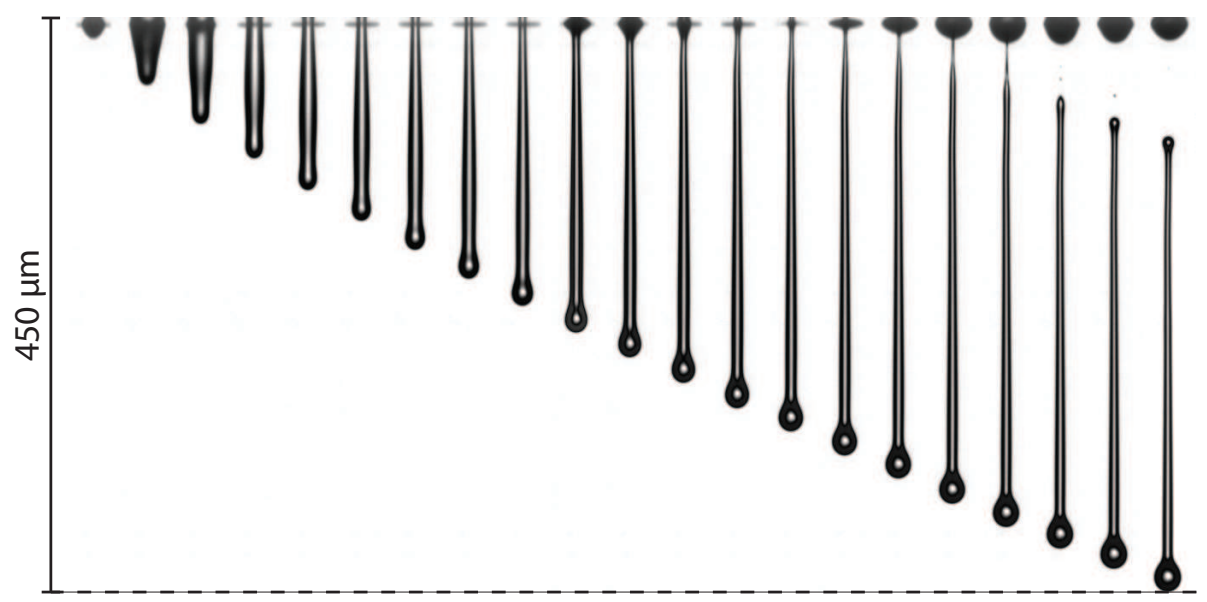

(b) - Single flash

Figure 5.2: A selection of images, showing the drop formation originating from a single inkjet channel as a sequence of time. The upper part shows the recordings made with Brandaris 128 (a), while the lower part shows the images captured with the single flash recording (b). The image illustrates the improved image quality of the single flash recording. Even tiny satellite (radius $<2 \mu \mathrm{m}$ ) droplets can be observed in the last three frames. 


\subsection{Data analysis}

Due to the large amount of recordings a program was developed in Matlab that fully automatically analyzes the experiments. The first step of the analysis is to extract the contour of the droplets from the images. Here it is assumed that the drop formation is axisymmetric around its central axis. The contour can then be used to calculate the radius, $R(x, t)$, as a function of time along the propagation axes $x$ (Figure 5.3). In the high speed recording this results into a single $R(x, t)$ curve per time step, but in the single flash recording five independent recordings were made per individual time step. Therefore the average curve $(\bar{R}(x, t))$ for $N$ recordings was determined by

$$
\bar{R}(x, t)=\frac{1}{N} \sum_{n=1}^{N} R(x, t, n) .
$$

The error between the $N$ different contours is used to estimate the reproducibility of the drop formation in section 5.5.1. In the remainder of this chapter the averaged curve is always used, and the bar is omitted. From the $R(x, t)$ curve

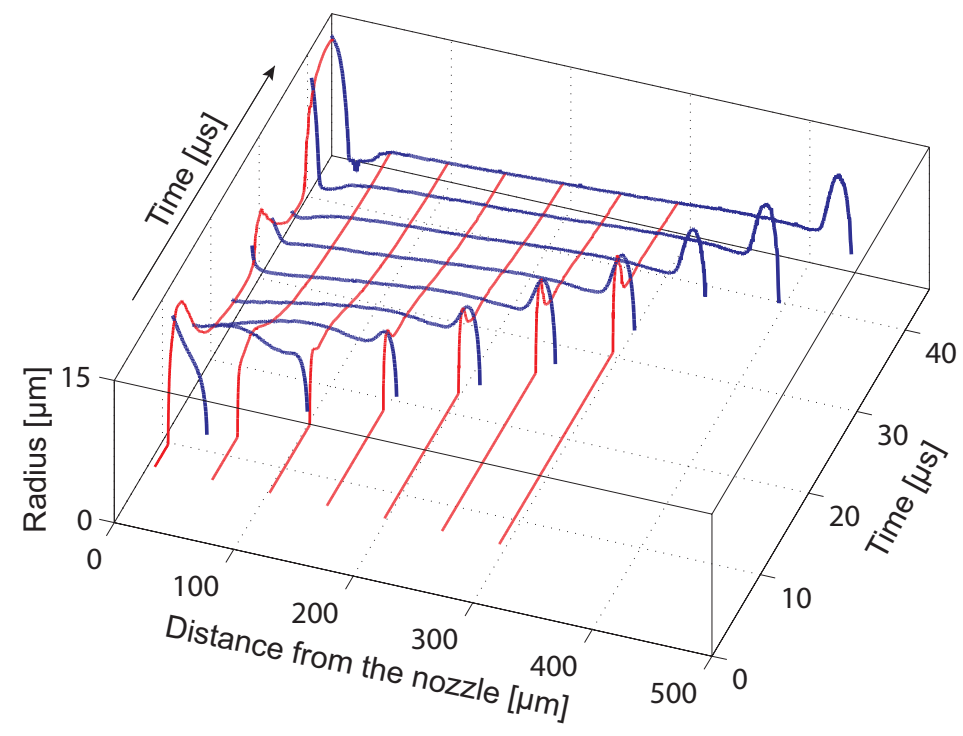

Figure 5.3: The $R(x, t)$ data is extracted from the experiment. The resulting data is gives the radial development, both as a function of time and space. The curves in blue show the $R(x)$ data for 9 values of $t$. The curves shown in red give the evolution of the drop $R(t)$ for 7 values of $x$ from the nozzle. 
the volume of the drop at time $t$ can be calculated by integrating over $x$,

$$
V_{\text {drop }}(t)=\pi \int_{x_{0}}^{x_{\max }} R(x, t)^{2} d x .
$$

Where $x_{0}$ is the nozzle position and $x_{\max }$ the tip of the drop. As a result of the imaging the values of $x$ are discrete, hence the integration becomes a summation over $x$,

$$
V_{\text {drop }}(t)=\pi \sum_{x=x_{0}}^{x_{\max }} R(x, t)^{2} \Delta x
$$

In this way the drop is treated as a discrete number of slices with a width of $\Delta x$ and an area of $\pi R(x, t)^{2}$. The value of $\Delta x$ corresponds to the scale of the image. For example in the flash recording $\Delta x=320 \mathrm{~nm}$ for a $20 \times$ magnification. By changing the summation limit $x_{0}$ in Equation 5.5 into an arbitrary point along the $\mathrm{x}$-axis, only the partial volume of the drop is calculated,

$$
V\left(x_{n}, t\right)=\pi \sum_{x=x_{n}}^{x_{\max }} R(x, t)^{2} \Delta x .
$$

Here $x_{n}$ is a point between the nozzle and the tip of the drop. Equation 5.6 gives the volume that has passed beyond point $x_{n}$ at time $t$. This is illustrated

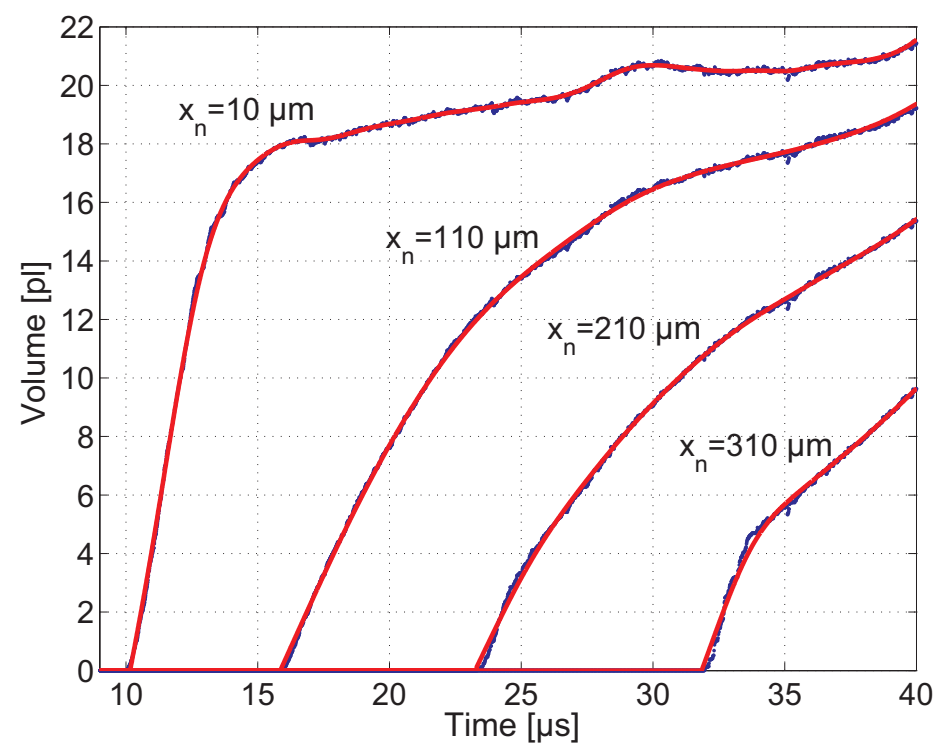

Figure 5.4: The figure shows the volume of droplet as a function of time for four different values of $x_{n}$. The data shown here is extracted from the flash recording. To remove fluctuations in the volume a smooth spline is fitted through the data (red). 


\subsection{DATA ANALYSIS}

in Figure 5.4, where for four different values of $x_{n}$ the volume development is shown. To remove the small oscillations in the data a smooth spline was fitted through the resulting volume data.

By differentiating Equation 5.6 with respect to time, the flux of liquid into a single slice is calculated. The flow rate at a point $x_{n}$ at time $t$ is thus given by

$$
Q\left(x_{n}, t\right)=\frac{d V\left(x_{n}, t\right)}{d t} .
$$

At this point the flow rate is determined for each slice and, with the surface, volume and mass already known, it is now possible to calculate the velocity and momentum in every slice $x_{n}$ within the drop. The velocity within the drop can be calculated by

$$
u\left(x_{n}, t\right)=\frac{Q\left(x_{n}, t\right)}{\pi R\left(x_{n}, t_{1 / 2}\right)^{2}} .
$$

Here we define $R\left(x_{n}, t_{1 / 2}\right)$ as the mean radius in between the two time steps, thus $R\left(x_{n}, t_{1 / 2}\right)=1 / 2 *\left(R\left(x_{n}, t\right)+R\left(x_{n}, t+d t\right)\right)$. Figure [5.5 shows the velocity within the droplet calculated for the flash experiment. 


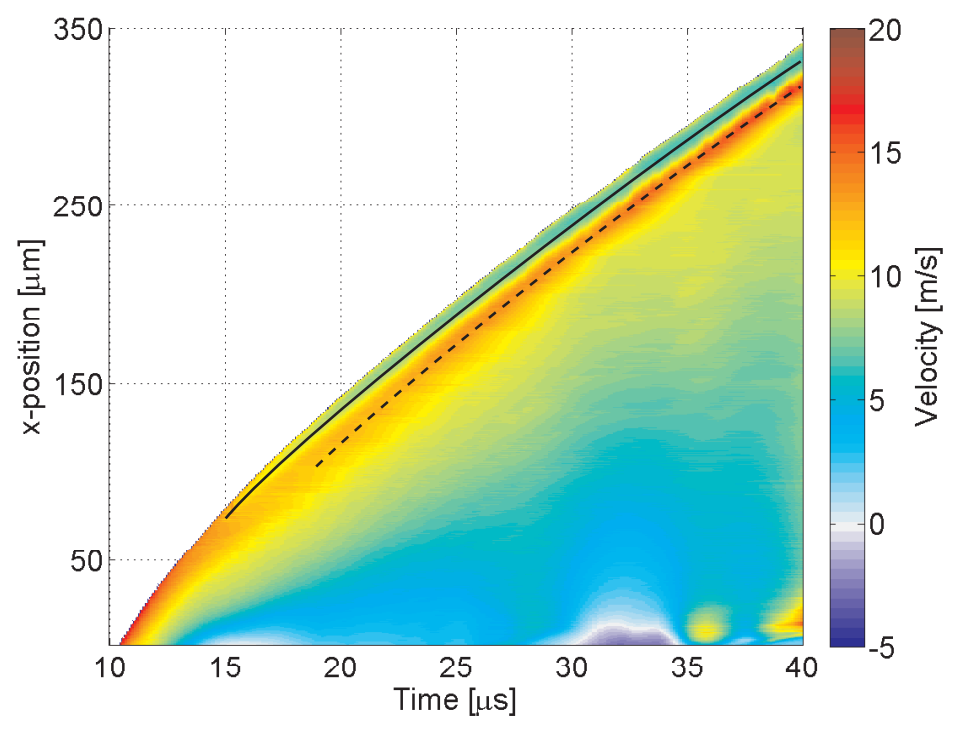

Figure 5.5: The velocity as a function of time and position $u(x, t)$. The colors indicate the velocity. The solid black line shows the position of maximum radius of the main drop, and the dashed black line that of the minimum neck radius behind the main drop. The velocity in the tail becomes negative at some point, as fluid is pulled back into the meniscus. 


\subsection{SPATIAL AND TEMPORAL RESOLUTION}

\subsection{Spatial and temporal resolution}

From the experiments the position at the tip of the drop was extracted (shown in Figure (5.6). The figure shows a difference in the slope of the curve between the Brandaris 128 (red) recording and the flash recording (blue). This difference is a result of a different voltage in the applied actuation pulse. In inset I of Figure 5.6 the velocity of the tip is shown. Here the initial velocity differs also due to the difference in the actuation pulse.

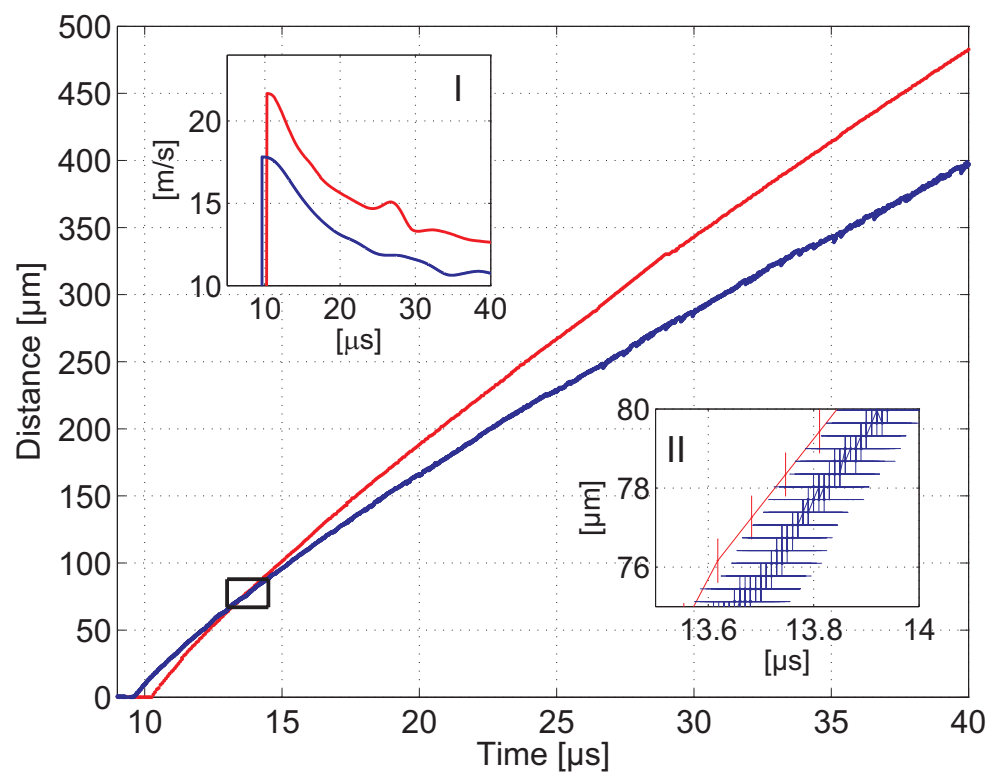

Figure 5.6: The position of the tip of the droplet as a function of time. The red curve corresponds to the data extracted from the high speed camera and the blue curve correspond to the single flash data. The actuation voltage for these two cases is slightly different. Inset I shows the corresponding velocity at the tip of the drop. Inset II shows a magnification of the position data, with the corresponding error in time $\left(t_{e r r}\right)$ and position $\left(x_{e r r}\right)$.

Figure [5.6]illustrates the small temporal error $t_{e r r}$ and spatial error $x_{e r r}$ in both methods, as is shown in inset II of Figure 5.6. In the high speed recording there is no observable temporal error between successive frames, as change in the rotation speed of the mirror turbine is negligible [80, 83]. In the flash recording the error in the temporal resolution is due to jitter in the delay between the droplet and light pulse. This error does not originate from the delay generator, which has a precision of less than a nanosecond, but from two other significant 
delays in the system. Firstly, there is a jitter of approximately $50 \mathrm{~ns}$ in the delay between the input trigger to the laser, and the output flash from the laser. Secondly, there is a synchronization error between the function generator and the delay generator, which can reach up to $25 \mathrm{~ns}$. This gives a total temporal jitter of 75 ns for the flash recordings.

The error in the spatial direction depends on the resolvable resolution of the system. This is illustrated by Figure 5.7, where the smallest observable length scale involved in the drop formation is shown. The figure shows the final stage of the drop formation, at which the drop detaches from the meniscus. At this point a thin tail is formed in between the meniscus and the end of the drop, which has a width of approximately $3 \mu \mathrm{m}$. The contour of the droplet is extracted by calculating the intensity along a single row of pixels. Figure 5.8 shows the extracted data for three different rows. The displayed intensity was normalized to the maximum intensity, where the overall noise level stays below 10 percent. The edge of the contour was chosen at an intensity of twice the noise level. The width of the slope between the noise level and the threshold level was used to define the spatial error. The calculated spatial error from the experiments varies per camera and per magnification and increases for radii smaller than $1 \mu \mathrm{m}$. Typical values for the spatial error for the $50 \times$ magnification are $x_{e r r}=0.4 \mu \mathrm{m}$ for the Brandaris 128 and $x_{e r r}=0.1 \mu \mathrm{m}$ for the flash recording (shown in inset II of Figure 5.6).

To compare the overall error from the high speed imaging with the error from the single flash imaging, the temporal error was rewritten into a spatial error by multiplying with the velocity. This gives a velocity dependant spatial error, corresponding to the amount displaced during time $t_{e r r}$. In addition, due the motion blur, as defined in section 5.3, one also gets a spatial error depending on the velocity and the magnification. If we define $x_{e r r}(0)$ as the static spatial error, the total spatial error is given by,

$$
x_{\text {err }}(u)=x_{\text {err }}(0)+u\left(t_{\text {err }}+\tau_{M}\right) .
$$

This is shown in Figure [5.9, where $x_{e r r}(u)$ is displayed as a function of the velocity. The figure shows that the total spatial error for the flash recording is much smaller for velocities below $10 \mathrm{~m} / \mathrm{s}$. It also shows that as long as the drop velocity is below $5 \mathrm{~m} / \mathrm{s}$, the spatial error for a $20 \times$ and $50 \times$ magnification is less than $1 \mu \mathrm{m}$.

\subsubsection{Reproducibility}

Due to the nature of the flash recording there could be an additional error in the experiments originating from the variation between individual drops. To 


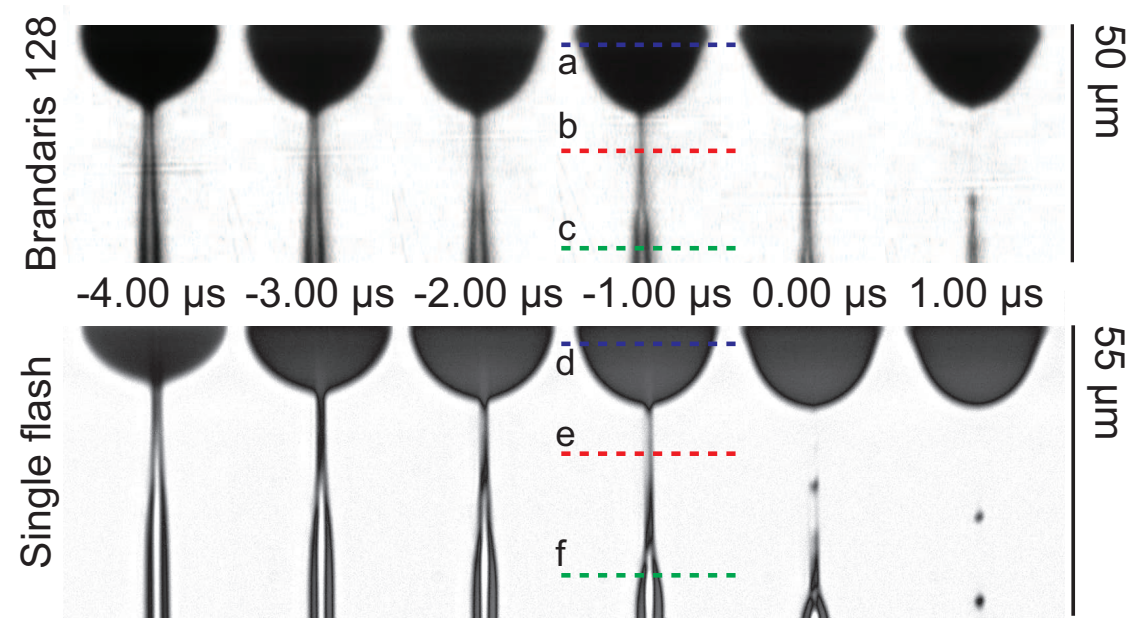

Figure 5.7: The last $4 \mu$ s before the pinch-off till $1 \mu$ s beyond the pinch-off. The slender tail formed between the meniscus and the drop is the smallest length scale involved and reaches a radius of less than $1 \mu \mathrm{m}$. The rows of pixels indicated by (a-f) correspond to the intensity graph shown in Figure 5.8 .

estimate the amount of this variation, a single contour $R(x, t, n)$ was compared to the mean contour $R(x, t)$ (determined in Equation 5.3). Therefore the radial variation for a single slice $x_{n}$ at time $t$ is defined as

$$
R_{e r r}\left(x_{n}, t\right)=\|\left(R\left(x_{n}, t\right)-R\left(x_{n}, t, n\right) \|_{\infty},\right.
$$

where $n$ is a curve at time $R\left(x, t_{n}\right)$. By calculating the mean variation for all slices one obtains $R_{e r r}(t)$. The value of $R_{e r r}(t)$ gives an estimate on the reproducibility of the drop. Figure 5.10 shows $R_{\text {err }}$ for a $10 \times$ and $20 \times$ magnification. In the first few microseconds, where the number of slices is relative low, the error is relatively large. Beyond $15 \mu$ s the error in the radius stays less than $100 \mathrm{~nm}$ per slice. The error level remains similarly low up to $45 \mu \mathrm{s}$, which is close to the pinch-off. The pinch-off produces large non-reproducible disturbances along the tail of the droplet, which causes the radial variation to increase rapidly.

The error in the drop volume $V\left(x_{n}, t\right)$ (Equation 5.6), can also be calculated in a similar way. For experiments done with a $20 \times$ magnification it was found that in the first $40 \mu \mathrm{s}$, the volume deviates $0.03 \mathrm{pl}$ per slice, whereas the average volume in each slices is approximately $0.7 \mathrm{pl}$. 


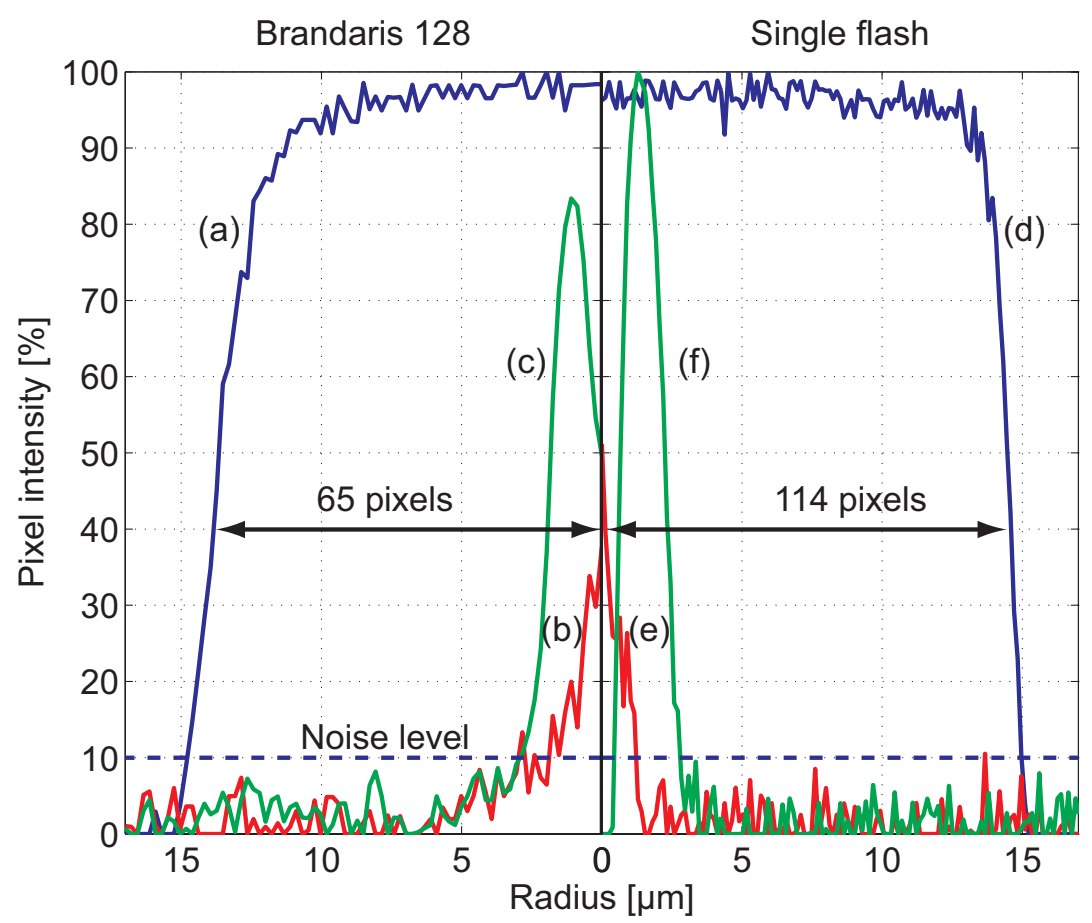

Figure 5.8: Comparison of the resolvable detail from the high speed recordings (left) compared to the flash recording (right). The curves give the intensity along a row of pixels from the image in Figure 5.7 where the curves (a-f) correspond to those in Figure 5.7 This illustrates the improved spatial resolution in the flash recording compared to the high speed recording.

\subsection{Velocity comparison}

The experiments show that both techniques give very detailed insight in the drop formation. The reproducibility of the droplet formation proves reliable enough to compare this method with the high speed imaging experiments. Aditionally both method overall give a very small error. For the $20 \times$ and $50 \times$ magnification the error in both methods increases above $1 \mu \mathrm{m}$ at locations where the velocity increases above $10 \mathrm{~m} / \mathrm{s}$. Therefore, at the tip, where the velocity is high, the error is relatively large. The radial velocities during the drop formation are much lower, hence they are expected to be very accurate.

The measurements made it possible to estimate the velocity within the drop for both methods, as is shown in Figure 5.11. Here the overall agreement between the high speed recording and single flash recording is very good, con- 


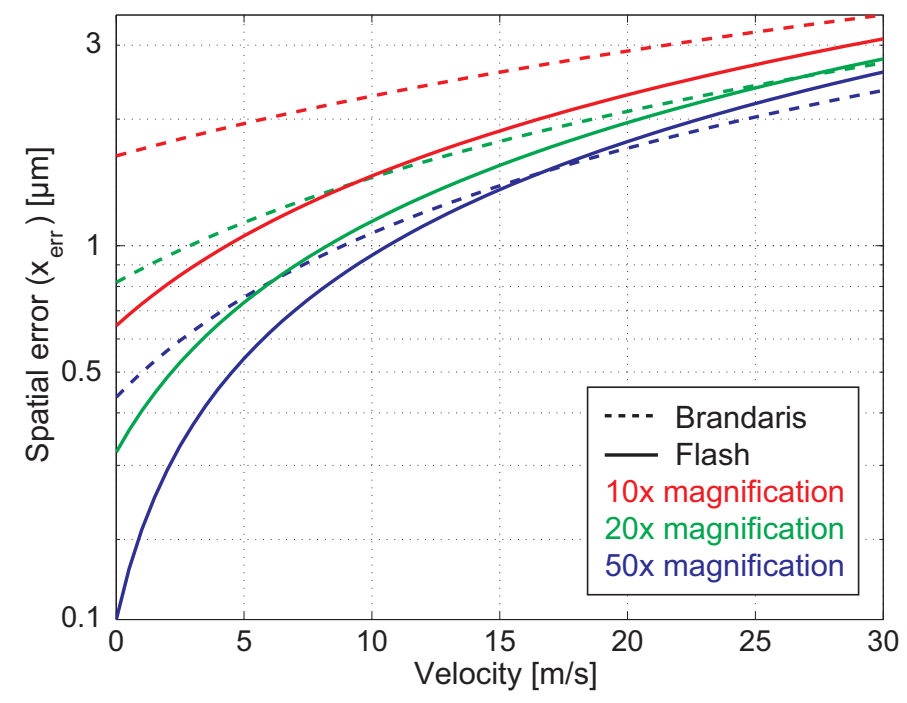

Figure 5.9: The spatial error depends on the magnification and the velocity. Here it can be seen that for the flash recording it is almost half that of the high speed imaging recording.

sidering the difference in the actuation voltage. The velocity within the drop in the two experiments is of similar order and close to the expected value. In the following section the results from the single flash method are compared with a one-dimensional lubrication model.

\subsection{Numerical model}

The dynamics of axisymmetric drop formation can be described by solving the Navier-Stokes equation within the lubrication approximation, as described in detail by Eggers and Dupont [84] and Shi, Brenner and Nagel [85]. In the onedimensional lubrication approximation it is assumed that the fluid propagates nearly unidirectional, omitting all radial transport. The dominating properties of the drop formation are the viscous stress, the surface tension, and the axial mass and momentum transport. The time scale at which the drop formation occurs is in the order of microseconds, whereas the velocity of the droplet is in the order of meters per second. Hence macroscopic properties, such as gravity and temperature decay, can be omitted. In an isothermal Newtonian fluid the viscosity and surface tension are constant. Also the short time of flight of the droplet allows us to neglect the effects of drag on the droplet. For 


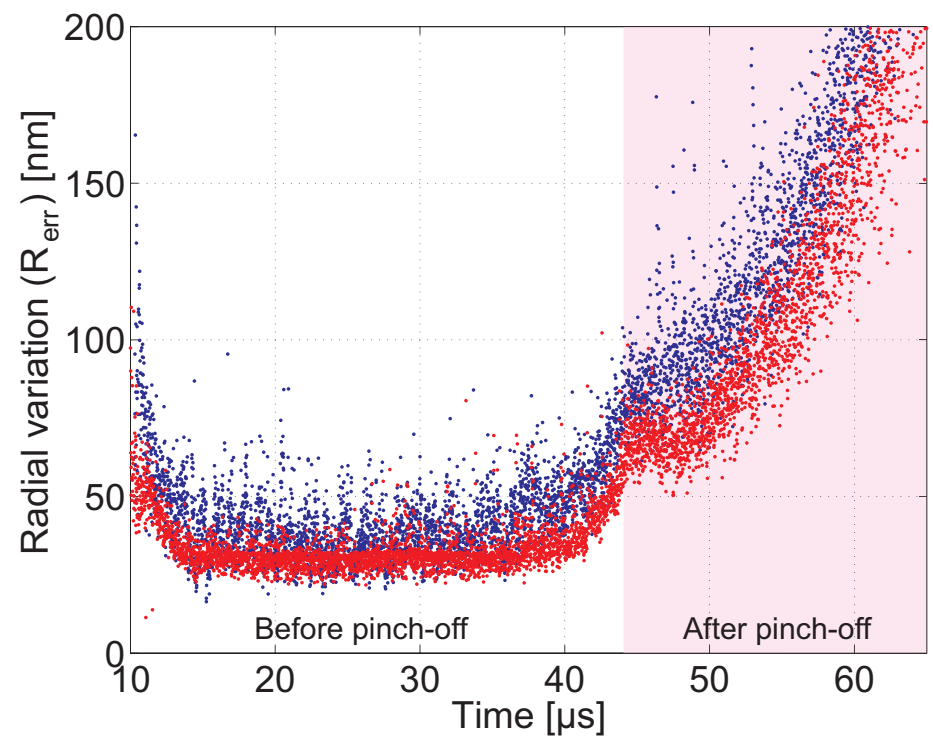

Figure 5.10: The radial variation between different experiments conducted at the same time, as a function of the drop formation time, given for a $10 \times$ (blue) and a $20 \times$ (red) magnification. The radial variation stays below $100 \mathrm{~nm}$ up to the time of the pinch-off $(45 \mu \mathrm{s})$ when the droplet detaches from the meniscus.

convenience the equations of lubrication approximation are shown in the next section, together with a short note on the numerical implementation.

\subsubsection{Governing equations}

The existing numerical models use the lubrication approximation derived in [84].

$$
\begin{gathered}
\partial_{t} R=-u \partial_{x} R-\frac{1}{2} R \partial_{x} u, \\
\partial_{t} u=-u \partial_{x} u-\frac{1}{\rho} \partial_{x} P_{\text {Lap }}+3 v \frac{\partial_{x}\left(R^{2} \partial_{x} u\right)}{R^{2}}, \\
P_{\text {Lap }}=\sigma\left[\frac{1}{R\left(1+\left(\partial_{x} R\right)^{2}\right)^{\frac{1}{2}}}-\frac{\partial_{x}^{2} R}{\left(1+\left(\partial_{x} R\right)^{2}\right)^{\frac{3}{2}}}\right],
\end{gathered}
$$

where $R$ is the radius, $u$ is the axial velocity, $x$ is the axial coordinate, $t$ is the time, $P_{\text {Lap }}$ is the Laplace pressure, $\sigma$ is the surface tension, $\rho$ is the density, and $v$ is the kinematic viscosity. The solutions to these equations are singular at 


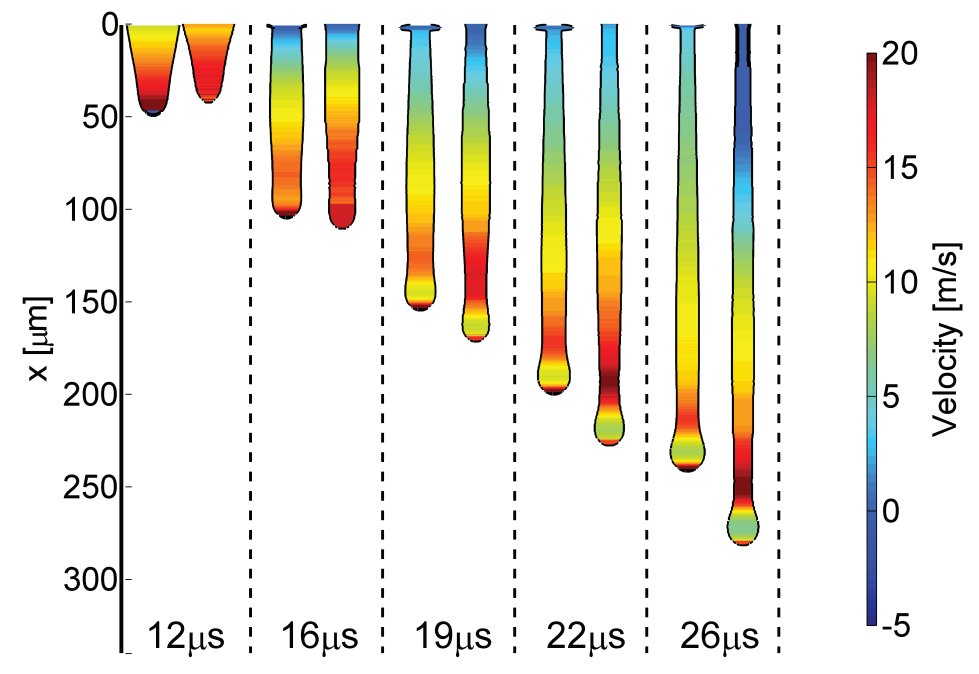

Figure 5.11: The velocity data from the drop formation was extracted from the experiments. For the flash recording this is shown on the left, and for the high speed recording this is shown on the right. The difference in total velocity of the drop is due to the difference in the actuation pulse.

each pinch-off [84], and at each collision of liquid bodies [86]. In order to create solution that converges closely to the exact physical system, these singularities have to be dealt with. As the solution of the system has to be calculated beyond the singularities it is essential to use a conservative numerical scheme [87].

A conservation equation of a hyperbolic system of equations is given by a time derivative of the conserved quantity, and the spatial derivative of the flux of the conserved quantity through the control volume.

$$
\partial_{t} a(x, t)+\partial_{x} f(a(x, t))=0
$$

where $a$ is the conserved quantity, and $f(a(x, t))$ is the flux function of this conserved quantity. Equation 5.11 is rewritten in a conservative form, by multiplying the balance with $\pi R$ on both sides:

$$
\partial_{t}(\rho A)+\partial_{x}(\rho u A)=0
$$

Equation 5.12 is integrated over the cross section of the jet, to obtain the conservation of momentum equation. The differential form of the conservation of momentum is

$$
\partial_{t}(\rho A u)+\partial_{x}\left(\rho A u^{2}\right)=\partial_{x}\left(\tau_{v}+\tau_{\sigma}\right)
$$


where $A$ is the cross sectional area of the jet, and the sum of the viscous tension $\tau_{v}$ and capillary tension $\tau_{\sigma}$ is the momentum flux due to tension. The viscous tension $\tau_{v}$ is given by

$$
\tau_{v}=3 \mu A \partial_{x} u,
$$

where $\mu$ is the dynamic viscosity. The capillary tension $\tau_{\sigma}$ is given by the integral of the Laplace pressure over the cross sectional area. In the conservative form this integral is rewritten as a momentum flux. This flux is given by the sum of the Laplace pressure integrated over the cross sectional area and the force exerted on the contour of the jet in the axial direction,

$$
\begin{aligned}
A \partial_{x} P_{\text {Lap }} & =\partial_{x} \tau_{\sigma} \\
& =\partial_{x}\left[A P_{\text {Lap }}-\sigma \frac{2 \pi R}{\left(1+\left(\partial_{x} R\right)^{2}\right)^{\frac{1}{2}}}\right] .
\end{aligned}
$$

A topological change, such as droplet pinch-off or coalescence, is singular in the continuum approximation. The nature of these singularities has been studied thoroughly [11, 20]. At a pinch-off in physical space, a point in time, and space exists, where the molecules of splitting bodies stop to feel each others presence. They start to 'live' on separate liquid bodies. In the continuum approximation however, this point in time and space will never be reached, since there is no lower limit on the pinch-off radius, such as the size of molecules. The temporal and spatial dimensions will become smaller and smaller, but will never reach the point of singularity. Due to the increase of surface to volume ratio when approaching the pinch-off singularity, the velocity diverges, and the numerical calculation will break down. In a numerical simulation of the breakup of liquid bodies in the continuum approximation, it is thus necessary to assume a lower limit on the singularities, when it is desired to calculate further after the first singularity.

To allow the lubrication approximation based model to transfer over the singular points, a small modification was added to the governing equations of the numerical model. The surface tension term is replaced by a weighted average of the physical surface tension, and a constant surface tension that allows a tiny cylinder to exist between the bodies of liquid. This operation regularizes the governing equations, and prevents getting to close to the singularities. The weighted averaging function is given by:

$$
\tau_{\sigma r e g}=\frac{R}{R+R_{c}} \tau_{\sigma}+\frac{R_{c}}{R+R_{c}} \tau_{c},
$$

where $\tau_{c}=-\sigma \pi R_{c}$ is the surface tension force in a cylinder of radius $R_{c}$. The cutoff radius $R_{c}$ scales with the spatial step of the numerical simulation, hence 


\subsection{COMPARISON}

the influence of the regularization vanishes as the spatial step goes to zero. When $R>>R_{c}$, the regularized capillary tension behaves like the physical capillary tension. In the case of $R<<R_{c}$, the regularized capillary tension behaves like a the constant capillary tension of a cylinder of radius $R_{c}$. The solution to the regularized equations will get arbitrary close to the singularity, from where the regularization takes over.

\subsubsection{Numerical implementation}

The regularized lubrication approximation allows for the use of a single Eulerian grid. When all droplets are part of single fluidic body, jet separated by an infinitesimal thin layer, no special effort has to be put into the jump conditions for singular events. To prevent numerical diffusion a second order accurate finite differencing scheme is used. The numerical diffusion tends to smear out high velocity gradients. The numerical model is validated by the Rayleigh-Plateau instability, which has been studied for many years [10, 11, 88]. The linearized analytical dispersion relation of the onset of the Rayleigh-Plateau instability is compared to the numerical result. Detailed information about the validation and the numerical implementation of the model can be found in [81].

\subsection{Comparison}

A preliminary parametric study was done to calculate for which value of the viscosity and the surface tension the modeled droplet matches closest to experimental results from the flash recording. The input conditions for the model, the flow rate and radius at a position $x_{n}$, are extracted from the experiment. As the model is a one-dimensional approximation, the flow profile within the drop is assumed to be flat. Close to the nozzle opening the flow profile is not flat, but a frequency dependant flow profile [40]. To prevent that this has a large influence on the calculation, the model starts the drop calculation at $x_{n}=50 \mu \mathrm{m}$ from the nozzle.

The drop formation was modeled for different values of the viscosity and the surface tension. Here the tip position of the drop was used to compare the experiment with the model. This is shown in Figure 5.12 for a surface tension of $28 \mathrm{mN} / \mathrm{m}$ and for viscosities ranging from $7 \mathrm{mPas}$ (a) to $15 \mathrm{mPas}$ (e). The inset of Figure 5.12 shows a magnification of the position curves at $42 \mu \mathrm{s}$, showing that here the closes agreement is found for a viscosity of $15 \mathrm{mPas}$.

Besides the viscosity also the surface tension was varied, ranging from $20 \mathrm{mN} / \mathrm{m}$ to $40 \mathrm{mN} / \mathrm{m}$. This resulted in three combinations of surface tension and viscosity at which a very good agreement in the position of the tip was found. These 


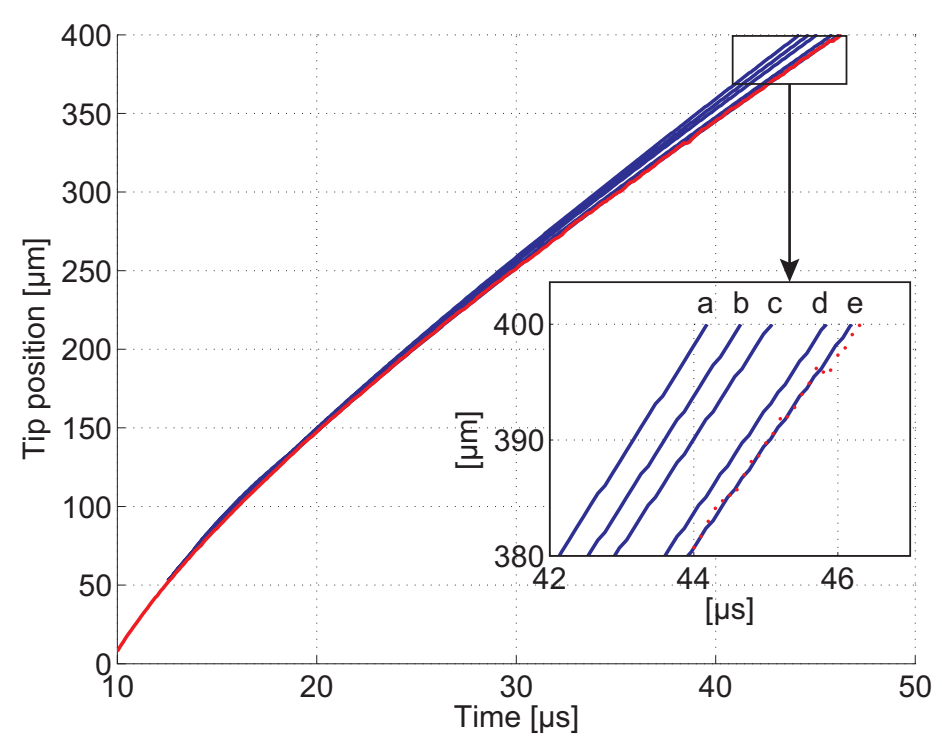

Figure 5.12: The modeled position of the tip of the drop for different viscosities (blue). The red dots show the experimental data. For all modeled curves the surface tension is $28 \mathrm{mN} / \mathrm{m}$. The viscosities range from $7 \mathrm{mPas}$ to $17 \mathrm{mPas}$. The inset shows a magnification at $42 \mu \mathrm{s}$. Here the letters correspond to different viscosities; (a) $7 \mathrm{mPas}$ , (b) 9 mPas, (c) $11 \mathrm{mPas}$, (d) $15 \mathrm{mPas}$, (e) $17 \mathrm{mPas}$.

are shown in Figure 5.13 at $40 \mu \mathrm{s}$. Enlarging the area around the neck reveals differences in the radial shape between the drops. The best agreement between the model and experiment is found for a viscosity of $11 \mathrm{mPas}$ and a surface tension of $34 \mathrm{mN} / \mathrm{m}$. In the experiments it was assumed that the viscosity is $10 \mathrm{mPas}$ and the surface tension $28 \mathrm{mN} / \mathrm{m}$. For this case the velocity inside the drop, for both the modeled drop and the experimental drop, was calculated and compared. This is shown side by side in Figure 5.14. 


\subsection{COMPARISON}
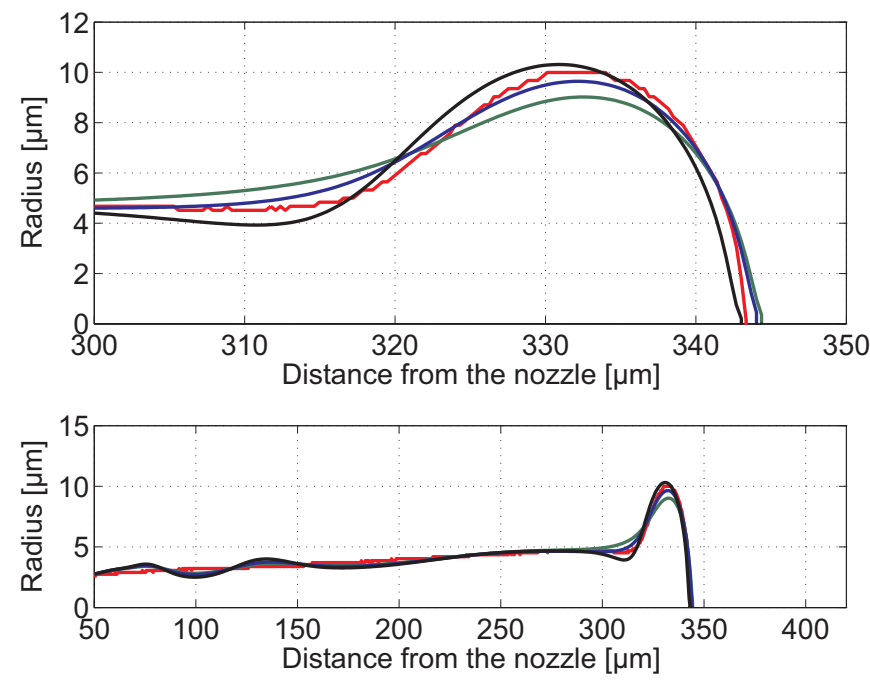

Figure 5.13: The radius as function of the position at $40 \mu \mathrm{s}$. The red curve shows the experiment, the modeled curves are shown in green $(\sigma=30 \mathrm{mN} / \mathrm{m}$ and $\mu=15 \mathrm{mPas})$, blue $(\sigma=34 \mathrm{mN} / \mathrm{m}$ and $\mu=11 \mathrm{mPas})$ and black $(\sigma=40 \mathrm{mN} / \mathrm{m}$ and $\mu=7 \mathrm{mPas})$

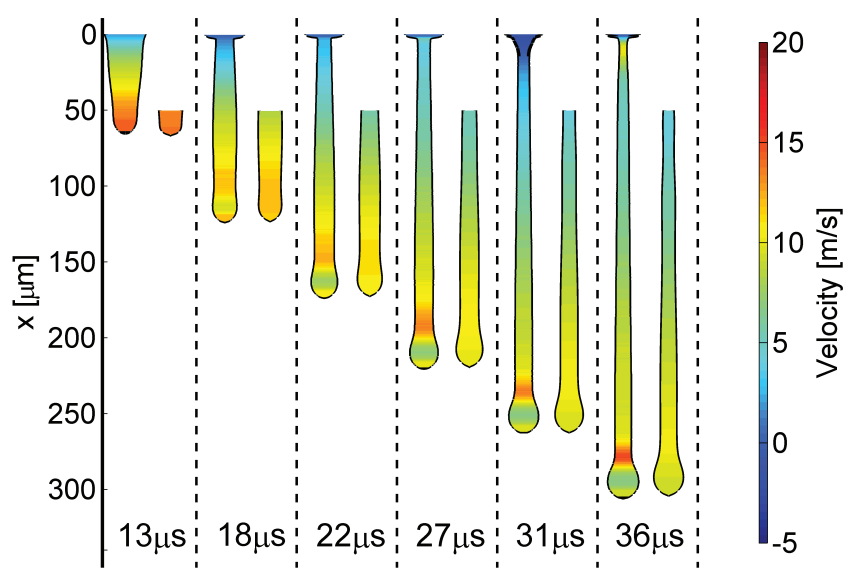

Figure 5.14: The drop formation of the experiment (left) next to the results from the one-dimensional model (right). Overall the velocities show good agreement, but in the neck area of the drop, the experiments show a higher velocity. 


\subsection{Discussion and outlook}

In this research the drop formation was experimentally studied using a high speed imaging technique and a single flash imaging technique. It was shown that, in a direct comparison (shown in table 5.1), the single flash is the better method on all aspects; resolution, field of view and imaging time scale. Further comparison between the two methods showed that the static error in the flash method is much smaller, but the error increases largely as a function of the velocity. Therefore, at velocities above $20 \mathrm{~m} / \mathrm{s}$, the recordings with the Brandaris 128 give a slightly better result. It was also shown that, if the drop formation reaches beyond the pinch-off, the drop formation is no longer reproducible. Here the high speed imaging becomes the preferred experimental method.

The comparison between the one dimensional model and the single flash experiment show overall good agreement, and the velocities are of the same order of magnitude. The surface tension found in the comparison $(\sigma=34 \mathrm{mN} / \mathrm{m})$ deviates from the assumed surface tension $(\sigma=28 \mathrm{mN} / \mathrm{m})$. Further research should be conducted to verify this result. Also a large difference was observed between the two methods in the velocity in neck of the drop. By comparing these results with validated CFD codes, such as ANSYS Flotran or Flow3D, this result could be verified.

The one-dimensional model also proves to be a fast tool for exploring different drop formation parameters. The results presented here are preliminary and already show promising agreement. It is planned, by applying the model, to study the effect of different inflow conditions, and the behavior of satellite droplets. Additionally the model can be extended to include effects of temperature gradients, surfactants and non-Newtonian liquids.

Overall the presented method, in which the single flash method is used to extract velocity and flow rate within the drop, is a very promising technique. The resolvable detail, both in temporal and in spatial resolution are close to the limits of visualizing the smallest details of the drop formation with visible light. The temporal error, as a result of the synchronization between the applied equipment, can easily be reduced by small improvements to the experimental setup. Moreover, if acoustic sensing is used to verify the reproducibility, the reproducibility can be verified, making the method a very valuable tool to study drop formation. 


\section{6}

\section{Controlled air entrapment in piezo acoustic inkjet printing}

Microbubbles are a major problem in piezo acoustical inkjet printing, as they can lead to a disruption of the inkjet printing process. Here a bubble entrapment pulse was applied that, for a certain class of printheads, always leads to air entrapment. The pulse produces a fully reproducible, but asymmetric drop formation, clearly revealing the presence of air bubbles. An acoustic sensing technique was applied to study the growth of the microbubble after the entrapment event.

\subsection{Introduction}

Inkjet printing is the most widely spread technological application of microfluidics. Besides the graphical printing industry, this drop deposition technique is used in dozens of other applications, such as solar printing, rapid prototyping and even printing DNA and protein substances [2, 3, 6]. Inkjet printing is characterized by its high drop productivity, small volumes and extreme reproducibility, as was also shown in chapter 5. All applications require hundred percent reliability and, for some applications, it is even fully unacceptable if a single droplet is missing. For example, if inkjet printing is applied to create electronics [89], the omittance of one drop can lead to circuit failures. Also when the pixels of displays are printed [28], defective pixels are costly reliability issues. Moreover, if medical decisions are based on DNA printed results, missing drops may have catastrophic consequences.

Several causes for a disrupted drop formation can be pointed out, among them an ink layer around the nozzle [16], dirt particles in the ink, or failure of the electronics. Though most of these causes can be prevented easily, there still remains one problem that is not fully understood. It can happen that during the print process, seemingly unpredictable, and without immediate cause, 
microbubbles are entrapped at the nozzle of the channel. The microbubbles react to the acoustic pressure field present inside the ink channel. This causes each bubble to grow due to rectified diffusion and, due to the Bjerknes forces, translate and coalesce with other bubbles [19, 20, 22, 47, 48]. The presence of the bubbles disrupts the drop formation process, and it can even lead to a full stop of the jetting [17]. This is illustrated in Figure [6.1, which shows the drop formation after a bubble entrapment. The susceptibility of an ink channel to microbubble entrapment seems to correlate with increasing drop repetition rates, hence preventing increased potential productivity of the printhead. Earlier research identified two correlated aspects leading to air entrapment, (i) dirt particles were found in droplets captured just before the entrapment of a microbubble. (ii) an ink layer around the nozzle can transport dirt into the droplets, but can also disturb the meniscus [2, 14-16].

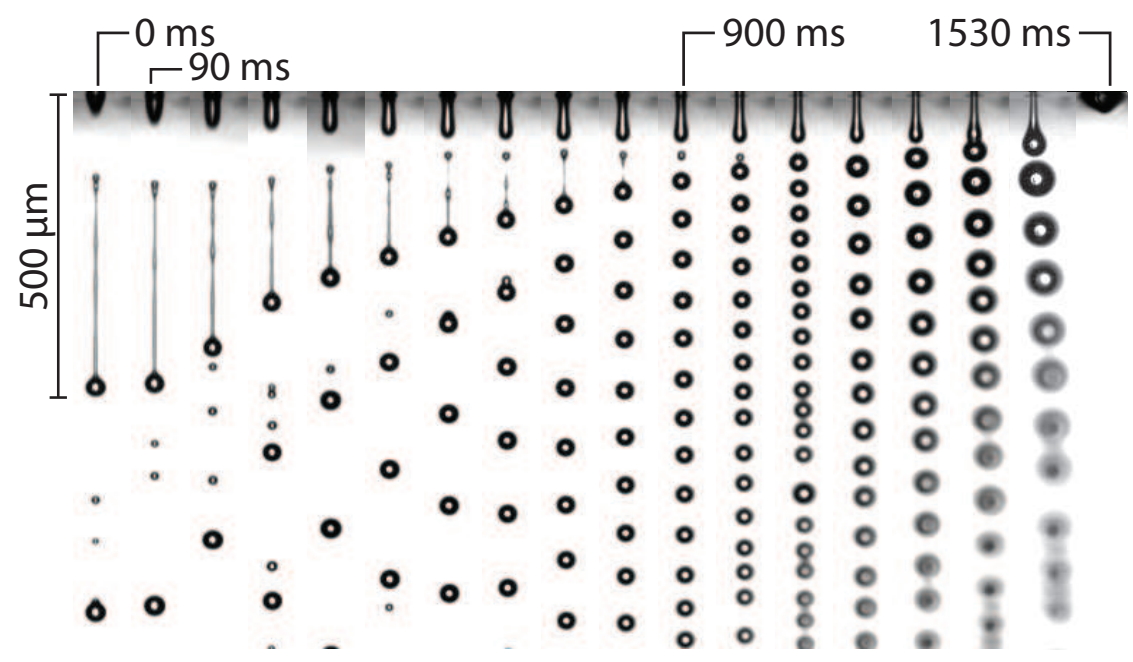

Figure 6.1: A sequence of images showing the drops emerging from a single nozzle after a micro bubble is entrapped. The images were recorded with a high speed camera (Photron, Fastcam SA1.1) at 75.000 frames per second. The bubble was entrapped at the start of the sequence, and after $1.6 \mathrm{~s}$ (32.000 droplets) the channel has stopped jetting.

The behavior of air bubbles inside the channels have been a subject of research for several years [2, 14, 17, 18, 49, 50, 90], but the actual mechanisms leading to air entrapment are less understood. The time scale of air entrapment is in the order of microseconds, thus requiring fast high speed cameras. Additionally, as the process of air entrapment is a transient process, it is impossible to predict when it occurs, making it difficult to study experimentally. Research 


\subsection{EXPERIMENTAL PARAMETERS}

in the past resolved to high actuating frequencies relative to normal operation conditions [50, 90], or to more exotic solutions, like using an air gun to force 'micro' bubbles into the channel [49]. In earlier work presented in chapter 2 and chapter 3 air bubbles were also entrapped by printing at high frequencies or blocking the channel. By using these methods the bubble dynamics inside the channel were studied elaborately [18, 49, 50, 90].

Though the experimental study of the air entrapment process has proven to be difficult, it is exactly this event that is important to investigate. Understanding the mechanism leading to air entrapment can be used for exploring methods to prevent it. In this research it was possible to study air entrapment by applying a pulse which, for a certain class of printheads, always leads to the entrapment of a microbubble at the meniscus. Here the fully reproducible drop formation is studied, and conditions leading to air entrapment are evaluated, increasing the insight in possible mechanisms. Additionally, by applying an acoustic sensing technique, the influence of the microbubble on the channel acoustics during the first milliseconds after the entrapment is studied.

\subsection{Experimental parameters}

Two similar inkjet printheads, both developed by Océ Technologies B.V., were used for this research, differing only in the incorporated piezo element. Though the difference between the printheads was small, we considered it as important to study two different ones. Firstly to confirm that, given comparable geometry, the method of controlled air entrapment is applicable to more than one printhead. Secondly, due to the nature of the bubble entrapment pulse, acoustic sensing proved to be difficult for one of the two printheads. Each printhead consist of 256 similar ink channels, where each individual channel has a rectangular actuator section of $118 \mu \mathrm{m}$ by $218 \mu \mathrm{m}$ and a length of $3.5 \mathrm{~mm}$. A cylindrical channel section with a radius of $125 \mu \mathrm{m}$ and a length of $1 \mathrm{~mm}$ connects the actuator section to the nozzle (Figure 6.2). The $50 \mu \mathrm{m}$ thick nozzle plate contains trumpet shaped nozzles with a radius of $15 \mu \mathrm{m}$. A piezo element is positioned in the actuation chamber. To create droplets, a trapezoidal pulse of $7 \mu \mathrm{s}(2 \mu \mathrm{s}$ rise, $3 \mu \mathrm{s}$ high and $2 \mu \mathrm{s}$ fall time) is applied. This results in droplets of $20 \mathrm{pl}$ with a velocity of approximately $8 \mathrm{~m} / \mathrm{s}$.

The liquid used is not water based, but a non-colored version of the CrystalPoint technology toner pearls [55, which instead of drying, crystalizes on the paper, resulting into very rapid solidification. To liquify the ink the printhead is operated at a temperature of $130^{\circ} \mathrm{C}$. At this temperature the viscosity, density and surface tension are $10 \mathrm{mPas}, 1080 \mathrm{~kg} / \mathrm{m}^{3}$ and $28 \mathrm{mN} / \mathrm{m}$, respectively.

The droplets were visualize with a setup, exactly as in chapter 5, where a 


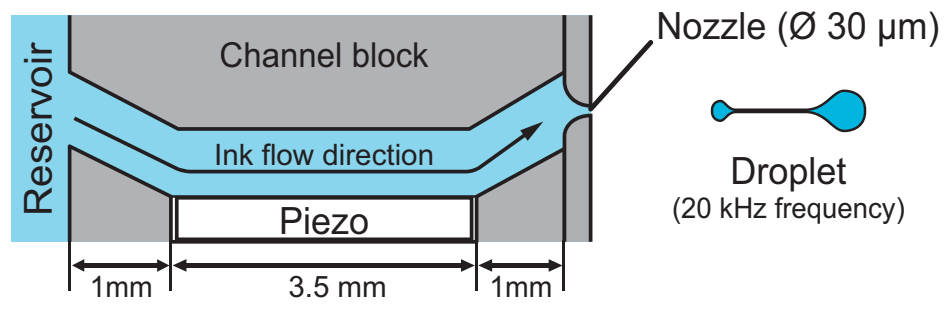

Figure 6.2: The channel inside the printhead is about $6 \mathrm{~mm}$ long and is actuated by a $3.5 \mathrm{~mm}$ long piezo. The piezo section is connected to the nozzle plate by a $1.5 \mathrm{~mm}$ long connection channel. The $50 \mu \mathrm{m}$ thick nozzle plate contains trumpet shaped nozzles with a radius of $15 \mu \mathrm{m}$. The typical drop repetition rate of this printhead is 20.000 droplets per second.

single flash technology with a CCD camera is applied. This flash is generated by laser induced fluorescence illumination (iLIF), giving an illumination time of only $7 \mathrm{~ns}$ (chapter 4). If the drop formation is fully reproducible, every image corresponds to a single droplet, resulting in very detailed visualization of the droplet.

An acoustic sensing method, as described in chapter 2, was used to measure the channel acoustics [17, [18, 50]. Here the actuation piezo is switched to sensing mode, giving an accurate measurement of the acoustic pressure inside the ink channel [13]. This technique was applied in chapter 2 and chapter 3 to detect the presence and size of air bubble with great accuracy.

\subsection{Characterization of the bubble entrapment pulse}

To induce the controlled entrapment of a microbubble, a special actuation pulse is applied. Figure 6.3 shows this bubble entrapment actuation pulse (BEP) next to a normal actuation pulse. The relative high amplitude of the BEP creates an amplified piezo response, hence resulting in higher acoustic pressures inside the channel. The consequence is a highly deviating drop formation (Figure 6.4) and, in most experiments, the jetting process comes to a full stop.

The rigidity, timing and amplitude of the slopes in the BEP are extremely crucial. As a result of the first slope, the piezo expands and, after $2 \mu \mathrm{s}$ (at $4.2 \mu \mathrm{s})$, a $16 \mathrm{pl}$ drop with a velocity of around $5 \mathrm{~m} / \mathrm{s}$ emerges from the nozzle. The second slope $(1 \mu \mathrm{s})$ sets in after $6.7 \mu \mathrm{s}$, contracting the piezo for $18.5 \mu \mathrm{s}$, after which the third slope $(1 \mu \mathrm{s})$ expands the piezo again. A secondary droplet emerges, $2 \mu \mathrm{s}$ after this last slope, at $29 \mu \mathrm{s}$. This drop is ejected very fast with a velocity of almost $20 \mathrm{~m} / \mathrm{s}$, which collapses violently at $35 \mu$ s with the 


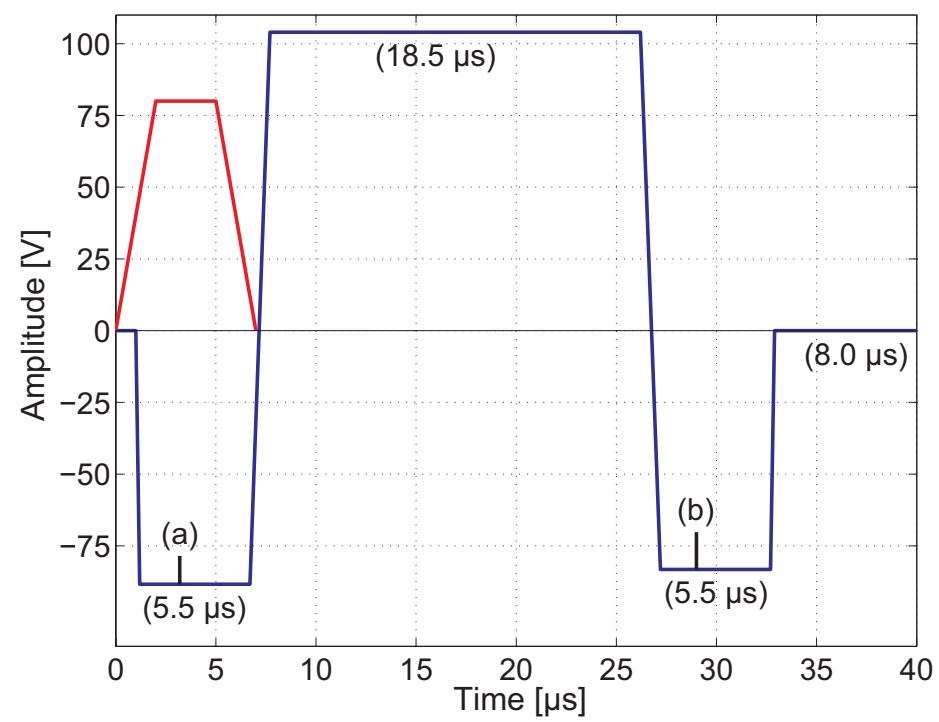

Figure 6.3: The bubble entrapment pulse (BEP) shown in blue, compared to a normal actuation pulse, shown in red. Due to the BEP a primary droplet emerges from the nozzle at (a) and a secondary at (b), which can be seen in Figure 6.4

primary drop. The merged drop has a final volume of approximately $50 \mathrm{pl}$, which is more than twice the normal volume of a droplet, and a velocity of approximately $14 \mathrm{~m} / \mathrm{s}$. The last slope, returning the piezo to its initial state, pulls the ink back into the nozzle. We noticed that the timing of this last slope affects whether or not the entrapment pulse is successful or not.

An interesting observation is that, during the collision of the primary and secondary droplet, a microbubble can be observed within the merged droplet as shown in the inset of Figure 6.4. It also appears that, during the collapse, part of the drop moves out of the focal plane of the microscope, thus implying asymmetric drop formation. This was confirmed by adding a second long distance microscope to the setup, and visualize along the side of the droplet, shown in Figure 6.5. This recording clearly shows the asymmetry in the drop formation. An additional observation is that the drop detaches from the meniscus after more than $60 \mu \mathrm{s}$.

If a normal drop is not directly ejected after the BEP, an another interesting event is observed, at approximately $100 \mu$ s after the pulse is applied: The meniscus expands beyond the nozzle, clearly revealing the presence of a microbubble inside the meniscus, as shown in Figure 6.6. A rough estimate of the bubble size gives a radius of $5 \mu \mathrm{m}$. The results, that were acquired using a single flash 


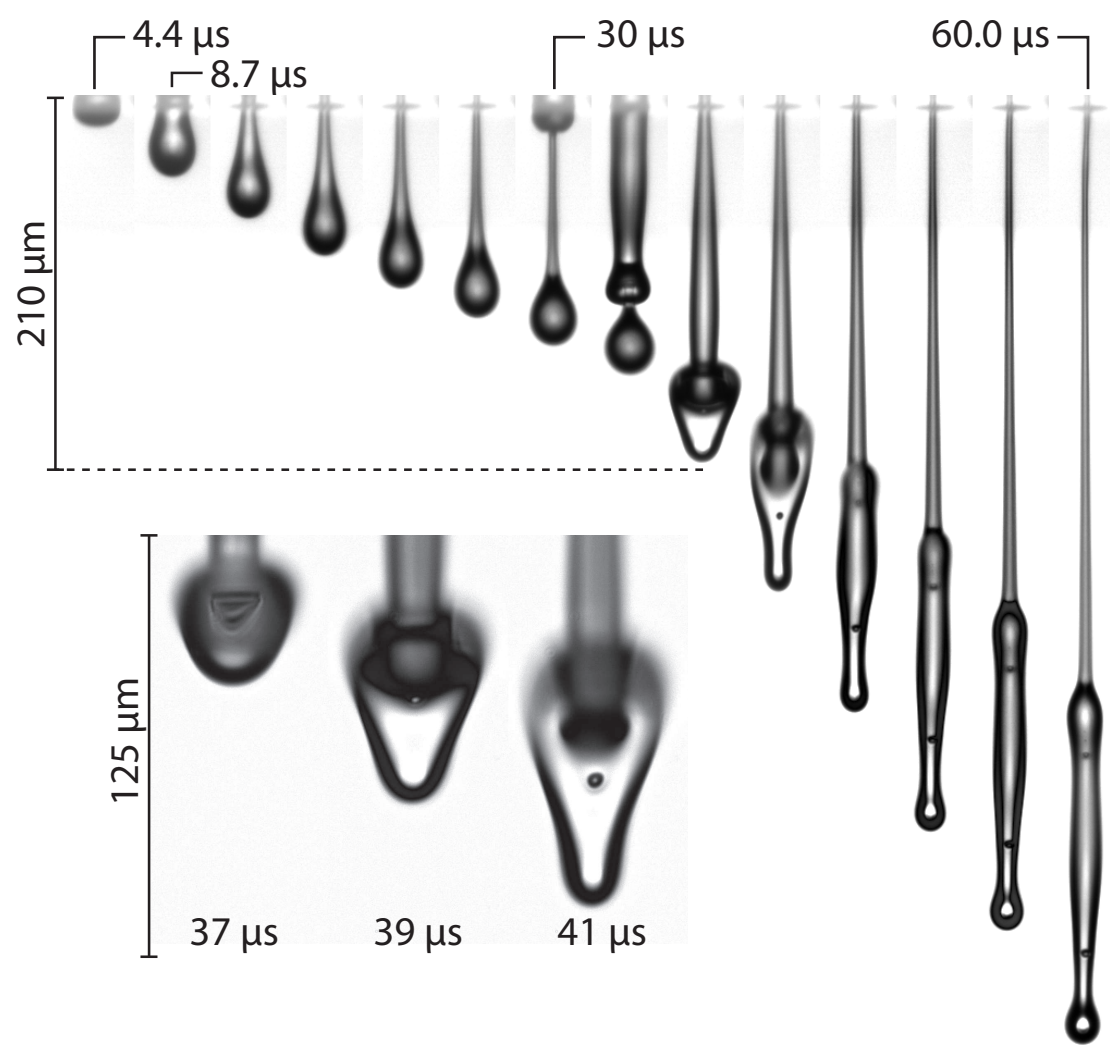

Figure 6.4: The droplet created when the BEP is applied clearly deviats from normal drops. The images show a primary and a secondary drop, colliding after $35 \mu$ s. During the collision a microbubble is formed, as can be seen in the inset.

method, where each image corresponds to a different droplet, shows the bubble at exactly the same position in every image. This confirms that the effect of the BEP, and entrapment of the microbubble is extremely reproducible.

The images reveal the disrupted drop formation and the clear presence of an air bubble in the meniscus. But, due to the non transparent nature of the nozzle plate, the actual entrapment inside the nozzle can not be visualized. Therefore, at this point it is still unsure whether more than one bubble is created behind the meniscus. In order to create insight into the mechanism that leads to the air entrapment the drop formation was simulated using a computational fluid dynamics package (ANSYS, FLOTRAN). The drop was modeled axisymmetrically and without the incorporation of air, hence the result gives only an estimate of the meniscus shape. A full 3D simulation would be 


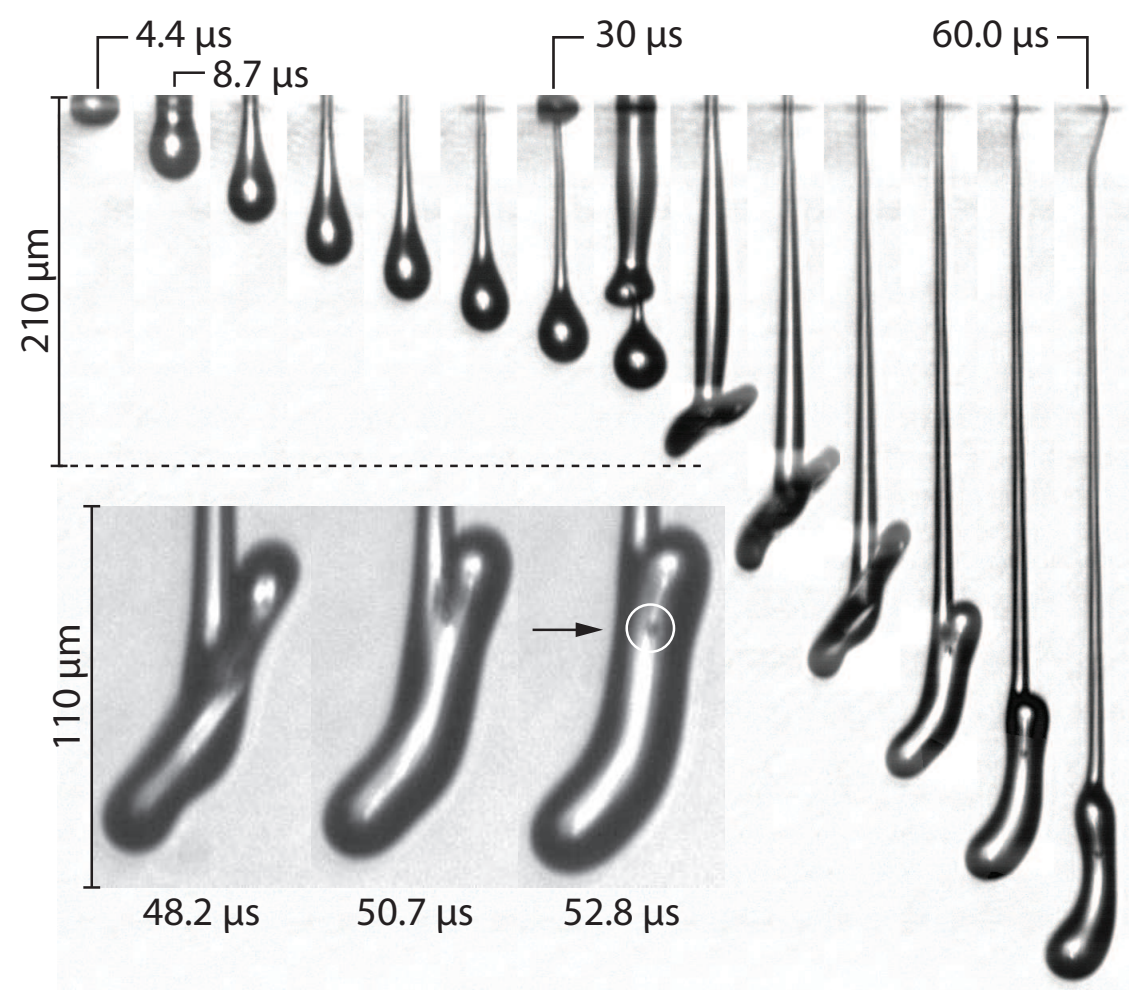

Figure 6.5: A side recording of the drop formation of the bubble entrapment pulse shows the asymmetric drop formation in detail. The asymmetric impact of the primary drop onto the secondary drop causes two air bubbles to become entrapped inside the droplet, one at the front, shown by the arrow in the inset, and one at the back side, visible in the inset of Figure 6.4.

extremely time consuming, with a timescale in the order of weeks rather than days. Figure 6.7 shows the simulated drop formation, and a magnification of the meniscus region. The simulation implies that, after the secondary droplet is ejected at $38 \mu \mathrm{s}$, the meniscus expands and entraps a small air cusp at $40.5 \mu \mathrm{s}$. The simulation creates a void due to the low pressure at this position. It seems essential for the entrapments that the tail of the second droplet has not jet detached from the meniscus. If the simulation is compared with the experiment, a very good temporal agreement is found. And the experiments clearly show (Figure 6.5) that the tail is deviating from the central axis. It remains unclear if this deviation is a requirement for air entrapment, or caused due to air entrapment. 


\section{CONTROLLED AIR ENTRAPMENT}

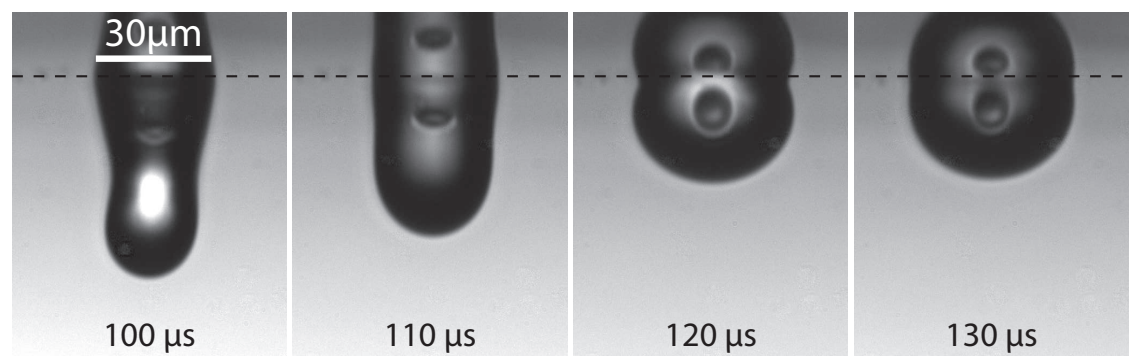

Figure 6.6: If, after the entrapment pulse, the actuation is stopped, at $100 \mu$ s the meniscus expands beyond the nozzle. Inside the meniscus the presence of a microbubble with a radius of approximately $5 \mu \mathrm{m}$ is clearly observed. The dotted line gives the position of the nozzle, above which a reflection of meniscus is visible.
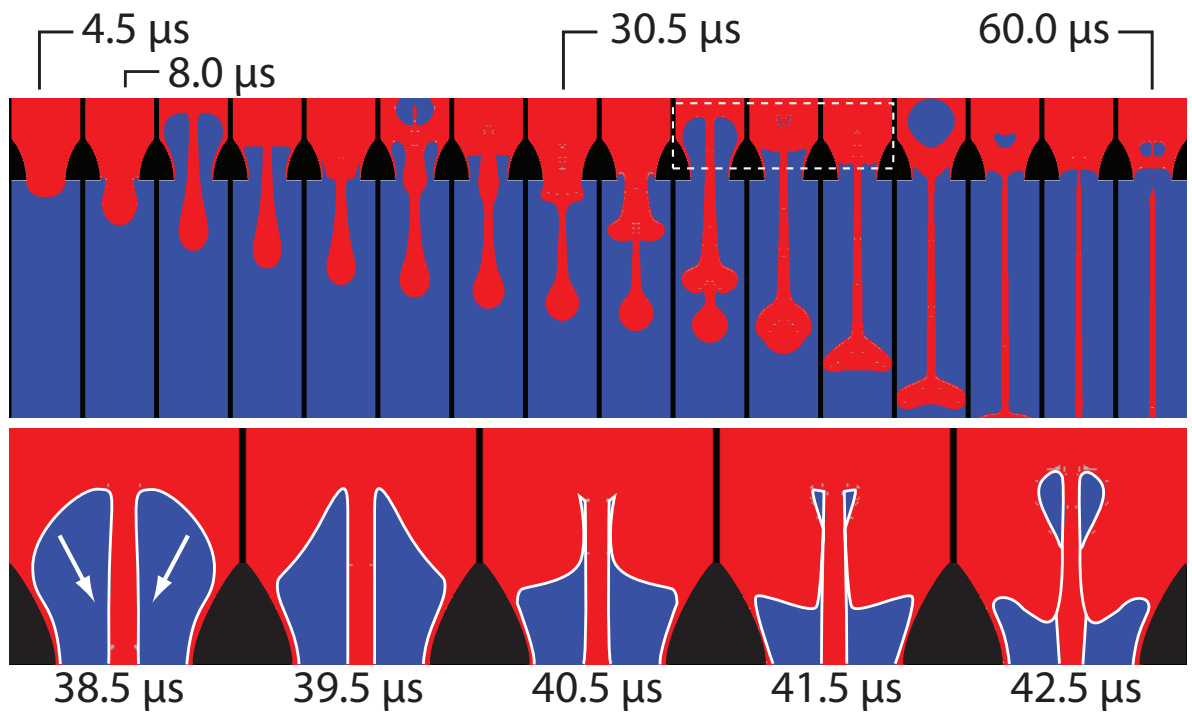

Figure 6.7: The figure shows a CFD simulation made with ANSYS FLOTRAN of the bubble entrapment pulse, which agrees with the drop formation shown in Figure 6.6 except that here the results are axially symmetric. The dotted area is shown in the magnification where, at $40.5 \mu \mathrm{s}$, it can be seen that a cavity is sealed by the forward motion of the meniscus. 


\subsection{ACOUSTICAL CHARACTERIZATION}

\subsection{Acoustical characterization}

The effect the BEP pulse has on the print process was already shown in Figure 6.1. where the velocity of the drop decreases in milliseconds after the BEP pulse, finally resulting in total nozzle failure after $1600 \mathrm{~ms}$, corresponding with 32.000 actuations. From this recording the velocity of the drops as function of time was determined, (Figure 6.8). In the figure it is shown that after bubble entrapment, the velocity decreases rapidly in two stages. First from $8 \mathrm{~m} / \mathrm{s}$ to $6.5 \mathrm{~m} / \mathrm{s}$, where it stays for a few milliseconds, before decreasing smoothly until the nozzle stops jetting. Here no increase in the velocity was observed, in contrast to what was seen for different nozzles in Ref. [17] and predicted in the model calculation in chapter 3. This suggests that a larger bubble is entrapped here.

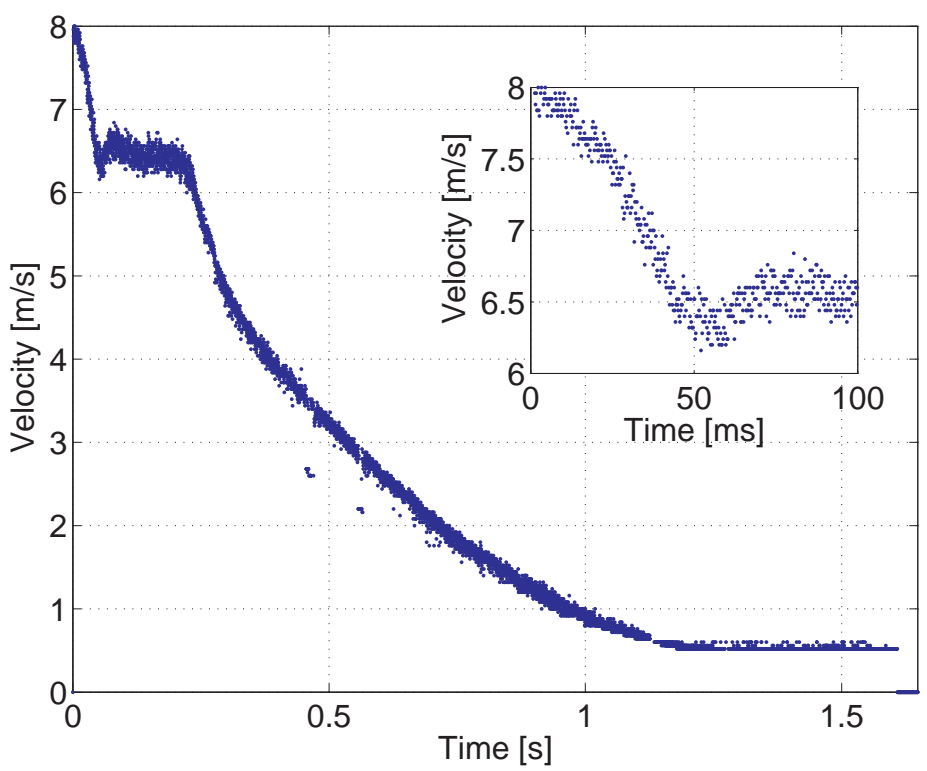

Figure 6.8: The effect of an air bubble entrapped by the BEP on the droplet velocity. After the BEP was applied actuation at $20 \mathrm{kHz}$ was continued. The inset shows a magnification of the initial velocity change after the BEP. The large decrease at the start suggests that a relative large bubble is entrapped. After $200 \mathrm{~ms}$ the velocity steadily decreases, until at $1.2 \mathrm{~s}$ it reaches a slow constant velocity. At $1.6 \mathrm{~s}$ the jetting process stops.

Using the acoustic sensing technique the acoustic pressure inside the channel could be measured. To illustrate the effect of the BEP on the channel 


\section{CONTROLLED AIR ENTRAPMENT}

acoustics, the variance of the relative acoustics signal was calculated (similar to reference [14]). In the relative acoustic signal $\Delta I$, the acoustics signal of a normal operating printhead $I_{r e f}$ is subtracted from the measured signal $I$. Figure 6.9 shows the variance in $\Delta I$ for four experiments. On two occasions the channel stopped jetting, while in the other two the channel continued jetting. In the magnification of figure 6.9 it is shown that, in all four experiments, the

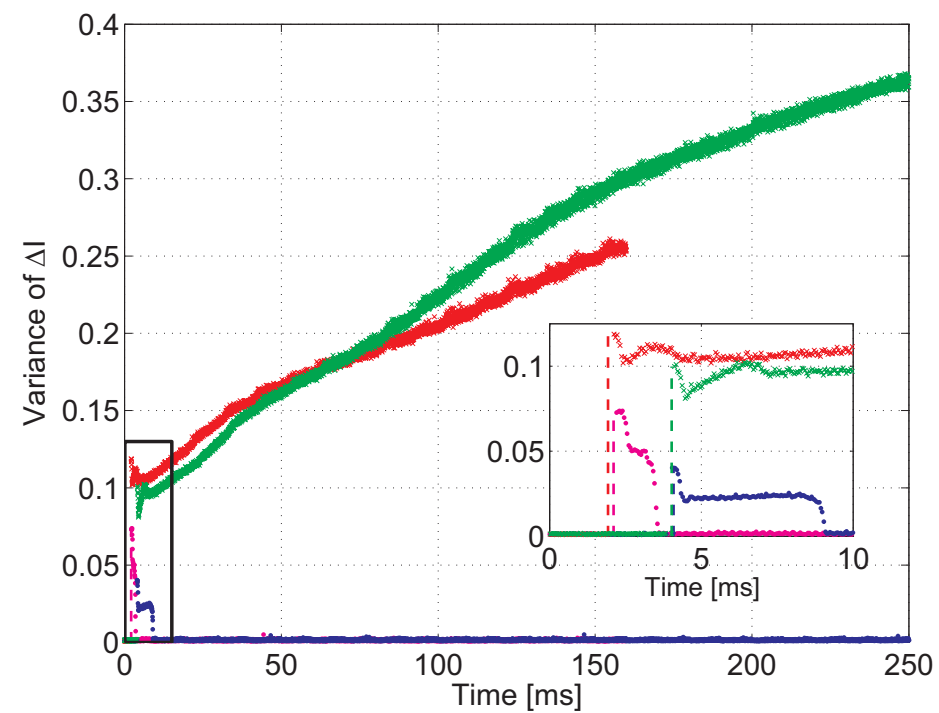

Figure 6.9: The variance of the relative acoustic signal $\Delta I$. The green and the red points give the variance for two occasions the nozzle stopped jetting after the BEP was applied. The blue and magenta points show the variance for two occasions after which the channel continued printing. In the magnification the disturbance due to the BEP is more clearly visible. Here the dashed lines show the time at which the BEP was applied. In all experiments the acoustics are disrupted for some time after the BEP. The amplitude of the variance seems to correlate with the bubble to maintain inside the channel.

acoustic signal is disturbed after the BEP is applied. The disturbance looks similar to the disturbance observed in the initial velocity change of drop (Figure 6.8, though there is a large difference the duration of the disturbance. For the experiments in which the channel did not stop jetting (magenta and blue), it can be seen that the amplitude of the variance is less compared to the two other situations where the channel stopped jetting. But in all four cases the acoustics are disrupted in the actuations following the BEP, where in the magenta and blue experiment the acoustics restored after $1.5 \mathrm{~ms}$ and $5 \mathrm{~ms}$, respectively. In these two specific occasions the bubble could have been jetted out, or could 


\subsection{SUMMARY \& OUTLOOK}

have been too small to sustain.

\subsection{Summary \& Outlook}

By visualizing the drop formation process, that unavoidable results in air entrapment, three conditions that could lead to air entrapment were observed. Firstly, from the CFD simulation it was found that air entrapment occurs relative far behind the nozzle, corresponding with a strongly retracted meniscus. In case of the BEP this is a result of a relative large droplet with roughly twice the volume of a normal droplet. This can explain that air entrapment is correlated with high jetting frequencies. At higher frequencies more droplets, hence volume, is ejected in time, possibly causing a retracted meniscus position.

A second point that is noticed is that the emerging droplet is still connected to the meniscus moments before air is entrapped. The connection suggests a very low velocity at this point, while the rest of the meniscus expands with a high velocity.

It was also observed that, by lowering the actuation voltage, a more symmetrical drop formation could be created, which didn't result in air entrapment. In [14] it was experimentally found that an asymmetrical drop formation, due to a small dust particle, precedes air entrapment. At present state it is unclear then, if asymmetry is a requirement for, or a result of the air entrapment.

There still remains the challenge to visualize the true nature of the air cusps in future work. In ongoing research it will be tried to apply a BEP on different geometries, such as used in chapter 2 and chapter 3 , where it is possible to visualize the presence of bubbles using a glass inset or infrared light inside silicon devices, and as such visualize the formation of the bubble.

The BEP is an important tool for further research in characterizing air entrapment, and studying the growth and translation of a bubble inside an ink channel. Ongoing research will be done to create fast detection methods and to find methods to prevent air entrapment. Till the problem of air entrapment is resolved, acoustic sensing methods, such as developed by Océ Technologies B. V., shall remain necessary for creating hundred percent reliable printheads. 
6. CONTROLLED AIR ENTRAPMENT 


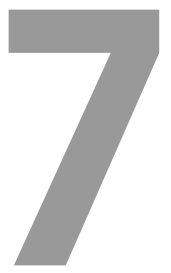

\section{Conclusions and outlook}

In this thesis the subject of air entrapment and drop formation in drop-ondemand piezo inkjet printing was investigated. There were several challenges at the beginning of this project; the mechanism that leads to air entrapment was unknown, moreover it was a challenge to measure the effect of an entrained microbubble on the acoustics of the printhead. This would be vital for validating the available acoustic model. Another challenge was introduced for the new MEMS printheads. For this geometry it was still unclear if microbubbles would be entrapped and what the size and position would be. The different challenges were approached with a similar methodology; by optical imaging, acoustic sensing and comparing the experiments with dedicated models.

In chapter 2 it was shown that the acoustics of a dissolving bubble could be measured, while simultaneously creating an optical image of the bubble. For the first time the dynamics of the microbubble were captured optically and acoustically. A one-dimensional acoustics model was applied to predict the size of the bubble from the acoustic signal. Optical imaging allowed for the verification of the calculated results. A very good agreement was found, which confirmed the quality of the model.

In chapter 3 it was shown that in the MEMS printheads, which is one order of magnitude smaller, it is still possible to entrap microbubbles, which consequently disrupt the drop formation. By using infrared illumination the presence of a microbubble in an operating printhead was confirmed. The bubble was found in a corner close to the nozzle plate of the channel. A similar location as was found for the conventional printhead described in chapter 2. It was shown that the smaller geometry could also be modeled with the acoustic model. The important contribution in this study is that, compared to the result obtained in chapter 2, these results were obtained from an unmodified printhead.

Chapter 4 introduces a novel flash illumination technique (iLIF), with an illumination time of only $7 \mathrm{~ns}$. The intensity of this light source was over one order of magnitude larger than other available light sources. ILIF is ideally suited for 
the visualization of drop formation in very high detail, as was shown in chapter 5 . Here the images, recorded with iLIF, were compared with recordings captured with the Brandaris 128, one of the fastest high speed cameras available. The comparison showed that the resolution of the images obtained with the flash illumination is superior to those acquired with the high speed camera. Additionally the reproducibility of the drop formation, which is required for single flash recording, was measured. This showed that, until the drop detaches from the meniscus, there is very little difference between individual drops, confirming the excellent reproducibility of the drop formation. From these experiments not only the velocity of the drop could be extracted, but also the velocity inside the drop. This allowed for a comparison with a fast one-dimensional drop model, which showed very good agreement.

The air entrapment process has always been very difficult to study as it is erratic and unpredictable. In chapter 6 another valuable instrument is introduced, the possibility to entrap air by using a bubble entrapment pulse (BEP). The different aspects of the pulse and the resulting drop formation were treated, and it was shown that this special pulse induces air entrapment. Additionally the disrupted drop formation clearly shows the presence of microbubbles. The experiments show that it is possible to entrap air in a controlled way. Air entrapment appears to coincide with a low refill of the nozzle at the time the drop detaches from the meniscus, which seems to be confirmed by CFD simulations. Acoustic measurements show that the amplitude of the acoustic disturbance correlates with a potential jetting failure.

In this last part of the thesis a short outlook will be given for applying the techniques developed in this thesis. The study on drop formation in inkjet printing is continuing and, as higher and higher drop repetition rates are an industrial requirement, it is anticipated that air entrapment will limit the productivity. It remains crucial to study all aspects of the acoustic signal in trying to achieve hundred percent reliability. Acoustic models could well be applied for this purpose, but experiments that verify the results will remain essential. It would be very valuable to expand the presented acoustic model, such that meniscus movement and drop formation is included.

One technique that will become important in ongoing research is iLIF illumination. The high intensity and short illumination time make it possible to capture the smallest details, even at high velocities, making it a superior instrument for visualizing droplets. The visualization of the air bubbles as a result of the BEP is a very good example of the improved value of the iLIF. This particular drop formation was already visualized with other light sources, but no air bubbles inside the drop were observed due to limitations of the light 
source. The applicability of iLIF illumination expands beyond inkjet, to all sorts of microfluidics experiments where high velocities and small length scales are involved.

The drop formation analysis that was shown in chapter [5 in combination with the drop formation model, are also a promising results. In ongoing experimental research it would be a valuable addition to incorporate acoustic sensing to confirm the repeatability of the drop formation. Moreover, with several modifications it is possible to develop an automated experimental setup that combines iLIF, image acquiring, acoustic sensing and pulse modulation. Such an experimental setup would open world of possibilities on studying drop formation and air entrapment. 
7. CONCLUSIONS 


\section{Bibliography}

[1] J. Eggers. Drop formation an overview. Z. Angew. Math. Mech. 85 (2005), pp. 400410., 85(6):400-410, 2005.

[2] H. Wijshoff. The dynamics of the piezo inkjet printhead operation. Phys. Rep., 491(4-5):77-177, 2010.

[3] Hue P. Le. Progress and trends in ink-jet printing technology. J. Imaging Sci. Technologie, 42:49-62, 1998.

[4] Xue Yan and P Gu. A review of rapid prototyping technologies and systems. Computer-Aided Design, 28(4):307 - 318, 1996.

[5] J. U. Park, M. Hardy, S. J. Kang, K. Barton, K. Adair, Deep K. Mukhopadhyay, C. Y. Lee, M. S. Strano, A. G. Alleyne, J. G. Georgiadis, P. M. Ferreira, and J. A. Rogers. High-resolution electrohydrodynamic jet printing. Nature materials, 6(10):782-9, 2007.

[6] M. Singh, H. M. Haverinen, P. Dhagat, and G. E. Jabbour. Inkjet printingprocess and its applications. Advanced materials (Deerfield Beach, Fla.), 22(6):673-85, 2010.

[7] W. Voit, W. Zapka, L. Belova, and K. V. Rao. Application of inkjet technology for the deposition of magnetic nanoparticles to form micronscale structures. Science, Measurement and Technology, IEE Proceedings -, 150(5):252 - 256, 2003.

[8] P. Calvert. Inkjet printing for materials and devices. Chemistry of Materials, 13(10):3299-3305, 2001.

[9] Mironov V., Reis N., and Derby B. Review: bioprinting: a beginning. Tissue Eng., 12(4):631-634, 2006.

[10] J. Eggers. Nonlinear dynamics and breakup of free-surface flows. Rev. Mod. Phys., 69(3):865-930, 1997.

[11] J. Eggers and E. Villermaux. Physics of liquid jets. Rep. Prog. Phys., 71 (3):036601, 2008.

[12] R. D. Deegan, P. Brunet, and J. Eggers. Complexities of splashing. Nonlinearity, 21(1), 2008. 
[13] M. A. Groninger, P. G. M. Kruijt, H. Reinten, R. H. Schippers, and J. M. M. Simons. A method of controlling an inkjet printhead, an inkjet printhead suitable for use of said method, and an inkjet printer comprising said printhead. European patent no. ep 1378360 a1, Océ Technologies B.V., 2003.

[14] J. de Jong, G. de Bruin, H. Reinten, M. van den Berg, H. Wijshoff, M. Versluis, and D. Lohse. Air entrapment in piezo-driven inkjet printheads. J. Acoust. Soc. Am., 120(3):1257, 2006.

[15] B. Beulen, J. de Jong, H. Reinten, M. van den Berg, H. Wijshoff, and R. van Dongen. Flows on the nozzle plate of an inkjet printhead. Exp. Fluids, 42:217-224, 2007.

[16] J. de Jong, H. Reinten, H. Wijshoff, M. van den Berg, K. Delescen, R. van Dongen, F. Mugele, M. Versluis, A. Prosperetti, and D. Lohse. Marangoni flow on an inkjet nozzle plate. Appl. Phys. Lett., 91(20):204102, 2007.

[17] J. de Jong, R. Jeurissen, H. Borel, M. van den Berg, H. Wijshoff, H. Reinten, M. Versluis, A. Prosperetti, and D. Lohse. Entrapped air bubbles in piezo-driven inkjet printing: Their effect on the droplet velocity. Phys. Fluids, 18(12):121511, 2006.

[18] R. Jeurissen, J. de Jong, H. Reinten, M. van Den Berg, H. Wijshoff, M. Versluis, and D. Lohse. Effect of an entrained air bubble on the acoustics of an ink channel. J. Acoust. Soc. Am., 123(5):2496-2505, 2008.

[19] T. G. Leighton. The Acoustic Bubble. Academic Press, London, 1994. ISBN 0124419208.

[20] C. E. Brennen. Cavitation and bubble dynamics. Oxford University Press, New York, 1995. ISBN 0195094093.

[21] M. S. Plesset and A. Prosperetti. Cavitation and bubble dynamics. Ann. Rev. Fluid Mech., 9(1):145-185, 1977.

[22] M. P. Brenner, S. Hilgenfeldt, and D. Lohse. Single-bubble sonoluminescence. Rev. Mod. Phys., 74(2):425-484, 2002.

[23] S. Qin and K. W. Ferrara. Acoustic response of compliable microvessels containing ultrasound contrast agents. Phys. Med. Biol., 51(20):50655088, 2006. 


\section{BIBLIOGRAPHY}

[24] S. Qin and K. W. Ferrara. The natural frequency of nonlinear oscillation of ultrasound contrast agents in microvessels. Ultrasound Med. Biol., 33 (7):1140-1148, 2007.

[25] C.F. Caskey, S. M. Stieger, S. Qin, P.A. Dayton, and K.W. Ferrara. Direct observations of ultrasound microbubble contrast agent interaction with the microvessel wall. J. Acoust. Soc. Am., 122(2):11911200, 2007.

[26] V. S. Ajaev and G. M. Homsy. Modeling shapes and dynamics of confined bubbles. Ann. Rev. Fluid Mech., 38:277-307, 2006.

[27] A. L. Klibanov. Ultrasound Contrast Agents: Development of the Field and Current Status, volume 222 of Top. Curr. Chem. 2002.

[28] R. J. Dijkink, J. P. van der Dennen, C. D. Ohl, and A. Prosperetti. The acoustic scallop: a bubble-powered actuator. J. Micromech. Microeng., 16 (8):1653-1659, 2006.

[29] K. S. F. Lew, E. Klaseboer, and B. C. Khoo. A collapsing bubble-induced micropump: An experimental study. Sens. Actuator. A Phys., 133:161172, 2007.

[30] B. Krasovitski and E. Kimmel. Gas bubble pulsation in a semiconfined space subjected to ultrasound. J. Acoust. Soc. Am., 109(3):891-898, 2001.

[31] P. Zhong, Y. Zhou, and S. Zhu. Dynamics of bubble oscillation in constrained media and mechanisms of vessel rupture in swl. Ultrasound Med. Biol., 27(1):119 - 134, 2001.

[32] J. Cui, M. F. Hamilton, P. S. Wilson, and E. A. Zabolotskaya. Bubble pulsations between parallel plates. J. Acoust. Soc. Am., 119(4):20672072, 2006.

[33] H. N. O guz and A. Prosperetti. The natural frequency of oscillation of gas bubbles in tubes. J. Acoust. Soc. Am., 103(6):3301-3308, 1998.

[34] E. Sassaroli and K. Hynynen. Forced linear oscillations of microbubbles in blood capillaries. J. Acoust. Soc. Am., 115(6):3235-3243, 2004.

[35] E. Ory, H. Yuan, A. Prosperetti, S. Popinet, and S. Zaleski. Growth and collapse of a vapor bubble in a narrow tube. Phys. Fluids, 12(6):12681277, 2000. 
[36] K. S. Kwon and W. Kim. A waveform design method for high-speed inkjet printing based on self-sensing measurement. Sens. Actuator. A Phys., 140: 75-83, 2007.

[37] J. F. Dijksman. Hydrodynamics of small tubular pumps. J. Fluid Mech., 139:173-191, 1984.

[38] D. B. Bogy and F. E. Talke. Experimental and theoretical study of wave propagation phenomena in drop-on-demand ink jet devices. IBM: J. Res. Dev., 28(3), 1984.

[39] Micronit Microfluidics B.V. P.O. box 214, 7500 AE Enschede, The Netherlands. info@micronit.com.

[40] J. R. Womersley. Method for the calculation of velocity, rate of flow and viscous drag in arteries when the pressure gradient is known. J. Physiol., 127:553-563, 1955.

[41] T. Young. Hydraulic investigations, subservient to an intended Croonian Lecture on the motion of the blood. Philos. Trans. R. Soc. Lond., 98:164 $-186,1808$.

[42] H. Callen. Thermodynamics and an Introduction to Thermostatistics. Wiley, New York, 1985.

[43] S. Thompson L. F. Shampine. Solving ddes in MATLAB. Applied Numerical Mathematics, 37(4):441-458, 2001.

[44] S. Mishra, K. L. Barton, A. G. Alleyne, P. M. Ferreira, and J. A. Rogers. High-speed and drop-on-demand printing with a pulsed electrohydrodynamic jet. J. Micromech. Microeng., 20(9):095026, 2010.

[45] E. Peeters. Challenges in commercializing mems. Computational Science Engineering, IEEE, 4(1):44 -48, 1997.

[46] C. Menzel, A. Bibl, and P. Hoisington. MEMS Solutions for Precision Micro-Fluidic Dispensing Application. Technical report, FUJIFILM Dimatix, Inc., 2004.

[47] S. Hilgenfeldt, D. Lohse, and M. Zomack. Response of bubbles to diagnostic ultrasound: a unifying theoretical approach. Eur. Phys. J. B, 4(2): 247-255, 1998. 


\section{BIBLIOGRAPHY}

[48] V. Garbin, B. Dollet, M. Overvelde, D. Cojoc, E. Di Fabrizio, L. van Wijngaarden, A. Prosperetti, N. de Jong, D. Lohse, and M. Versluis. History force on coated microbubbles propelled by ultrasound. Phys. Fluids, 21 (9):092003, 2009.

[49] K. S. Kwon. Methods for detecting air bubble in piezo inkjet dispensers. Sens. Actuator. A Phys., 153(1):50-56, 2009.

[50] R. Jeurissen, A. van der Bos, H. Reinten, M. van Den Berg, H. Wijshoff, J. de Jong, M. Versluis, and D. Lohse. Acoustic measurement of bubble size in an inkjet printhead. J. Acoust. Soc. Am., 126(5):2184-2190, 2009.

[51] J. Chung, C. P. Grigoropoulos, and R. Greif. Infrared thermal velocimetry in mems-based fluidic devices. J. Microelectromech. Syst., 12(3):365-372, 2003.

[52] G. Han, J. C. Bird, K. Johan, A. Westin, C. Zhiqiang, and K. S. Breuer. Infrared diagnostics for measuring fluid and solid motion inside silicon microdevices. Microscale Thermophys. Eng., 8(2):169-182, 2004.

[53] D. Liu, S. V. Garimella, and S. T. Wereley. Infrared micro-particle image velocimetry in silicon-based microdevices. Exp. Fluids, 38(3):385-392, 2005.

[54] E. Bassous, H. H. Taub, and L. Kuhn. Ink jet printing nozzle arrays etched in silicon. Appl. Phys. Lett., 31(2):135, 1977.

[55] Océ Technologies B.V. P.O. Box 101, 5900 MA Venlo, The Netherlands. http://global.oce.com/technologies/ crystalpoint-technology.aspx

[56] E. Hecht. Optics 4th edition. Pearson Education, 2001. ISBN 9780321188786.

[57] M. W. Davidson and M. Abramowitz. Optical microscopy. Encyclopedia of Imaging Science and Technology, 2:1106-1141, 2002.

[58] ANSYS, Inc. ANSYS CFD. http://www.ansys.com/

[59] A. M. Worthington. The splash of a drop. New York: E. \& J. B. Young \& CO., 1895.

[60] H. E. Edgerton and J. R. Killian. Moments of vision : the stroboscopic revolution in photography. MIT Press, Cambridge, Mass., 1979. 
[61] S. T. Thoroddsen, T. G. Etoh, and K. Takehara. High-Speed Imaging of Drops and Bubbles. Ann. Rev. Fluid Mech., 40(1):257-285, 2008.

[62] R. V. Vasil, B. K. Lubsandorzhiev, and P. G. Pokhii. A nanosecond light source for scintillation-and Cerenkov-detector calibration. Instrum. Exp. Tech. (USSR), 43(4):570-572, 2000.

[63] C. N. Scholfield and M. Murdock. Pulse-modulated light source for psychometric and vision experiments. J. Neurosci. Methods, 19(3):203-207, 1987.

[64] B. K. Lubsandorzhiev, R. V. Poleshuk, and Y. E. Vyatchin. LED based powerful nanosecond light sources for calibration systems of deep underwater neutrino telescopes. Nucl. Instrum. Methods. Phys. Res. A, 602(1): 220-223, 2009.

[65] S. Miyashiro and H. Grnig. Low jitter reliable nanosecond spark source for optical short-duration measurements. Exp. Fluids, 3:71-75, 1985.

[66] High Speed Photo Systeme - Nanolite. Von-Linne-Str. 12, D-22880 Wedel, Germany. http://www.hsps.com/.

[67] E. J. Takahashi, P. Lan, O. D. Mücke, N. Yasuo, and M. Katsumi. Infrared Two-Color Multicycle Laser Field Synthesis for Generating an Intense Attosecond Pulse. Phys. Rev. Lett., 104(23):233901, 2010.

[68] H. Dong, W. W. Carr, and J. F. Morris. Visualization of drop-on-demand inkjet: Drop formation and deposition. Rev. Sci. Instr., 77(8):085101, 2006.

[69] T. Juhasz, G. A. Kastis, C. Suárez, Z. Bor, and Walter E. Bron. Timeresolved observations of shock waves and cavitation bubbles generated by femtosecond laser pulses in corneal tissue and water. Lasers Surg. Med., 19(1):23-31, 1996.

[70] A. Zijlstra and C. D. Ohl. On fiber optic probe hydrophone measurements in a cavitating liquid. J. Acoust. Soc. Am., 123(1):29-32, 2008.

[71] T. Iwai and T. Asakura. Speckle reduction in coherent information processing. Proc. IEEE, 84(5):765-781, 1996.

[72] J. W. Shan, D. B. Lang, and P. E. Dimotakis. Scalar concentration measurements in liquid-phase flows with pulsed lasers. Exp. Fluids, 36:268-273, 2004. 


\section{BIBLIOGRAPHY}

[73] K. R. Rau, P. A. Quinto-Su, A. N. Hellman, and V. Venugopalan. Pulsed Laser Microbeam-Induced Cell Lysis: Time-Resolved Imaging and Analysis of Hydrodynamic Effects. Biophys. J., 91(1):317 - 329, 2006.

[74] Fritz P. Schäfer, Werner Schmidt, and Jürgen Volze. Organic dye solution laser. Applied Physics Letters, 9(8):306-309, 1966.

[75] I. M. Hutchings, G. D. Martin, and S. D. Hoath. High speed imaging and analysis of jet and drop formation. J. Imaging Sci. Technologie, 51(5):438, 2007.

[76] S. P. Lin and R. D. Reitz. Drop and spray formation from a liquid jet. Ann. Rev. Fluid Mech., 30(1):85-105, 1998.

[77] W. van Hoeve, S. Gekle, J. H. Snoeijer, M. Versluis, M. P. Brenner, and D. Lohse. Breakup of diminutive rayleigh jets. Phys. Fluids, 22(12):122003, 2010.

[78] A. U. Chen and O. A. Basaran. A new method for significantly reducing drop radius without reducing nozzle radius in drop-on-demand drop production. Phys. Fluids, 14(1):L1-L4, 2002.

[79] W. T. Pimbley and H. C. Lee. Satellite droplet formation in a liquid jet. IBM J. Res. Develop., 21:385-388, 1977.

[80] C. T. Chin, C. Lancée, J. Borsboom, F. Mastik, M. E. Frijlink, N. de Jong, M. Versluis, and D. Lohse. Brandaris 128: A digital 25 million frames per second camera with 128 highly sensitive frames. Rev. Sci. Instr., 74(12): 5026-5034, 2003.

[81] R. Jeurissen and T. Driessen. One-dimensional drop formation- and interaction model. 2010. Unpublished results.

[82] H. R. Kang. Water-based ink-jet ink. III, Performance studies. J. Imaging Sci. Technologie, 35(3):195-201, 1991.

[83] E. A. Igel and M. Kristiansen. Rotating-Mirror Streak and Framing Cameras. 1997. ISBN 9780819424617.

[84] J. Eggers and T. F. Dupont. Drop formation in a one-dimensional approximation of the navier-stokes equation. J. Fluid Mech., 262:205-221, 1994.

[85] X. D. Shi, M. P. Brenner, and S. R. Nagel. A cascade of structure in a drop falling from a faucet. Science, 265(5169):219-222, 1994. 
[86] L. Duchemin, J. Eggers, and C. Josserand. Inviscid coalescence of drops. J. Fluid Mech., 487(-1):167-178, 2003.

[87] Arthur H. Lefebvre. Atomization and Sprays. Hemisphere Publishing Corporation, 1989.

[88] F. R. S. Lord Rayleigh. On the capillary phenomena of jets. Proc. R. Soc. London, 29:71-97, 1879.

[89] Kateri E. P., William S. W., Steven E. R., and Robert A. S. Additive jet printing of polymer thin-film transistors. Appl. Phys. Lett., 83(10): 2070-2072, 2003.

[90] S.J. Lee, D. H. Kwon, and Y. S. Choi. Dynamics of entrained air bubbles inside a piezodriven inkjet printhead. Appl. Phys. Lett., 95(22):221902221902, 2009. 


\section{Summary}

Piezo drop-on-demand inkjet printers are used in an increasing number of applications for their reliable deposition of droplets onto a substrate. The technology is used to create droplets of a few picoliters with drop repetition rates in the order of $10 \mathrm{kHz}$. However, entrapment of an air microbubble into the ink channel can severely impede the productivity and reliability of a printing system. The air bubble disturbs the channel acoustics resulting in disrupted drop formation or temporally failure of the jetting process.

The research described in chapter 2 was done to investigate the effect of the microbubble on the channel acoustics. The influence of the bubble was studied by measuring the acoustics while a bubble was let to dissolve. The channel acoustics could be measured by using the piezo that generates the acoustic pressure field, simultaneously as a sensor. The acoustic signal is a highly reproducible for normal drop formation. However, when a microbubble is entrapped the acoustic signal changes significantly. To understand the acoustic signal an acoustical model was developed that included the two-way coupling between the channel acoustics and the disturbing bubble. The model can be used to predict the acoustic signal for a given geometry and bubble volume. The inverse problem is to infer the bubble volume from an experimentally obtained piezo current. By solving this inverse problem, the size and of the bubble can thus be measured acoustically.

To validate the results from the numerical model, the volume of the bubble was also measured optically. This was done by adding a glass inset to the inkjet printhead, such that the bubble could be imaged. The results from the acoustical model correspond closely to the results obtained from the optical measurement, confirming the validity of the acoustic model.

Océ Technologies B.V. is also developing a Micro-Electro-Mechanical Systems (MEMS)-based printhead. This printhead is made on a wafer-scale and is one order of magnitude smaller compared to the printhead used in chapter 2. The smaller design allows for higher frequencies, making it possible to print with drop repetition rates up to $100 \mathrm{kHz}$. At these high frequencies the channel becomes more susceptible to air entrapment.

In chapter 3 it is researched if the bubble can be visualized without modifying the channel. The MEMS printhead is mostly made out of silicon, making it possible to use infrared light to visualize the presence of air bubbles inside the channel. The infrared visualization technique allowed for an accurate sizing of the bubble and the bubble dynamics inside an unmodified ink channel. 
As in chapter 2 the acoustical signal was captured by using the actuating piezo also in receive mode. The acoustic signal clearly identified the presence of an air microbubble inside the channel during failure of the jetting process. The acoustics model, that was also applied in chapter 2 was used to predict the bubble size from the acoustic measurements. The comparison between the results from the infrared detection and the results acquired from the acoustical model showed very good agreement, confirming the applicability of the acoustical model. Besides calculating the presence and the size of a microbubble inside an ink channel, the model was used to predict the change in the velocity of droplets after air is entrapped.

Besides studying air entrapment also the drop formation itself was studied. These drop velocities are typically in the order of $10 \mathrm{~m} / \mathrm{s}$, and the typical length scale is in approximately $25 \mu \mathrm{m}$. Hence, to visualize all details from the drop formation, a very fast high speed camera is required. However, the high reproducibility of the drop formation allows for a more affordable solution; single flash stroboscopic imaging. To record high quality images free of motion blur a very short flash is required. In chapter 4 we present an illumination technique based on laser-induced fluorescence which delivers high intensity light pulses of $7 \mathrm{~ns}$. The light source consists of a Q-switched Nd:YAG laser and a laser-dye solution incorporated into a total internal reflection lens, resulting in a uni-directional light beam with a millimeter-sized circular aperture and $3^{\circ}$ divergence. The laser coherence, considered undesirable for imaging purposes, is reduced whilst maintaining a nanoseconds pulse duration.

In chapter 5 we study the details of droplet formation with the Brandaris 128 ultrahigh-speed imaging facility at frame rates of up to 10 million frames per second. We compare these result with the stroboscopic technique described in chapter 4. The stroboscopic recordings excel in visualizing details and image quality. The highly reproducible recordings were analyzed to give the local flow rate and velocity distribution within the droplet.

Additionally a one-dimensional model based on the lubrication approximation was introduced. In the model the equations are solved on a Eulerian grid with a second order accurate scheme. The pinch-off singularity is prevented by regularization of the surface tension at small radius. The results from the model are compared with the experimental data. Overall the drop model shows good agreement with the experimental observations. Both the model and the experimental method show promising results for future research.

The air entrapment studied in chapters 2 and 3 was always induced uncontrol- 
lably by using very high actuation frequencies. To study air entrapment in a controllable fashion chapter 6 introduces a bubble entrapment pulse (BEP). The BEP pulse results in a highly disturbed drop formation which is visualized with the stroboscopic illumination technique. The images reveal the presence of air bubbles inside the drop and at the meniscus. The stability and reproducibility of the bubble size and positions is excellent. By comparing the drop formation with the drop formation modeled with a Computational Fluid Dynamics simulation, a possible mechanism for air entrapment was found.

Here also the acoustic sensing technique was applied to measure the channel acoustics after the BEP, confirming the nozzle failure due to air entrapment. It also showed that on some occasions the channel restores relatively quick after the BEP. The amplitude of acoustic disturbance in the first actuations after the BEP appears to correlate with potential failure of the drop formation. 
SUMMARY 


\section{Samenvatting}

Afdrukken maken met behulp van inkjet-printers is tegenwoordig een ingeburgerde technologie, en één van de meest toegepaste technieken voor de depositie van druppels. Dit komt mede door de zeer goede reproduceerbaarheid van de druppels, de hoge betrouwbaarheid en het brede werkgebied van bruikbare vloeistoffen. In dit proefschrift is onderzoek gedaan naar printkoppen van Océ Technologie B.V. die gebruikt worden voor grootformaat drukwerk. Een enkele inkjet printkop bevat enkele honderden kanalen. In deze kanalen worden ongeveer 20.000 druppels per seconde gevormd, waarbij elke druppel een vast volume van enkele picoliters bevat. Om de druppels te genereren is een akoestisch drukveld vereist, dat wordt gegenereerd door een piëzo element dat in het kanaal is geplaatst.

Hoewel het inkjet-proces tot één van de betrouwbaarste druppelvormingstechnieken behoort, zijn er toch omstandigheden die tot een verstoorde druppelvorming leiden. Één van de mogelijke verstoringen is het invangen van een luchtbel bij de nozzle. Het akoestische drukveld in het kanaal zorgt ervoor dat de luchtbel groeit en dieper binnenin het kanaal terecht komt. De aanwezigheid van de luchtbel verstoort het akoestische drukveld met als gevolg een verstoorde druppelvorming. Dit kan er zelfs toe lijden dat het kanaal tijdelijk uitvalt. In dit proefschrift is onderzoek gedaan naar de vorming van inkjet-druppels en de gevolgen van luchtbellen in het kanaal.

In hoofdstuk 2 van dit proefschrift is onderzocht hoe de luchtbel het akoestisch veld beïnvloed. Het akoestisch drukveld is gemeten door de piëzo die gebruikt wordt om het akoestisch veld te genereren tegelijkertijd als sensor dienst te laten doen. Per druppel en per kanaal wordt dan één akoestisch signaal gemeten. De hoge reproduceerbaarheid van de druppelvorming gaat gepaard met een eveneens reproduceerbaar akoestisch signaal. Een verstoring in de druppelvorming veroorzaakt door een luchtbel zorgt echter voor een significante verandering in het akoestische signaal. Door een ingevangen luchtbel op te laten lossen en tegelijkertijd de piëzo op een lage frequentie te actueren, was het mogelijk de akoestiek voor een luchtbel van verschillende groottes te meten. De gemeten akoestische signalen werden vergeleken met een 1-dimensionaal numeriek model dat de akoestiek van het kanaal uitrekent. In dit numerieke model is zowel het effect van de luchtbel op de akoestiek, als het effect van de akoestiek op de luchtbel meegenomen. Aangezien de geometrie van het kanaal bekend is kan uit een enkel akoestisch signaal de grootte van de luchtbel berekend worden.

Om de resultaten van het model te kunnen verifiëren is tegelijk met de akoestische meting een visuele meting naar de grootte van de bel. Dit was 
mogelijk omdat een deel van het kanaal in glas was uitgevoerd. De optische gemeten bel grootte is vergeleken met bel grootte bepaald met behulp van het akoestische model. De onafhankelijke verkregen resultaten komen zeer goed overeen. Dit resultaat bevestigt de kwaliteit van het akoestische model en maakt het tot een waardevol gereedschap om verstoringen beter te kunnen detecteren.

Océ Technologie B.V. ontwikkelt een nieuwe generatie Micro-elektromechanisch systeem(MEMS)-printkoppen. Door gebruik te maken van uit de chipindustrie afkomstige technologie kunnen de printkoppen op wafer-schaal geproduceerd worden. Deze technologie leent zich goed voor miniaturisatie, waardoor het mogelijk is de printkoppen meer dan een orde kleiner te maken. Door de schaalverkleining is het mogelijk hogere druppelfrequenties te halen. In het huidige ontwerp kan een individueel kanaal tot 100.000 druppels per seconde printen. Echter, bij deze hoge frequenties neemt de kans op het invangen van luchtbellen toe.

In hoofdstuk 3 zijn de aanwezigheid en gevolgen van luchtbellen in deze nieuwe geometrie onderzocht. Ook hier is de piëzo als sensor gebruikt om zo het effect van de luchtbel op de akoestiek te meten. Het numerieke model uit hoofdstuk 2 is gebruikt om uit het akoestische signaal de grootte van de luchtbel te bepalen. Omdat de printkoppen voor het merendeel uit silicium bestaan, was het mogelijk om met infrarood licht in het kanaal te kijken. Op deze manier kon grootte en positie van de luchtbellen gemeten worden in een werkende printkop zonder dat er printkop modificaties nodig waren. Ook hier is een erg goede overeenkomst gevonden tussen de bel grootte gemeten met infrarood en de belgrootte bepaald met het akoestisch model. Dit toont aan dat het model ook bij deze kleinere geometrie een waardevol gereedschap is om de akoestiek te berekenen. Met het akoestisch model kan ook de stroomsnelheid van de inkt berekend worden, en zo voorspellen hoe de druppelsnelheid veranderd. Het model laat zien dat na het invangen van een luchtbel de druppelsnelheid eerst iets toeneemt, maar als de bel groeit zakt de druppelsnelheid in.

De druppels die gevormd worden bij het inkjet-printen hebben een relatief hoge snelheid in de orde van $10 \mathrm{~m} / \mathrm{s}$. Deze snelheid is relatief hoog ten opzichte van de lengteschaal van de druppel, die in de orde van $25 \mu \mathrm{m}$ is. Om de druppelvorming goed te visualiseren zijn camera's met beeldfrequenties van meer dan 1 miljoen beelden per seconde vereist. Doordat de druppelvorming zeer reproduceerbaar is, is het ook mogelijk om, in plaats van een hogesnelheidscamera, een goedkopere stroboscopische methode te gebruiken. Hierbij 


\section{SAMENVATTING}

is een zeer korte belichtingstijd vereist om bewegingsonscherpte te voorkomen. Hoofdstuk 4 presenteert een nieuwe belichtingstechniek die uitermate geschikt is voor stroboscopische opnamen. Deze belichtingstechniek maakt gebruik van een Q-switched ND:YAG laser. De laser belicht een totale-interne-reflectie-lens, waarin een kleine holte is gemaakt. In deze holte bevindt zich een oplossing met fluorescente deeltjes. Het resulterende fluorescente licht geeft een incoherente, egaal uittredende lichtbundel die hoofdzakelijk in één richting is georiënteerd. De belichtingstijd van de lichtbron is $7 \mathrm{~ns}$, vergelijkbaar met de belichtingstijd van de gebruikte laser.

In hoofdstuk 5 wordt de druppelvorming onderzocht met de Brandaris 128 hogesnelheidscamera en bovenstaande stroboscopische methode. Uit beide metingen wordt het volume van de druppel, de stroomsnelheid van de vloeistof en de snelheid in de druppel bepaald. De gevisualiseerde details van de druppelvorming met deze nieuwe belichtingstechniek excelleren in verhouding met de visualisatie met andere beschikbare lichtbronnen met een korte pulsduur.

Daarnaast wordt in dit hoofdstuk ook een 1-dimensionaal Euleriaans druppelmodel beschreven dat gebruikt kan worden voor snelle berekeningen van de druppelvorming. De vergelijkingen van het model zijn gebaseerd op de lubrication theorie. Door een slimme numerieke implementatie van de vergelijkingen treed er geen singulariteit op als de druppel insnoert. Dit maakt het ook mogelijk om het opbreken en de samensmelting van druppels te modelleren.

De resultaten van de experimenten worden gebruikt als initiële condities voor het model waarmee vervolgens de viscositeit en de oppervlaktespanning van de inkt berekend kunnen worden. Ondanks het feit dat bij deze eerste experimenten de voorspelde viscositeit en oppervlaktespanning nog niet overeenkomen met de bekende waarden biedt het model in combinatie met de zeer gedetailleerde stroboscopische metingen goede vooruitzichten voor toekomstige metingen.

Het invangen van luchtbellen in hoofdstuk 2 en 3 is onwillekeurig en het is onbekend wanneer dit optreedt. Om het invangen van lucht in het kanaal gestructureerd te onderzoeken wordt in hoofdstuk 5 gebruik gemaakt van een zelf ontwikkelde bel-invang-puls (BEP). De druppelvorming als gevolg van de $B E P$ is asymmetrisch en verstoord, maar wel volledig reproduceerbaar. Uit visualisaties van de druppelvorming blijkt dat er luchtbellen ingevangen worden in de druppel en in de meniscus. We laten zien dat zowel de verstoorde druppelvorming als de luchtbellen volledig reproduceerbaar zijn. Simulaties met een computational fluid dynamics pakket laten zien hoe, tijdens de actuatie met de BEP, lucht in de teruggetrokken meniscus wordt ingesloten.

Naast de visualisatie van de druppelvorming is ook de akoestiek voor en na de 
BEP gemeten met dezelfde methode als in hoofdstuk 2. De metingen laten zien hoe het akoestisch signaal enkele milliseconden na de BEP nog is verstoord, en dat in een aantal gevallen het kanaal uitvalt. De amplitude van het verstoorde akoestische signaal vlak na de BEP lijkt een maatstaf te zijn voor mogelijk uitval van het betreffende inktkanaal. 


\section{Acknowledgement - Dankwoord}

The research described in this thesis is part of the II-A atomization research program of MicroNed. The thesis was carried out at the Physics of Fluids research group at the faculty of Science and Technology of the University of Twente. I gratefully acknowledge the support given by this organization.

Het is alweer ruim vier jaar geleden dat ik samen met Jos de Jong en Professor Lohse een kijkje mocht nemen bij de printerfabrikant Océ. Ik moest op dat moment nog afstuderen en overwoog een promotie bij de vakgroep, maar dan wel binnen een bedrijf. Tijdens dit bezoek werd ik voorgesteld aan de 'drieeenheid' achter de inkjet samenwerking; Marc van den Berg, Herman Wijshoff en Hans Reinten. Deze drie, samen met de zeer enthousiaste Roger Jeurissen, overrompelden mij met hun resultaten, mogelijkheden en vragen. Ik stond te duizelen van al deze nieuwe feiten. Kort samengevat kwam het op het volgende neer: "De komende vier jaar willen we een belletje bestuderen, en als je goed je best doet zijn wij er daarna voorgoed vanaf". Hoewel ik niet direct enthousiast was, lonkten de kijkopstellingen. Want deze lego-achtige meetopstellingen, met al hun apparaten, schermen, draden en knoppen, oefenden een bijzondere aantrekkingskracht op me uit. Op dat moment was ik verkocht, al realiseerde ik me toen niet dat ik met deze opstelling de komende jaren een bijzondere haat-liefde verhouding zou krijgen. Mijn sollicitatie eindigde die dag met een potje voetbal tegen Hendrik, Mareike en niemand minder dan professor Lohse op het doel.

Vanaf hier begon het nieuwe 'inkjet' tijdperk in mijn leven en zou ik één keer per week in mijn snelle Honda-tje over de A31 naar Limburg reizen. De jaren die volgenden waren prachtig. I $k$ voelde me bijzonder welkom op de DV afdelingen van Cobalt en Solaris. Daarom wil ik Océ niet alleen bedanken voor de financile support van dit project, maar ook voor de technische en wetenschappelijke support. In het bijzonder wil ik daarbij mijn begeleiders Hans, Herman en Marc bedanken. De samenwerking is vanaf de eerste dag goed en erg gezellig geweest, waarbij ik me altijd een volwaardig collega heb gevoeld. Hans bedankt voor alle support en de mogelijkheid om je twenty-four-seven te kunnen overvallen met vragen. Marc en Herman, bedankt voor alle adviezen en de geweldig leuke en interessante discussies.

Bij deze wil ik ook alle mensen van Océ bedanken die me op verschillende technische vlakken hebben ondersteund en hierdoor een belangrijke bijdrage aan dit proefschrift hebben geleverd. In het bijzonder dank ik Jan Simons voor de ver- 
schillende akoestische kastjes, en Wilbert Classens en Ron Berkhout voor jullie goede technische ondersteuning.

Naast de samenwerking met de medewerkers van Océ heb ik de afgelopen jaren met veel mensen plezierig samengewerkt. Daarbij wil ik in het bijzonder mijn voorganger, Jos de Jong bedanken. De samenwerking aan het begin van mijn promotie heeft me een vliegende start gegeven. Het was een uitkomst dat Jos na het afronden van zijn promotie bij Océ ging werken. Hierdoor heb ik door de jaren heen nog veel inhoudelijke en ongevraagde auto adviezen gehad.

Ook wil ik de andere AIO's op dit project bedanken voor een goede samenwerking. Roger Jeurissen heeft mij geleerd meer oog voor details te hebben en alles goed uit te zoeken voor je ergens aan begint. Ik heb veel baat gehad bij zijn kennis van numerieke modellen en artikelen. Afgelopen jaar is ook Theo Driessen als $\mathrm{PhD}$ begonnen. Al tijdens zijn afstuderen was samenwerken erg prettig, en dit heeft zich vloeiend tijdens zijn promotie doorgezet. Theo en Roger bedankt voor jullie numerieke werk en jullie bijdrage aan dit proefschrift.

Tijdens mijn promotie heb ik het voorrecht gehad met veel studenten te werken. Het was verassend leuk en leerzaam. Theo Driessen en Tim Segers bleken een gouden combinatie en hebben beide een belangrijke bijdrage aan dit proefschrift geleverd. Daarnaast wil ik Jacco Hettinga, Richard Stevens en Tim Jannink bedanken voor hun inzet, discussies en resultaten. Ook kijk ik er naar uit dat mijn laatste student, Mark Jan van der Meulen, verder gaat met het inkjet project en heb er alle vertrouwen in dat hij mooie resultaten gaat halen.

De vakgroep Physics of Fluids is voor mij een zeer welkome plek geweest. Mede daardoor zijn de afgelopen jaren voorbij gevlogen. Veel heb ik geleerd van Michel Versluis op het gebied van organiseren, structureren, formuleren en presenteren. Ook heeft hij me regelmatig in contact gebracht met verschillende boeiende instanties, zoals het Nederlands Forensisch Instituut. Bedankt hiervoor, ik weet zeker dat alles wat ik geleerd heb in de toekomst nog goed van pas komt. Verder wil ik Gerrit de Bruin, Devaraj van der Meer, Chao Sun bedanken voor adviezen, support en gezellige gesprekken. Ook vind ik het een eer om Leen van Wijngaarden als voorzitter van mijn promotiecommissie te hebben. Jacco Snoeijer wil ik speciaal bedanken voor zijn heldere inhoudelijke adviezen, tips over begeleiden en het spreekwoordelijke steuntje in de rug.

Naast de wetenschappelijke staf is ook de ondersteunde staf essentieel om onderzoek te kunnen doen. Het bouwen van een experimentele opstelling was 
onmogelijk geweest zonder het werk van Gert-Wim Bruggert en Martin Bos. Daarnaast was de vakkennis van Bas Benschop onmisbaar bij het opzetten van digitale snelwegen met Océ en de nodige hardware support. En natuurlijk Joanita Leferink, die een onmisbare functie in onze groep vertegenwoordigt, waarbij ze bijna onopvallend, opvallend veel voor iedereen doet. Ik wil daarom de volledige technische staf bedanken voor de ondersteuning op technische, en administratieve vlakken, maar ook voor de koffiepraat en de mooie anekdotes. Not only has the group physics of fluids a high standard in creating researchers, but also in creating an impressive professional soccer team PoF-United. It was a great pleasure to be captain and player of this team, which employed many students, PhD's, post-docs and staff members over the years. If this team is able to maintain this level of commitment and fair-play, I'm very confident that one day they will actually win matches!

An important reason that these last few years were really fantastic is the good atmosphere amongst fellow PoF-members. It was always a great pleasure to work with all the students, PhDs and Post docs, and it was even a greater pleasure to visit events, such as the FOM-days, the Christmas dinners and the group outings.

Throughout the years there were a lot of new members and farewells at the group, and many of them I consider as good friends. I would like to thank some members with whom I collaborated, shared an office with, namely Francisco Fontenele Araujo, Raymond Bergmann, Theo Driessen, Valeria Garbin, Henk Jan van Gerner, Stephan Gekle, Roger Jeurissen, Jos de Jong, Sylvain Joubaud, Julian Martinez Mercado, Jeroen Sijl and Peichun Amy Tsai.

I would like to give special thanks to my colleagues Aaldert Zijlstra and Erik Gelderblom for their contribution to the iLIF and the corresponding chapter in this thesis. I also owe gratitude to Rory Dijkink, for helping the inkjet research during his post-doc at our group. Additionally I would like to thank Wim van Hoeve for all his scientific support during high school visits, forensic research and drop visualizations.

And I still enjoy the occasional discussions on 'the science of beer' at the Beiaard and the Molly Malone, together with colleagues and good friends Erik, Lonneke, Aaldert, Wim, Marlies, Rory, Anja, James and Álvaro. I would like to thank you guys for these very great times.

In de afgelopen jaren heb ik altijd geprobeerd werk en privé in balans te houden, 
maar mede door een hechte vriendengroep sloeg deze balans af en toe een beetje door. Ik wil Wilbert, Astrid, Joost, Hermine, Joris, Marjolein, Michel, Jantina, Gerald, Klaas Jan, Linda, Gert, Liliane, Daniel en Jouke dan ook hartelijk bedanken voor alle borrels, bruiloften en feestjes.

Dan is er ook nog 'Las Palmas' met wie ik onvergetelijke road-trips en wereldreizen heb gemaakt. Koos, Menno, Merijn, Gijs, Alfons en Henk bedankt voor de vele avonden bier! Ook wil ik Lucas, Woutske en alle andere bewoners en oud bewoners van Calslaan 56-2 bedanken voor de jaren van gezelligheid, de voetbal en de kerstdiners!

Ik wil ook graag mijn familie bedanken voor de jarenlange support. Niet alleen tijdens mijn promotie maar ook tijdens mijn hele studiecarrire hebben pa en ma me altijd volledig gesteund. Ik ben blij dat ik altijd terug kan vallen op een warm gezin met geweldige ouders, broers, zus, zwager en schoonzusjes. Ook vind ik het erg leuk dat mijn twee broers, Erick en Martien mijn paranimfen zijn. Ik ben erg blij dat ik jullie tot mijn beste vrienden kan rekenen.

De vier jaar promotie hebben me niet alleen een geweldige tijd, leerzame ervaring, goede vrienden en mooie resultaten gebracht, maar ook een fantastische vriendin, Marlies je vult me aan en ondersteunt me met onuitputtelijke energie. Jij maakt me gelukkig, geeft me rust en vertrouwen en ik kan niet anders dan mijn uiterste best doen om jou zoveel mogelijk hetzelfde terug te geven!

Nu ruim vier jaar later is mijn boekje klaar en professor Lohse is Detlef geworden. En hem wil ik bovenal ontzettend bedanken voor de promotieplek, de enorme hoeveelheid ervaring die ik heb opgedaan tijdens het werk in Enschede en door de verschillende conferenties en cursussen op velerlei plekken op de wereld. Het is een grote eer om met zo'n gerenommeerde en goede professor te mogen werken. Ik wil je dan ook van harte bedanken voor alle support en het letterlijk dag en nacht klaarstaan voor mij en alle mensen in onze vakgroep!

En hoe de voetbalwedstrijd aan het einde van mijn sollicitatie eindigde; Jos en ik verloren de wedstrijd met twee tegen acht. Maar hoe dan ook, deze dag was het begin van een fantastisch mooie en leerzame tijd! 


\section{About the author}

Arjan van der Bos was born on September the 20th, 1979 in Ermelo, the Netherlands. He graduated from high school (VWO) at "Chr. College Groevenbeek" in Ermelo in 1998. In the same year he started studying Applied Physics at the University of Twente in Enschede. During his studies he did an internship at Sercalo Microtechnolgy in Switzerland on 'Polarization Maintaining MOEMS Switch'. In 2006 he received his master degree in the Physics of Fluids group with prof. dr. Detlef Lohse, dr. Devaraj van der Meer and dr. Raymond Bergmann on 'Development and collapse of cavities formed by the impact and immersion of solid objects on water'. Thereafter he continued research in the Physics of Fluids group, on the subject of air entrapment and drop formation in piezo-driven inkjet printheads. This project was supervised by prof. dr. Detlef Lohse and dr. Michel Versluis, and conducted in close cooperation with Océ Technologies B.V. 